Bound 1939

\section{HARVARD UNIVERSITY}

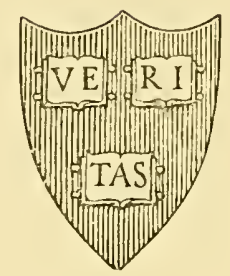

\section{LIBRARY}

OF THE

MUSEUM OF COMPARATIVE ZOÖLOGY

GIFT OF

E. A. Boyden
67046

June 26,1926 


alter $7+$ E. 1907

JUN 261926

$$
67.046
$$

$59.11 .856: 51.23$
WITH COMPLIMENTS OF

H. E. NALTEF,

BROWN UNIVERSITY,

PROVIDENCE, R.I.

CONTRIBUTIONS FROM THE ZOÖLOGICAL LABORATORY OF THE MUSEUM OF COMPARATIVE ZOÖLOGY AT HARVARD COLlege. E. L. MARK, Director.

No. 193.

THE REACTIONS OF PLANARIANS TO LIGHT.

By Herbert Eugene Walter.

From the Jodrial of Experimental Zoölogy, Vol. V., Nos. 1, 2.

CAMBRIDGE, MASS., U.S.A.

DEсемbеR, 1907. 
$-\sqrt{2}+n^{2}$

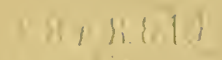

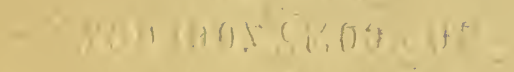

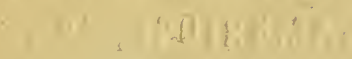

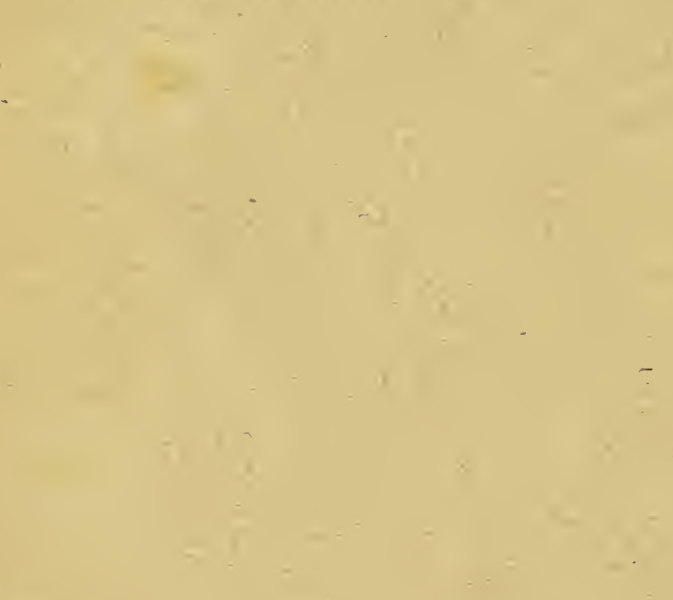

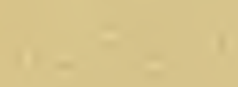
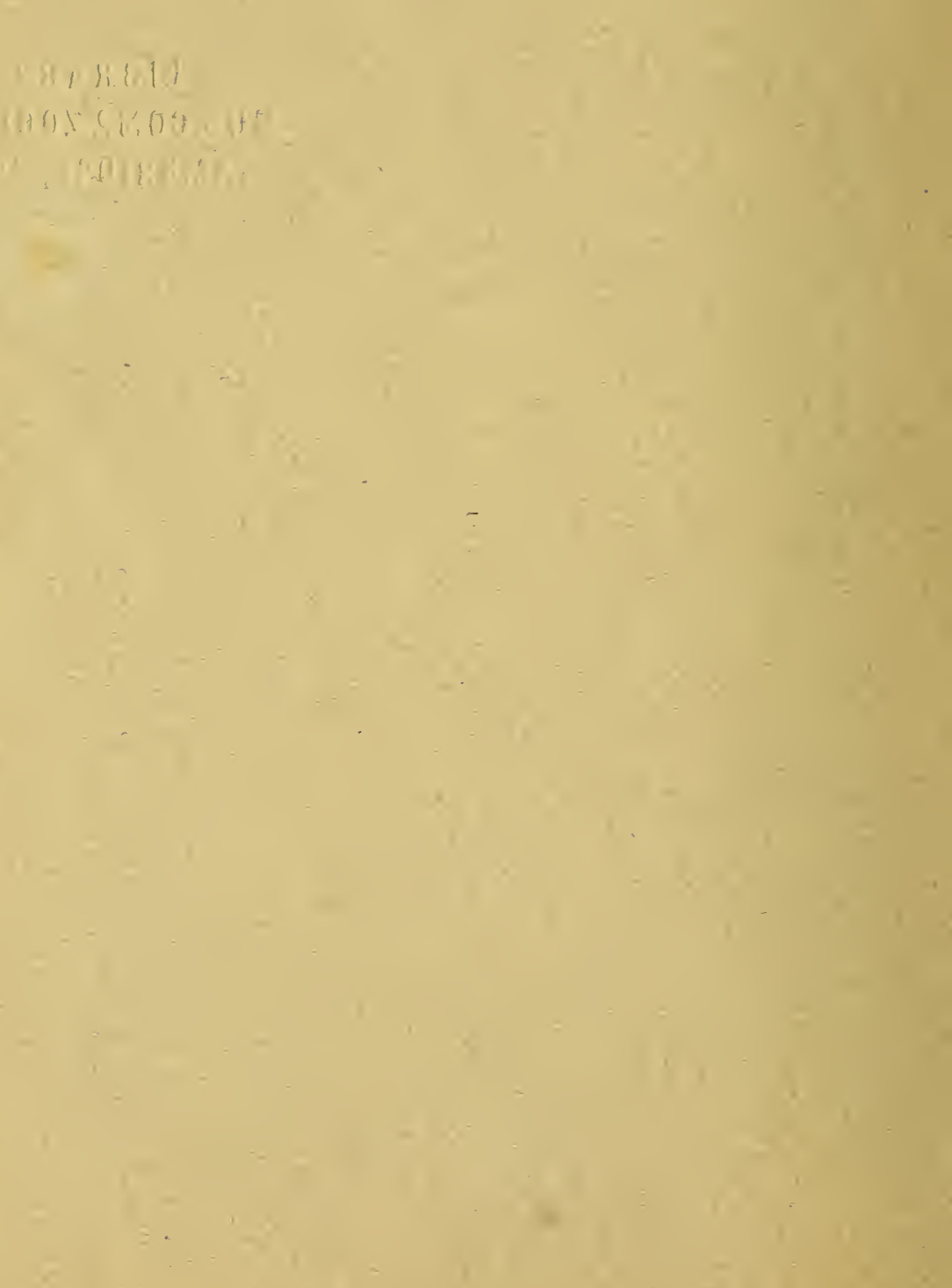


\section{$59.11 .856: 51.23$}

CONTRIBUTIONS FROM THE ZOÖLOGICAL LABORATORY OF THE MUSEUM OF COMPARATIVE ZOÖLOGY AT HARVARD

COLLEGE. E. L. MARK, Director.

No. 193.

\section{THE REACTIONS OF PLANARIANS TO LIGHT.}

By Herbert Eugene Walter.

From the Jodrnal of Experimental Zoölogy, Vol. V., Nos. 1, 2.

CAMBRIDGE, MASS., U.S.A.

DeCEMBER, 1907. 
है 


\section{THE REACTIONS OF PLANARIANS TO LIGHT \\ BY}

\section{HERBERT EUGENE WALTER}

Witu Fourteen Figures

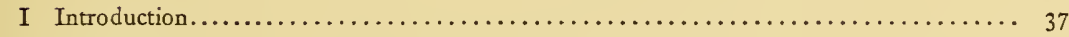

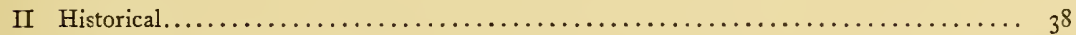

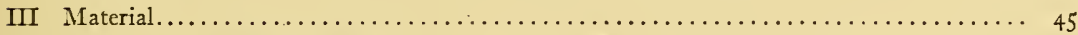

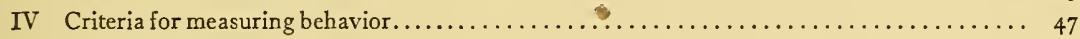

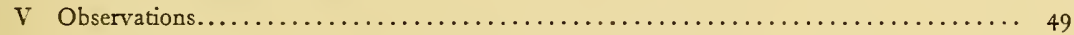

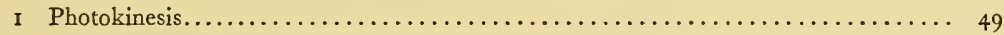

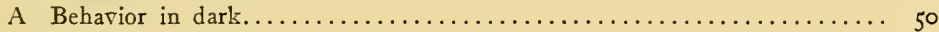

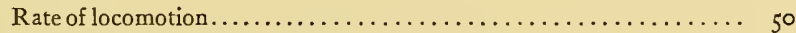

Turning.....................

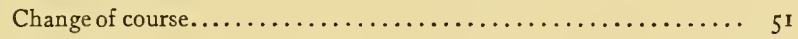

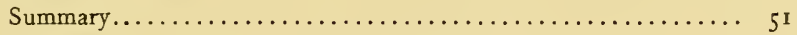

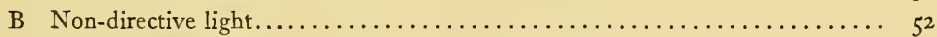

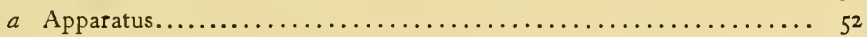

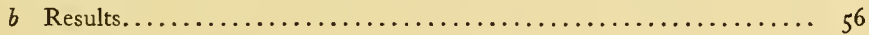

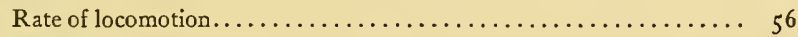

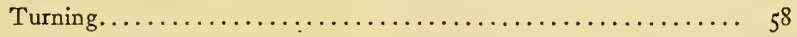

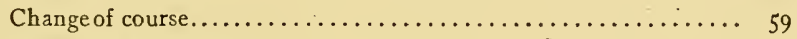

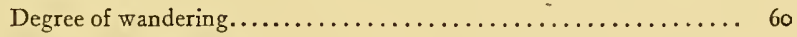

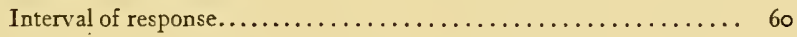

Manner of coming to rest.....................

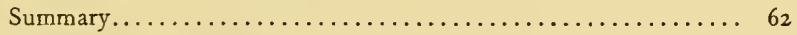

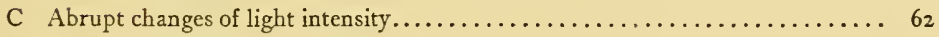

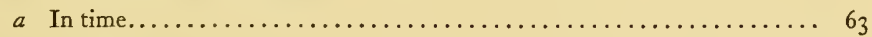

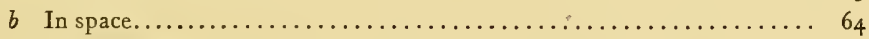

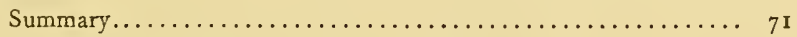

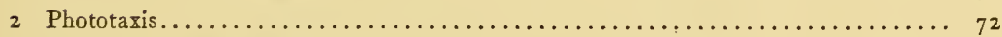

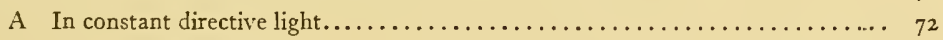

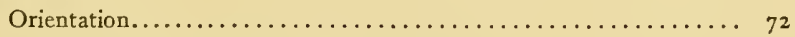

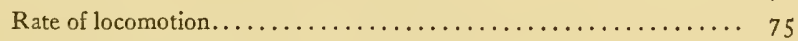

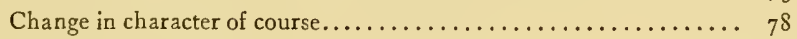

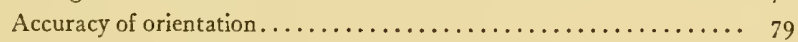

Degree of wandering................................ 80

Duration of activity $\ldots \ldots \ldots \ldots \ldots \ldots \ldots \ldots \ldots \ldots \ldots \ldots \ldots \ldots \ldots \ldots$

Time required to leave a unit circle $\ldots \ldots \ldots \ldots \ldots \ldots \ldots \ldots 8_{2}$

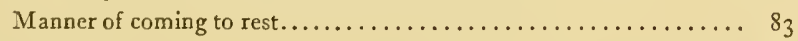

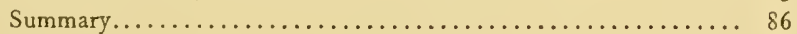

The Jolrnal of Experimental Zoölogy, vol. v, No. I. 


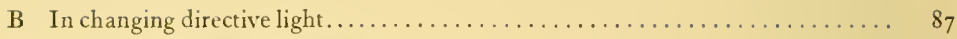

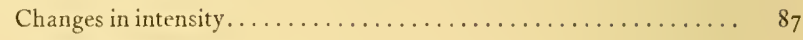

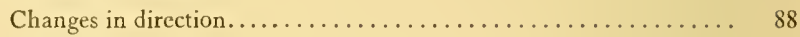

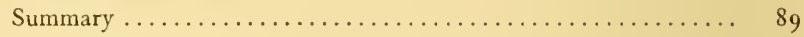

C In combination with other responses....................... 89

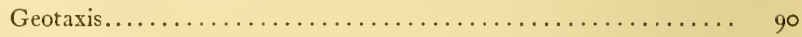

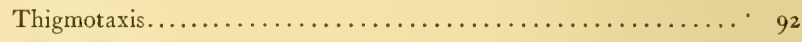

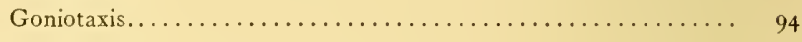

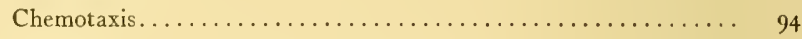

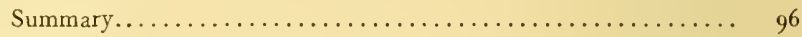

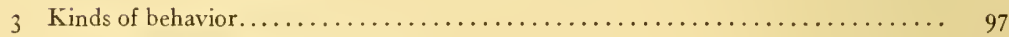

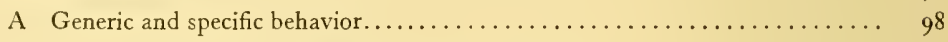

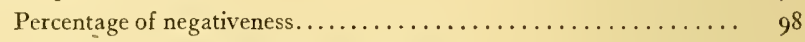

Character of the course in directive light $\ldots \ldots \ldots \ldots \ldots \ldots \ldots .99$

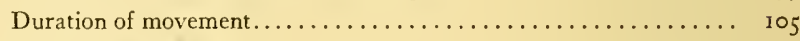

Degree of wandering.............................. 106

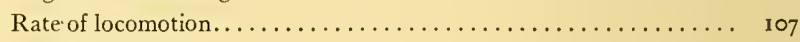

Time required to'leave a unit circle................. 107

The effects of fatigue ......................... 108

Responses to changes in intensity................. 109

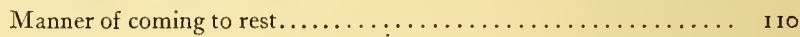

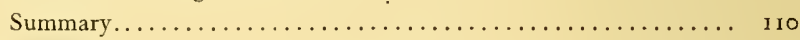

B Individual behavior........................... II

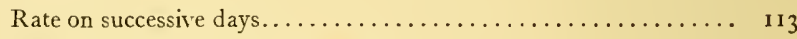

Relative value of individual behavior................ 112

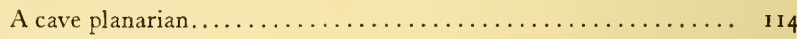

Summary........................... 116

(Pages II7 to 162 are printed in vol. v. no. 2)

4 Basis of behavior.

A Morphological basis of behavior.......................... I17

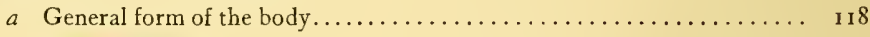

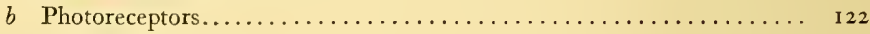

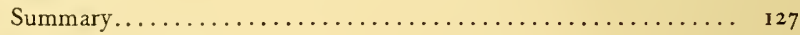

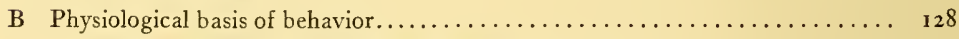

a Classification of physiological states................... I 29

$b$ Changes in physiological states induced by light.............. I 30

Effect of different intensities...................... I 30

Effect of excessive light...................... I

Effect of sudden change in light conditions............... 131

Effect of continued exposure to light ................ I $\mathbf{3}^{\mathbf{I}}$

Effect of previous exposure to dark.................. $\mathbf{1}_{32}^{2}$

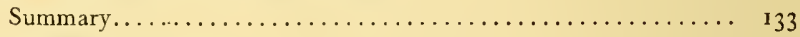

C Psychological basis of behavior.............................. ${ }^{1} 34$

a How much can planarians see ?..................... I34

$b$ Are planarians able to learn ?..................... 135

Summary...................... $\mathbf{1}^{8}$ 


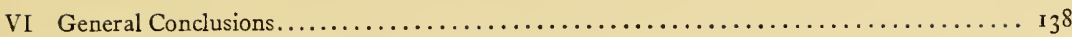

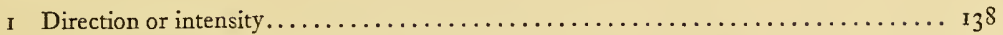

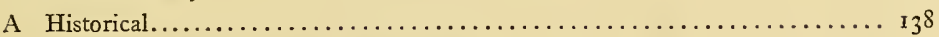

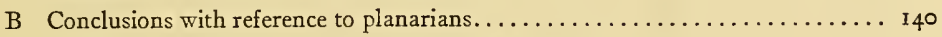

a The distinction between direction and intensity................ I 40

$b$ The modifying influence of direction...................... I 4 I

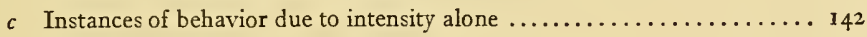

$d$ The modifying effect of other factors......................... 144

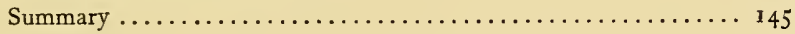

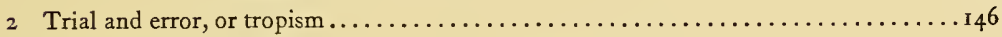

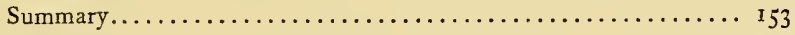

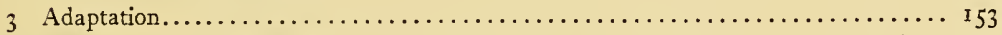

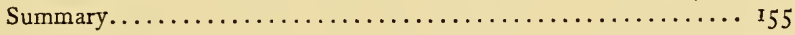

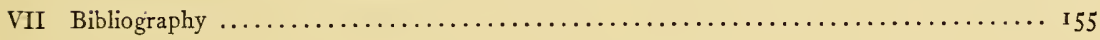

\section{INTRODUCTION}

Light is one of the physical factors which influence the behavior of organisms. The great majority of living things are normally subjected to regular periodic changes in the amount of light to which they are exposed during the alternation of day and night. In addition to these constant periodic changes, there are innumerable irregular gradations in both the intensity and the character of the light naturally acting upon any organism. An agent of such wide range and almost universal influence as light ought, therefore, when properly analyzed, to prove of material service in interpreting the behavior of animals and plants. The dependence upon light of animals provided with organs of sight, is self evident. The direct bearing, too, of light upon chlorophyllaceous plants in the manufacture of their food substance, is plain. But how far light plays a direct part in the life of non-photosynthetic plants and of animals which cannot "see," is less clear.

Although possessing eyes, it is very probable that planarians are unable to see in the sense of distinguishing shapes, and it is questionable how far they can distinguish between even large regions of different light intensity.

The object of the following paper is to examine the relation of light to animal behavior as applied to certain planarians. 


\section{Historical}

Our knowledge of planarians, as of most other animals, has passed through certain historical phases, during which emphasis has been laid first upon taxonomy and anatomy and latterly upon embryology and zoögeography. The results of these various forms of investigation are highly important since they make the foundation for all future work upon this group of animals. They have, however, only an indirect interest in the present connection and do not, therefore, require review.

Perhaps the most modern advance in our knowledge of planarians is represented by the school which treats of them as living objects whose individual behavior is to be intimately correlated both with their structure and environment. The most noteworthy contribution from this standpoint has been made by Pearl ('03), who has analyzed in considerable detail the reactions of freshwater planarians (notably Planaria maculata, Planaria dorotocephala and Dendrocolum lacteum) to various stimuli. He has not, however, discussed the effects of light except incidentally.

The earliest reference to the relation of planarians to light is by Dalyell ('I4). In his interesting volume on planarians a great number of keen observations upon the general habits and structure of planarians are made, which have since been confirmed, together with certain statements which have not fared as well with the advance of scientific knowledge.

He makes the statement ('I4, p. 9) that "most planariæ court the light indeed $;{ }^{1}$ but $\mathrm{P}$. flexilis rather inclines to shun it, less, we may conjecture, from being warned of its presence by the specks or eyes, than from some disagreeable sensation produced on the body." Again, referring to P. felina (' 14, p. 46), "This planaria, like the rest of its genus, is powerfully excited to motion by the presence of light. If a number be confined in a glass vessel, the whole assemble in a quiescent state, on the side next the light. ${ }^{1}$ It is a little surprising that Dalyell should have received the impression that the majority of planarians "court the light," since he clearly points out the nocturnal habits of these worms. $\mathrm{He}$

The italics are mine. 
doubts whether the eyes are of service in finding food and says of worms under aquarium conditions ('14, p. 107), "If remaining a considerable time unchanged, the planariæ decrease more rapidly, they become languid, scarcely moving either by the influence of the light or heat, and at last adhere entirely to the side of the containing vessel, where they perish.",

Dugès ('28) observed that when light is concentrated by means of a lens upon either Dendrocœlum (?) or Planaria, movement results which is most pronounced when directed toward the anterior end of the worm. He tested the effects of direct sunlight and of diffuse daylight as well as of candle-light, and concluded that the response increases with the intensity of the light. The nondioptric character of the eyes he has described remarkably well for one working so long before the days of the microtome, and his conclusion, already suggested by Dalyell and later confirmed by Kennel ('88), and others, that the eyes play no part in the finding of food, is noteworthy. He also notes that planarians seek the dark.

Dalyell ('53, p. 99), in a later volume says, "On April 29 I procured a fine specimen of Planaria cornuta, which spawned soon afterward. The spawn had been breaking up for two or three days preceding May 24, when multitudes of extremely minute yellow specks were seen swimming in the water. Their motion was sufficiently active, without being very quick; it was pursued in all directions and the spawn being contained in a small cylindrical jar, the specks crowded to the sides next the light whereon numbers remained almost stationary." Again ('53, p. 104), "When withdrawn from the dark the young Planariæ rose in great numbers toward the surface of the water, congregating on the sides next the light." It is extremely doubtful whether the organisms here described were really young planarians. It is more likely that they were the young of some other aquatic animal. Dalyell correctly describes Planaria lactea (Dendrocœlum lacteum?) as being nocturnal. He observed that numbers of this species, beginning activity in the evening, rose on the sides of the jar, although many had descended again by morning.

More recently attention has been specifically directed to the 
light relations of planarians in various papers by Loeb, whose important contribution in I 890 , "Der Heliotropismus der Thiere und seine Uebereinstimmung mit dem Heliotropismus der Pflanzen," paved the way in general for all work on this subject. He found ('93b, p. IOI) that Planaria torva is not "heliotropic" in the strict sense, but rather "unterschiedsempfindlich," that is to say, it did not always move away from the source of the light in the direction of the rays and remain as far removed as possible, but moved about more or less at random, coming to rest in some area of lessened light intensity.

In a later paper Loeb ('94, p. 255) states that when planarians are suddenly brought into the light they begin to move, an increase in light intensity leading to activity and conversely a decrease, to rest. The grounds for this conclusion are not made clear. $\mathrm{He}$ further confirms the view that planarians are active at night, coming to rest in situations of lowered light intensity in daytime.

In further experiments $P$. torva when decapitated was found to react to light precisely as normal worms do with the difference that the reaction required more time. Thysanozoön brochii, a polyclad, on the other hand, lost its power to respond to light when the eyes and brain were amputated, from which Loeb draws the conclusion that animals which are closely related morphologically may exhibit wide physiological differences.

Hesse ('97), in his classic study of the anatomy of the turbellarian eye, mentions some experiments and observations on the behavior of planarians and in addition makes valuable contributions to the morphological basis of light reactions. He observed that planarians become active at twilight and he also experimented upon decapitated worms, apparently without being aware of the previous work by Loeb, with whose results his own agreed. $\mathrm{He}$ found, as Loeb did, that worms deprived of eyes finally come to rest in areas of lesser intensity much as do normal worms but after a longer time. Hesse found, too, that Dendrocœlum lacteum came to rest in the dark II9 times out of a possible I20, whereas with Euplanaria (Planaria) gonocephala the same result was effected in only 88 out of I 20 times, notwithstanding the fact that the latter has more highly developed eyes than Dendrocœlum. 
This led him to state ('97, p. 552) that "die Stärke der Reaction auf Lichtwirkung nicht der Stärke der Lichtwahrnehmung entspricht," and he ascribes this difference in behavior to a difference in the "Gefühlston" of the two species. Among other observations described by Hesse, the two following are of importance in this connection, namely, that a sudden introduction of light caused an almost immediate turning away on the part of the worm, and, that worms with eyes could not be made to remain in the light when escape was possible. In his opinion this apparent perception on the part of the worm is due not to the animal's ability to distinguish light but rather to unpleasant chemical reactions set up within the organism as the result of light stimulation. And, lastly, Hesse showed that the general position of the eyes of a planarian, together with the arrangement of their sensory portion, partly enclosed as it is within pigment cups, affords a device whereby the worm can be oriented to light. By means of this simple apparatus it receives a localized stimulus, which enables it to distinguish the direction from which the light comes. If light, striking the eye of a worm, fell upon sense cells which were unscreened in any way by pigment, there would result a general stimulation without localization of the stimulus and consequently orientation could not be effected.

Parker and Burnett ('oo) sought, by quantitative methods and with more accuracy than Loeb or Hesse, to establish the part played by the eyes in light responses of planarians. They came to the same general conclusion as these authors since they found that Planaria gonocephala without eyes reacts to light essentially as normal animals do, except that the reaction time is somewhat longer. They also showed that worms when pointed toward the source of light travel at a slower rate than when headed in the opposite direction. With regard to the mechanism of the light response they say ('oo, p. $3^{83}$ ): "We have seen nothing in our experiments that supports the opinion suggested by Hesse (p. 55 I) that reactions such as we have described are due to the direct influence of light on the internal parts of the planarians, and we are more inclined to the view that these reactions are initiated by the effect of light on the integument of the animal, i.e., are 
due to what Graber (' $\delta_{3}$, p. 229) has called a 'dermatropic' function.'

Bardeen ('o Ia, p. I3), speaking of Planaria maculata, states that "susceptibility to light is apt to become lost if worms are kept in captivity," and he notes the fact, already brought out by Chich koff ('92), that pigment becomes reduced in sunlight. Hesse had previously emphasized the point that the pigment of the eye of any organism has in itself primarily nothing whatever to do with light perception. Bardeen further found that small pieces of planarians capable of locomotion will respond to light in the same way as uninjured animals, and he notes ('ora, p. I3), that the worms seem "to move about more by night than by day." In a later paper ('oIb) he speaks of the fact that when a dish containing planarians is brought into light the worms are commonly roused to activity, although how far such activity is due to light and how far to mechanical disturbances he does not make clear.

Lillie ('OI), experimenting upon the regeneration of Dendrocœlum lacteum, discovered that posterior headless parts fail to give the typical reaction to light and are incapable of regeneration. He draws the conclusion ('OI, p. I32) that "any symmetrical piece of Dendrocœlum capable of regeneration tends to come to rest in the shaded part of the dish precisely like a normal individual" and that parts incapable of regenerating "also become incapable, after a day or two, of performing the usual reactions to light." These results on Dendrocœlum, it will be seen, are similar to those Loeb obtained in experiments upon the polyclad Thysanozoön.

Curtis ('02) reports from laboratory observations 42 cases of fission in Planaria maculata, of which number 39 occurred between IO p. m. and 6 a. m. He adds, however ('o2, p. 524), that "this did not seem due to the amount of light to which the animals were subjected during the day, for some of the dishes were so shaded that there was practically no light, day or night, except when they were being examined, and the division was the same in these as in others which were exposed to full daylight." A case of division in Bipalium also occurring by night is described by Lehnert ('9I).

In a contribution to the geographical distribution of Planaria 
gonocephala, P. cornuta and P. alpina, ${ }^{2}$ Voigt ('O4) incidentally refers to the manner in which these animals come to rest in the darkest part of a dish. He affirms that when an aquarium is suddenly lighted at night only those that are hungry, $i . e$., those with comparatively empty digestive tracts, are found in motion, and. he notes that in certain conditions worms may remain quiescent for weeks. The statement made earlier by Dugès, that the eyes of planarians play no part in finding food, Voigt confirms. These organs he explains are an aid in distinguishing differences in light intensity as well as the direction from which light comes but are entirely incapable, owing to the simplicity of their structure, of discerning the form of objects. In his opinion worms crawl into hollow stems and similar sheltered places to escape light rather than for warmth, as Wilhelmi ('O4) suggests. Neither author, apparently, considers the possible part played by thigmotaxis under such circumstances. Of the delicacy with which worms react to light Voigt says ('04, p. I73): "Die Empfindlichkeit der Planariden gegen plötzliche Belichtung tritt so scharf hervor, das sie für den Unterricht eines der anschaulichsten Beispiele zur Demonstration der Lichtflucht bei niederen Tiere darbieten." Notwithstanding this high degree of sensitiveness to light, he finds that the worms when seeking their food leave the shade and come out even into direct sunlight. And, finally, concerning the bearing which light has on the problem of distribution, he concludes ('O4, p. I75):. "Auf die Verbreitung im Allgemeinen hat die Belichtung der Bäche wenig Einfluss, da sich in der Regel genug dunkele Schlupfwinkel finden, in denen sich die Tiere verbergen können."

Darwin ('44, p. 242) observed that land planarians, "especially Planaria tasmania, had an immediate apprehension and dislike of light, which they showed by crawling, when the lid of the box was taken off, to the under side of pieces of rotten wood," and in his enumeration of the places where various species of land planarians were found, their avoidance of light is plainly shown.

A note by Leidy ('58) refers to finding Rhynchodemus sylvaticus crawling about on fences frequently at night, but rarely by day.

${ }^{2}$ P. alpina $=$ P. torva according to Borelli ('93). 
Moseley ('74, p. I I I) states that "land planarians are probably all of them nocturnal in habit." Speaking of the Ceylon land planarians in particular he says: "They are found in dark places, such as under large fallen leaves, and in confinement they coil themselves up away from light." He mentions also the fact that Planaria torva and Dendrocolum lacteum choose the dark side of the ressel in which they are contained.

As has already been mentioned, Lehnert ('9I) found Bipalium kewense undergoing fission in the dark. Both Bipalium and Geodesmus, he says, seek continually to hide in shadowy places avoiding even diffuse daylight. Concerning the degree of light perception possessed by planarians, he offers the opinion ('9I, p. 326) that "Bipalium scheint mit seinem Augen die Umrisse von Gegenständen in Lichte wahrnehmen zu können."

Hogg ('97) notes that Bipalium is nocturnal in habit, remaining sluggish during the day.

Only incidental references to the polyclads are found bearing upon the question of light reactions, as for example this sentence, which occurs in Lang's exhaustive monograph ('84, p. 64I), "Die meisten Arten scheuen das directe Sonnenlicht." The behavior of Thysanozoön with reference to light has already been mentioned (Loeb, '94).

Concerning the light reactions of the rhabdocoeles, especially certain green forms in which the green cells are probably symbiotic, a considerable literature may be found. The principal papers relating to these forms are as follows: On Convoluta schultzii, by Geddes ('79), Barthélémy ('84) and Delage ('86); on Convoluta roscoffensis, by Haberlandt ('9r), Bohn ('oza, 'ozb, 'о3c), Gamble and Keeble ('o3) and Fühner ('o6). Vortex viridis and Mesostomum viridatum (?) are discussed by Schultze ('5I), von Graff ('84) and Sekera ('o3). A résumé of these papers is, however, out of place here, since the presence of green cells in the organisms involves an entirely different problem from that which is under consideration.

The foregoing historical sketch furnishes the basis of the following general summary of facts which have thus been established with more or less certainty regarding the reactions of planarians to light. 
I Planarians are nocturnal, seeking the dark when exposed to light.

2. The eyes are useless in finding food.

3 The anterior end of the body is the part most responsive to light

4 Decapitated worms act normally except for a slower reaction time.

5 Orientation to light depends largely upon the character of the pigment cups of the eyes.

6 The relative energy of the response is dependent upon the intensity of the light.

7 Pigment is reduced in sunlight.

8 Pieces of worms which are large enough to move or regenerate react to light.

9 Fission may occur more readily in the dark.

IO Different species respond differently to light.

I I Light reactions diminish during "captivity."

I2 Planarians are "unterschiedsempfindlich" instead of "heliotropic."

\section{Material}

The species principally used in the following investigations were Planaria maculata Leidy; Planaria gonocephala Dugès; Phagocata gracilis Leidy; Dendrocœlum lacteum Oersted; and Bdelloura candida Giard, all of which are inhabitants of fresh water except Bdelloura, a salt-water species, found living semiparasitically on the horseshoe crab (Limulus polyphemus). Some observations also were made upon a cave planarian, that as yet has not been identified but which may belong to the genus Phagocata. This interesting worm was kindly placed at my disposal by Dr. A. M. Banta.

At any season of the year an ample supply of fresh material was easily obtained except in midwinter, when it was necessary to cut through the ice and dredge up from the bottom water-weeds to which the worms cling.

The source of supply for Planaria gonocephala was a small pond to the west of Fresh Pond in Cambridge, Mass., while Pla- 
naria maculata, Dendrocœlum and Phagocata were chiefly obtained from a pond at Falmouth, Mass., where they are especially abundant. Twice, through the kindness of Professor Parker, aquaria were generously stocked with Dendrocœlum, from a spring on Mount Monadnock, N. H. Bdelloura was obtained from Wood's Hole, Mass., during the summer from freshly caught horseshoe crabs and, later in the year, from specimens kept in captivity.

The setting-up of balanced aquaria in which planarians would thrive did not prove to be a difficult matter. The following method, based largely upon suggestions by Wilhelmi ('O4), was used. Jars were filled to the depth of two or three inches with cinders, dirt and dead leaves, over which was spread an equally deep layer of clean sand. Clear water was then poured into the remaining space and the whole allowed to settle, after which a few such plants as Anacharis or Myriophyllum, with whatever microscopic life might adhere to them, were added, together with a handful of large pebbles to diversify the bottom. The jars were kept covered from dust in a cool place and occasionally a crushed snail was dropped into each one to supply the worms with food.

Planarians require pure water. Whenever for any reason the water in which they are kept becomes foul they will desert their places of concealment and crawl up the sides of the jar, while water that has been standing in lead or iron pipes quickly causes them to disintegrate. Rainwater or water taken directly from some natural source, gives better results than that which has been conveyed through pipes. Naturally the least chemical disturbance takes place when the worms are kept in water dipped up at the time and place of their capture.

Planarians will live without being fed for over three months when isolated in jars containing nothing except pure water, but meanwhile they decrease regularly in size. It seems to be impossible to "starve" them in the sense in which higher animals may be forced to die from lack of food leaving behind a dead body. These worms instead simply consume their own substance almost to the vanishing point.

During a part of the summer of I 905 observations and experiments were carried on at the laboratory of the U. S. Fisheries 
Bureau at Wood's Hole, Mass., and I wish here to express my thanks to the director, Dr. F. B. Sumner, as well as to others in authority there, for their uniform courtesies. The bulk of the investigation, however, was made at Harvard University. I am deeply indebted to Professor Mark for the privilege of having a place in his laboratory and particularly to Prof. G. H. Parker, under whose immediate direction the work was done and whose daily counsels and generous suggestions were indispensable.

\section{iV Criteria for Measuring Behavior}

Both the form and the structure of an animal set a limit to the character and degree of its movements, which no combination of stimuli, external or internal, can force it to overstep. In estimating the influence of light upon planarians, therefore, it is necessary to know not only the normal behavior of the worms but also the possible range of their reactions under any circumstances. For example, the ordinary gliding locomotion of planarians is accomplished by means of cilia beating in a mucus track and augmented by muscular contraction. It is physically impossible for this sort of locomotion, even under the most favorable conditions, to exceed a certain rate. By the use of excessive stimuli, however, a worm may be forced to abandon this accustomed gliding for a somewhat faster method of progression known as "crawling" or "humping," in which the muscles are used more than the cilia. But when this is done the limit of possible rate of locomotion has been reached, at least for fresh water planarians, which cannot be urged to abandon entirely contact with some support and to swim freely in water, although the marine form, Bdelloura, does have this addition to its repertory of behavior.

The following observations may illustrate more specifically what is meant by range of behavior. Planaria maculata, when gliding on the bottom of a dish, was lightly touched on the anterior end with a hair mounted on a glass rod. During one hundred trials of this kind eight different responses resulted, which may be indicated as follows: 
Animals which, like planarians, present a limited range of behavior are, therefore, more favorable subjects for experimentation than higher forms whose structural complexity increases their possible responses, making in consequence the analysis of cause and effect in their activities more difficult. It is evidently desirable, then, to have as many different ways for measuring behavior as possible, in order not to state these responses loosely from general impressions but in quantitative terms. The principal criteria of planarian reactions to light used in this study, follow:

I Rate of Locomotion. Since the entire range of possible rates of locomotion depends upon the structure of the worm and is not very great, slight differences become significant.

2 Amount and Character of $\mathcal{T}$ urning, that is, whether persistent or irregular, decided or vague, clockwise or contra-clockwise.

3 Change of Course. A change in the character, but not necessarily in the direction, of the course is referred to here. "Circus movements," for example, would not be included under this heading because the curving path in such cases, although constantly changing in direction, does not change in character. Tangents to a circle, however, as well as angular and abrupt deviations from a straight line may properly be regarded as changes of course.

4 Interval of Response. The apparent effect of light is not immediate in all cases, therefore, the time elapsing between the application of the stimulus and the response to it is a valuable measure of reaction.

5 Degree of $W$ andering. In a sense the degree of wandering shown by a worm is a measure of its indifference to the stimuli acting upon it. It must be noted, however, that apparent indif- 
ference may sometimes be due to a balance of opposing stimuli, in which case wandering or aimlessness is not a true measure of the effect of any single stimulus.

6 Orientation. This is a measure of behavior with reference to the source of the light. It is expressed by the degree of positiveness or negativeness which the worm exhibits.

7 Duration of Movement. The time it takes a worm to tire out when subjected to certain stimuli or, in other words, a measure of fatigue.

8 Effect of Repetition. A measure of response is here referred to which may be expressed quantitatively in units of time or qualitatively in manner of behavior.

9 Wigwag Movements. These are waving movements of the anterior end of the planarian, which appear to be a definite attempt on the part of the worm to become adjusted to the stimuli acting upon it.

Io The Time Required to Leave a Unit Circle. This is a rather unsatisfactory criterion because it may indicate in some cases a combination of several conditions as, for instance, latency of response, rate of locomotion and degree of wandering.

I I Manner of Coming to Rest. Included under this heading are such points as the position assumed, the locality selected, and the abruptness of the act.

Naturally some of the foregoing measures of behavior will be seen to have more application and value than others in the following study.

\section{Observations \\ I PHOTOKINESIS}

The term photokinesis was introduced by Engelmann ('83) to denote the activities which are induced solely by the intensity of light when the directive or orienting factor has been eliminated.

In this section will be considered, (A) the behavior of planarians in the absence of light; (B) their behavior in different intensities of non-directive light, and (C) the effect of abrupt changes, both in time and space, in the intensity of non-directive light. 


\section{A Behavior in Dark}

Darkness may be called the zero point in the scale of light intensities. That light is not essential to the activity of planarians is shown by their performances in its absence, as is demonstrated by the following facts.

Rate of Locomotion. The average rate of ten individuals of Planaria gonocephala was found to be $0.50 \mathrm{~mm}$. per second in the dark while the same ten worms, subjected to a light from above of ${ }_{3} 8 \mathrm{c.m} .,^{3}$ with all the other conditions unchanged, averaged 0.82 $\mathrm{mm}$. per second.

Again, ten worms of the same species were allowed to travel in the dark ten minutes in one set of experiments and six minutes in another, when their average rates were found to be 0.42 and 0.57 $\mathrm{mm}$. per second, respectively.

The method devised for obtaining the above records, previously used in experiments upon fresh water snails (Walter, 'o6), although tedious was comparatively accurate. A clean glass plate was submerged in a dish of water and the latter placed in a light-proof receptacle. A single worm was then allowed to travel on this glass for a unit of time, after which the plate was removed and "developed" by pouring over it powdered carmine shaken up in water. A sufficient number of the insoluble carmine particles adhered to the mucus-track left on the glass by the gliding worm to make it possible to wipe dry the reverse side of the plate and to trace thereon in ink the exact course taken by the worm. This permanent ink line was then measured by means of a map measurer such as is in common use for measuring sinuous lines.

A series of experiments, to be described more in detail later (Table III, p. 57), forms a basis of comparison with the foregoing records in the dark, and further shows that there is an increase in the rate of locomotion in the light.

Ten worms, subjected to various intensities of light projected from above and ranging from less than one to several hundred candle meters, showed rates which in all cases were greater than the rate traveled in the dark.

${ }^{3}$ The abbreviation c.m. is used to denote candle meters. 
Turning. That planarians do more turning in the dark than they do in various intensities of non-directive light is apparent from the following table of percentages.

TABLE I

Per cent of turnings of Planaria gonocephala in the dark and in various intensities of light

\begin{tabular}{|c|c|c|c|c|c|c|c|c|c|c|}
\hline Light in candle meters...... & $\begin{array}{c}0 \\
\text { (dark) }\end{array}$ & 0.94 & II & 39 & 78 & 126 & 155 & 217 & $43 \mathrm{I}$ & $\begin{array}{l}\text { Av. of all } \\
\text { intensities }\end{array}$ \\
\hline Per cent of turning... & 87 & 76 & 66 & 69 & $8 \mathrm{I}$ & 67 & 75 & 77 & 65 & 72 \\
\hline Per cent of straight paths.... & 13 & 24 & 34 & $3 \mathbf{I}$ & 19 & 33 & 25 & 23 & 35 & 28 \\
\hline Number of observations............ & 71 & 79 & 67 & 85 & 57 & 62 & 67 & 57 & $5^{8}$ & \\
\hline
\end{tabular}

Furthermore, out of a total of 46 cases of turnings made by different individuals of Planaria gonocephala in the dark 23 were clockwise and 23 contra-clockwise. This perfect balance in behavior did not recur when the same worms performed turning evolutions in the light.

Change of Course. As to what constitutes "definite" and what "indefinite" changes of path, an S-shaped course is to be regarded as an indefinite aimless wandering, whereas angles in a straight path or tangents in a curving path are classed as definite responses because they are what would normally occur if some directive stimulus were interposed. It was found that P. gonocephala made indefinite changes in its course more frequently in the dark than in any series of light intensities to which it was subjected for an equal length of time. On the other hand definite changes occurred oftener in the light, although the factor of directive light had been excluded.

Table II summarizes $35^{\circ}$ records on Io different worms with the results reduced to percentages.

It will be seen that the per cent of S-shaped ("indefinite") paths in the dark decidedly eclipses that which was made in any intensity of light, while the per cent of angular and tangential paths ("definite") laid in the dark is exceeded in every instance by that made in any intensity of light with one exception, viz: I I c.m., which, however, is not sufficient to change the average result.

Summary. Planarians move about in the dark but at a slower rate than in non-directive light whatever the intensity. They 
turn more in the dark than in the light, going clockwise or contraclockwise with equal readiness. Finally, they make more indefinite changes in their paths in the dark, but fewer definite changes than in the light.

TABLE II

Percentage of definite and indefinite changes in the character of the course in dark and in light of different intensities

\begin{tabular}{|c|c|c|c|c|c|c|c|c|c|c|}
\hline \multirow[b]{2}{*}{ Light in candle meters.................. } & \multirow[b]{2}{*}{$\begin{array}{c}\circ \\
(\text { dark })\end{array}$} & \multirow[b]{2}{*}{$\begin{array}{l}\text { Average } \\
\text { for all in- } \\
\text { tensities }\end{array}$} & \multicolumn{8}{|c|}{ Details of the several intensities employed } \\
\hline & & & 0.94 & II & 37 & $7^{8}$ & 126 & 155 & 217 & $43^{x}$ \\
\hline $\begin{array}{l}\text { Definite changes (angular or tangential } \\
\text { changes), per cent................. }\end{array}$ & I8 & $28 \cdot 5$ & 30 & 15 & 27 & 32 & 35 & 21 & $3^{2}$ & 40 \\
\hline 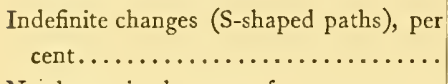 & 47 & 23 & 21 & 30 & 23 & 20 & 26 & 34 & 20 & 99 \\
\hline No change in character of course, per cent & 35 & $48 \cdot 5$ & 49 & 54 & $5 \circ$ & $4^{8}$ & 39 & 45 & $4^{8}$ & $5^{1}$ \\
\hline Number of observations.............. & 34 & $3^{16}$ & 49 & 35 & $4^{8}$ & 37 & $3^{1}$ & $4^{8}$ & 35 & 33 \\
\hline
\end{tabular}

\section{B Non-Directive Light}

\section{a Apparatus}

To test the effect of purely non-directive light, it is of course necessary to eliminate the possible influence of directive light. This may be done by projecting the light upon the moving worms in such a way that they are unable to go either toward or away from the source of the light. Whatever effect is obtained under such circumstances must be ascribed to the non-directive power of light.

The elimination of the directive influence of light can be accomplished by means of various devices. (I) The light may be made to fall vertically from above upon a horizontal field; (2) it may be reflected vertically from below so as to pass through a transparent field at right angles to the plane of the field; (3) methods I and 2 may be combined. The apparatus finally used in the majority of experiments with non-directive light, was based upon the method first mentioned. 
Fig. I shows a diagrammatic vertical section of this apparatus. The light $(A)$, an incandescent electric lamp, was mounted in a black sheet-iron hood $(B)$ to prevent the escape of any lateral light. This hood was suspended from the ceiling of the dark room where the experiments were carried on and was arranged so that it could be easily raised or lowered, thus changing the height and consequently the intensity of the light with reference to any fixed point below. In the hood, beneath the light, was supported

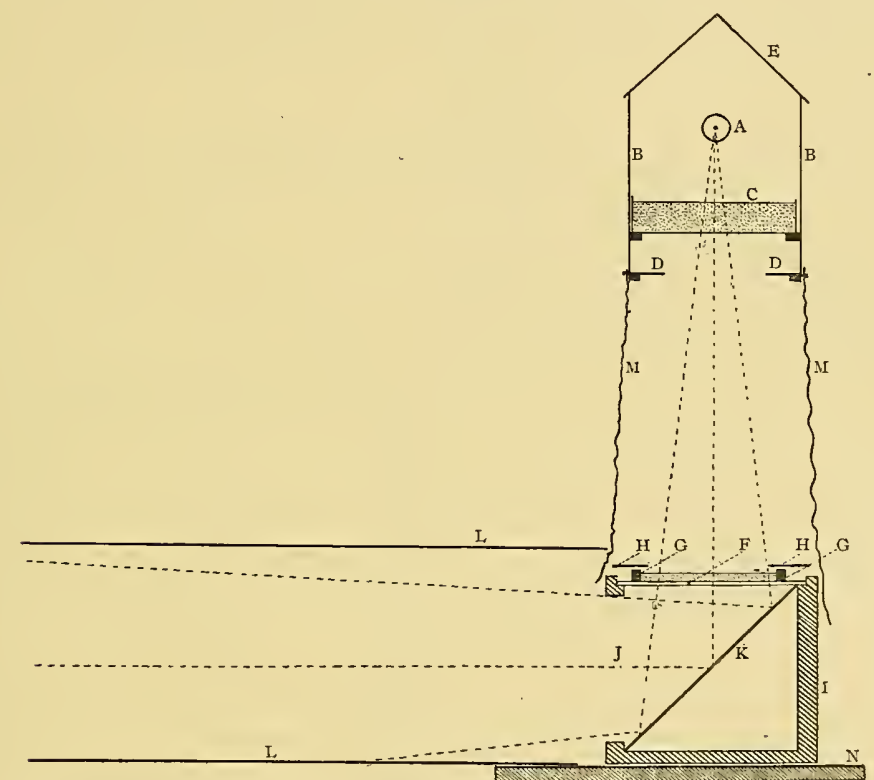

Fig. I $A$, light; $B$, walls of hood; $C$, heat screen; $D D$, diaphragm; $E$, roof of hood; $F$, plate-glass floor of aquarium; $G$, paraffine wall of aquarium; $H H$, diaphragm to cut off light reflections from paraffine wall; $I$, wall of reflector box; $\mathscr{F}$, open side of reflector box; $K$, mirror; $L$, walls of tunnel; $M M$, black draperies; $N$, table.

a flat-bottomed, clear-glass dish $(C)$ containing distilled water to a depth of about three centimeters. The heat screen thus obtained effectually filtered out the heat rays, allowing only the light rays to pass through. A few inches under the heat screen was inserted a diaphragm $(D)$, painted black, the purpose of which was to aid in cutting out side reflections besides allowing only a central column of light to escape below. A black sheet-iron roof $(E)$ con- 
fined the upward rays to reflections within the hood itself, at the same time permitting the escape of heated air. On a table directly under the suspended light lay a horizontal sheet of plate glass $(F$,$) affixed to the upper surface of which was a circular ring$ $(G)$ made of a mixture of paraffine and lampblack. There was thus formed a circular water-tight aquarium twenty centimeters in diameter and two centimeters deep, in which the worms could be observed. On the top of this circular ring rested a black diaphragm $(H)$, the aperture of which was sufficiently small to exclude any side reflections which might come from the black paraffine wall.

The aquarium, it must be explained, did not rest directly on the table but was mounted as the cover of a box $(I)$, the interior of which had been rendered largely free from reflecting surfaces by the use of black camera-paint. One side of the box was removed and, facing the opening thus made, a mirror $(K)$ was placed at an inclination of $45^{\circ}$ with the horizon. The end of a square tunnel $(L)$, ten feet long and made of black cloth stretched upon a framework of wood, fitted close up to this opening. Suspended from the lower edge of the hood and surrounding the aquarium were adjustable black draperies $(M)$ designed to shut out possible side light and at the same time to allow a hole for the eye of the observer. It will be seen that all light reaching the aquarium comes from the lamp above by passing through the heat screen.

After illuminating the field of observation the light passes through the glass floor of the aquarium and is reflected by the mirror into the black tunnel. Most of the light is absorbed in the tunnel, only an insignificant minimum being reflected back to the aquarium floor. Otherwise complications in the character and intensity of the light might arise.

By moving the hood $(B)$ up and down and by using lamps of different candle powers a variety of intensities was obtained. The lamps used were tested by means of a Lummer-Brodhun photometer, the loss by reflection from the surface of the water both at the heat screen and at the aquarium being reckoned out in determining the different intensities employed.

By simple observation, data for such criteria of behavior as 
amount of turning, changes in course, degree of wandering, interval of response and manner of coming to rest, could be obtained in this apparatus with approximate correctness. To determine the rate of locomotion, however, required a device which would measure accurately the distance traveled in a unit of time. The

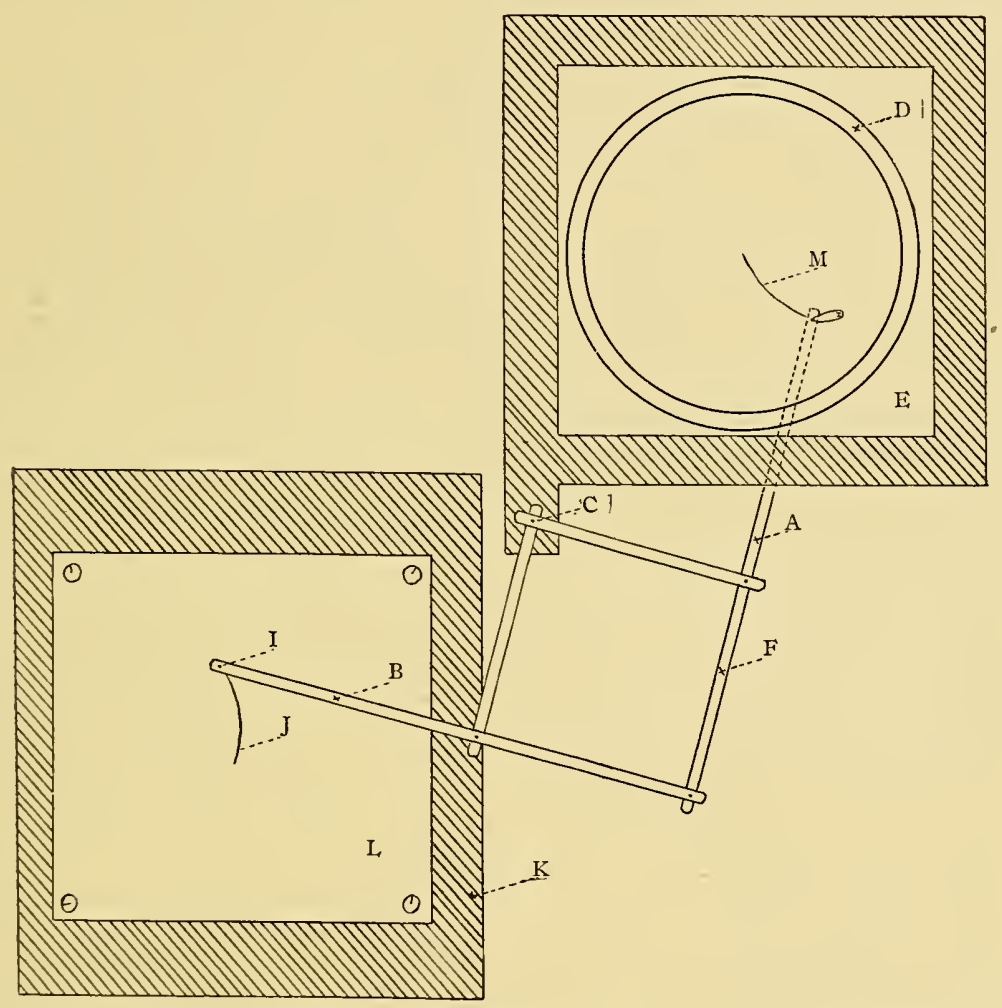

Fig. $2 A B C F$, pantograph; $C$, fixed point; $D$, paraffine wall of aquarium; $E$, plate glass bottom of aquarium; $F$, place where the $\operatorname{arm} A$ is grasped by the operator. A style is located at end of $\operatorname{arm} A$, in contact with under side of aquarium floor. $I$, style at end of tracing $\operatorname{arm} B$, in contact with smoked paper; $\mathcal{F}$, beginning of a course traced on the smoked paper; $K$, drawing board for attachment of smoked paper; $L$, sheet of smoked paper fastened to drawing board; $M$, actual course of the worm.

method already mentioned of measuring rate from mucus-tracks developed by means of powdered carmine, proved too tedious and uncertain except for the worm's maneuvers in the dark, when it seemed the only available way. 
To avoid the inconveniences of this method an attachment was devised for directly duplicating the path of a worm by means of a style traveling over a sheet of smoked paper. The records thus traced were made permanent by immersing the smoked sheets in a weak solution of resin in alcohol and allowing them to dry, after which the paths could be accurately measured and the rates computed.

The arrangement of this attachment, as seen from above, is shown in Fig. 2. The diaphragm (Fig. I, $H$ ) has been removed for the sake of clearness. At the tip of $\operatorname{arm} A F$ a style directed upward comes in contact with the under surface of the aquarium bottom (Fig. I, $F$ ), while at the tip of $\operatorname{arm} B$ a similar style that is pointed downward traces a line on the sheet of smoked paper $L$ at the left. After a little practice it was not difficult to keep the style of $\operatorname{arm} A$ directly under the posterior end of a gliding worm, thus duplicating its movements with considerable accuracy. The expiration of any time interval can be indicated on the smoked paper record by a crosswise scratch in the path.

$\operatorname{Arm} A$ was rendered as non-reflecting as possible by black camera paint as well as by being made triangular in cross section with the apex of the triangle upward. Thus whatever rays struck it from above were mostly either absorbed or reflected in a horizontal direction, so that they did not reach the worm under experiment.

\section{b Results}

Rate of Locomotion. Planaria gonocephala moves somewhat more quickly in non-directive light than it does in dark. Ten apparently normal and representative worms were selected and isolated in individual aquaria. They were kept in the dim light of the dark room in water of the same temperature as that of the experimental aquarium in which they were observed. At the end of thirty-four days of experimentation these worms showed practically the same average rates under the same intensities of light as they did at first. By alternating the individuals these trials were so made that fatigue effects had little part in the results, while the succession of light intensities was varied in such a way 
that cumulative effects and the influence of previous exposures were largely avoided.

The results obtained in 259 trials are condensed in Table III.

TABLE III

Rate of locomotion in millimeters per second of Planaria gonocephala in various intensities of non-directive light

\begin{tabular}{|c|c|c|c|c|c|c|c|c|c|}
\hline 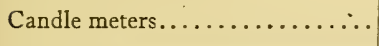 & $\circ$ & 0.94 & I I & 39 & 78 & 126 & 155 & 217 & $43^{I}$ \\
\hline Average $\mathrm{mm}$. per sec..... & 0.57 & 0.66 & 0.69 & 0.75 & 0.64 & 0.66 & 0.69 & 0.70 & 0.63 \\
\hline Number of records...$\ldots \ldots \ldots$ & 30 & 28 & 30 & 29 & 27 & 30 & 30 & 27 & 28 \\
\hline
\end{tabular}

The mechanical stimulus resulting from the removal of the worms, by means of a camel-hair brush, from their individual aquaria to the observation aquarium was practically the same in all cases as were all the other external stimuli except light. The difference in the rate of locomotion appearing in these averages is, therefore, clearly due to differences in the light intensity employed.

It will be seen also that rate does not increase progressively with intensity. The series of rates and intensities under Table III, if plotted in a frequency curve would give two modes, one at 39 and the other at 217 candle meters, with a slight depression between the two. Still, as has been already pointed out, any intensity of light gives a faster rate than no light at all.

The slowest average rate was made under the highest intensity of light employed. Certain facts to be brought forward later favor the opinion that this was not an accidental result.

Under continuous exposure to one intensity of light the rate of locomotion decreases. The worms seem to "run down" gradually, so that at the end of ten minutes their rate is only about half that during the first minute. Data illustrating this point are given in Table IV.

The rate of locomotion depends not so much upon the intensity of light as upon other factors which tend to produce individual behavior upon the part of each particular worm. Stated in another way, there is greater variation between different individuals in the average rate of their locomotion under all intensities than there 
is in the average rate of all individuals collectively under different intensities. The data for this latter point based upon the average rate of ten worms (259 observations) under different intensities has already been given in Table III (p. 57). The extremes in rate there shown are $0.57 \mathrm{~mm}$. per sec. at zero intensity and 0.75

TABLE IV

Average rate of locomotion of Planaria gonocephala in successive minutes of expssure to 39 c.m. of nondirective light

\begin{tabular}{|c|c|c|c|c|c|c|c|c|c|c|c|c|}
\hline Number of minute...... & Ist & $2 \mathrm{~d}$ & $3^{d}$ & $4^{\text {th }}$ & $5^{\text {th }}$ & 6 th & $7^{\text {th }}$ & 8 th & $9^{\text {th }}$ & roth & IIth & I 2 th \\
\hline No. of records averaged. . & 17 & 15 & 12 & 7 & 5 & 4 & 4 & 3 & 3 & 2 & 2 & 2 \\
\hline Rate in mm. per second. . & .63 & .625 & $\cdot 5^{6} 5$ & .55 & $\cdot 53$ & $\cdot 55$ & $\cdot 375$ & $\cdot 39$ & $\cdot 39$ & .29 & .25 & .29 \\
\hline
\end{tabular}

$\mathrm{mm}$. per sec. at $39 \mathrm{c} . \mathrm{m}$. intensity, which makes a range of o. $8 \mathrm{~mm}$. per sec. When the same data are rearranged to show the average rate for each individual for all intensities, as in Table $V$, the extremes are $0.49 \mathrm{~mm}$. per sec. and $0.83 \mathrm{~mm}$. per sec. with a range of $0.34 \mathrm{~mm}$. per sec.

In fact the individual behavior of these ten worms, despite their apparent similarity, was sufficiently distinct to allow each one to be thereby identified.

Turning. Attention has already been called to the fact that there is less turning in light of various intensities than in the dark. A return to Table I will make plain that there fails to be any

TABLE V

Average rate of locomotion for each of ten worms (Planaria gonocephala) based on trials with non-directive light of various intensities

\begin{tabular}{r|c|c|c|c|c|c|c|c|c|c}
\hline Identification number of worm....... & I & 2 & 3 & 4 & 5 & 6 & 7 & 8 & 9 & I0 \\
\hline $\begin{array}{r}\text { Average rate in eight intensities ex- } \\
\text { pressed in mm. per sec............ }\end{array}$ & 0.79 & 0.57 & 0.68 & 0.64 & 0.83 & 0.70 & 0.72 & $0.5^{8}$ & 0.49 & 0.62 \\
\hline
\end{tabular}

definite correlation between the degree of intensity of the light and the amount of turning, although the least turning occurs under the highest intensity. This latter point, however, rests upon a very slight difference and may not be significant. It is nevertheless worth mentioning, since it is in line with the effect of the 
highest intensity upon rate, as well as with certain other evidence to be discussed later.

The small excess of clockwise over contra-clockwise turnings is not explainable upon the ground of varying intensities of light. A distribution of the cases under the several intensities of light (Table VI) makes it plain that this peculiarity is due rather to individual causes than to light intensities. Indeed it would be difficult to conceive theoretically how varying intensities of nondirective light could influence a worm in such a way as to affect the direction in which it turns. The natural expectation according to chance would be an equal number of turnings in either direction. The excess of clockwise turns seems, therefore, undoubtedly due to internal causes which render certain worms more liable to go one way than another. In fact, when the records were arranged according to individual behavior it was found that of the ten worms seven averaged a majority of clockwise turns while only three fell in the contra-clockwise column.

TABLE VI

Character of turning of Planaria gonocephala in non-directive light of various intensities

\begin{tabular}{ll|c|c|c|c|c|c|c|c|c|c}
\hline Light in candle meters............. & 0 & 0.94 & I I & 39 & 78 & I26 & I55 & 217 & 43 I & Total \\
\hline Clockwise turns................ & 23 & 25 & 2 I & 32 & I7 & I7 & 22 & 24 & 22 & 203 \\
Contra-clockwise turns............ & 23 & 23 & I7 & 20 & I7 & I8 & I7 & I7 & I4 & I66 \\
\hline
\end{tabular}

Change of Course. A greater number of "definite" changes occur in the light than in the dark, but fewer "indefinite" changes. This point requires no further exposition as its corollary has already been given.

The behavior of the worm in this respect seems to be more closely correlated with the highest intensity (43 I c.m.) than with any other. In the highest intensity employed there are indicated (Table II, p. 52) 40 per cent of definite changes, which is considerably in excess of the percentage of such changes made in any other intensity. On the other hand indefinite, or S-shaped, changes constitute only 9 per cent of all records taken at the highest intensity, which is less than half the number of indefinite paths made in any other intensity. 
While the extremes of the series of definite changes indicate a general rise in the percentage of their occurrence with an increase of intensity, and while in the same way the extremes of the series of indefinite changes suggest in general a decrease of frequency with the increase of intensity, it can hardly be maintained that the character of the changes in course is definitely correlated in the majority of cases with changes in intensity.

Degree of $W$ andering. Wandering is not closely correlated with the intensities of light. In Table VII, which deals with the percentage of straight paths made by $\mathrm{P}$. gonocephala under different intensities of non-directive light, this fact is expressed negatively, since it is held that a straight path is a good indication of the absence of aimlessness or wandering and may thus serve as a negative measure of such behavior.

\section{TABLE VII}

Percentage of straight paths made by $P$. gonocephala in the dark and also in non-directive light of different intensities

\begin{tabular}{r|c|c|c|c|c|c|c|c|c}
\hline Light in candle meters................. & 0 & 0.94 & II & 39 & 78 & I26 & I55 & 217 & 43 I \\
\hline Percentage of straight paths.............. & I3 & 24 & 34 & 31 & 19 & 33 & 25 & 23 & 35 \\
\hline
\end{tabular}

In this respect again the behavior of the worms under the highest intensity is more pronounced than under any other intensity since the greatest number of straight paths were laid at an intensity of 43 I c.m.

Interval of Response. There seems to be some evidence that the interval of time elapsing between the reception of a light stimulus on the part of a worm and its consequent response, may be quite considerable. Three facts were established that may support this conclusion.

First, when two-minute records were made under various intensities, it was found that the worms averaged a faster rate during the second minute of exposure to the light than during the first, in spite of the facts that the mechanical stimulus due to placing the worm in the light machine had a more quickening influence during the first minute and that the fatigue effects were more likely to appear during the second minute. The actual figures 
for the above statement, based upon 240 two-minute trials under various intensities, are $0.645 \mathrm{~mm}$. per sec., the average during the first minute, as against $0.713 \mathrm{~mm}$. per sec., the average during the second minute.

Secondly, in these 240 trials, the percentage of turning under all intensities is greater during the first minute than during the second, being 87 per cent and 57 per cent, respectively. This result may possibly be conceived to be due to a greater steadying influence of the light during the second minute than during the first and to a consequent greater turning than during the first minute. But on the other hand a similar decrease of turning, although not so pronounced, took place during the second minute when the worms were in the dark. It must be admitted, therefore, that the fact of less turning during the second minute may have nothing to do with the interval of response.

Thirdly, on several occasions a notable piece of behavior was observed, which may have a bearing on the interval of response. The phenomenon in question always occurred in connection with a modification of the experimental field within the light machine to be more fully described later. Briefly this modification consisted in making a field. of two distinct intensities of light, the latter being projected vertically from above in such a way that a sharp line of demarkation formed a boundary between the two areas. Ordinarily when the worms reached this boundary line as they glided from one intensity to another, they responded promptly to the stimulus caused by the change of intensity. Several times, however, they were observed to travel indifferently exactly along this dividing line for a distance of several centimeters with half the body in one intensity and half in the other. This curious fact lends itself to various interpretations, one of which is that the response to a new intensity may not be, in all cases, immediate.

Manner of Coming to Rest. During the experiments made in the non-directive light apparatus previously described, normal worms could never be induced to come to rest in the light. If allowed to remain in the aquarium they would wander about until they reached the shadow under the diaphragm (Fig. I, $H$ ), 
where they finally stopped, usually in the angle formed by the paraffine wall and the bottom.

Loeb's conclusion ('93b, p. IOI) that planarians subjected to directive light come to rest in regions of least intensity, seems therefore to be equally true of planarians in non-directive light.

Summary. In non-directive light Planaria gonocephala moves faster, turns less and makes more "definite" but fewer "indefinite" changes than in the dark. Rate of locomotion; amount of turning; changes in the character of the course, as well as the amount of wandering, do not appear to be correlated with varying light intensities, unless in the following instance. Under the highest intensity employed, namely, 43 I c.m., occurred the slowest rate; the least turning; the greatest number of "definite" and the fewest "indefinite" responses, together with the straightest paths. The excess of clockwise over contra-clockwise turnings throughout the series of intensities is probably not attributable to light.

Continuous exposure to light results in a decreasing rate of locomotion, although in the second minute of movement as compared with the first an increase in the rate of locomotion takes place, while fewer turnings occur.

Rate of locomotion is less influenced by differences in light intensity than by certain internal factors which go to make up what may be termed the individuality of different worms. Individual worms may sometimes fail to respond for a considerable interval of time to light stimuli that ordinarily produce immediate effects.

Finally, planarians subjected to non-directive light come to rest in regions of lessened light intensity the same as they do in directive light.

\section{Abrupt Changes in Intensity}

Abrupt changes in intensity may be of two kinds: either with reference principally to time or to space. First, those changes are abrupt in time in which light or dark is suddenly thrown upon the worm, and secondly, those changes are abrupt in space in which a moving worm passes immediately from an area of one intensity into a sharply defined area of a different intensity. This topic 
will be discussed here only in its relation to non-directive light, the effects of sudden changes in directive light coming more properly in a later section.

a Abrupt Changes of Light Intensity in Time

Whenever worms were left over night in the experimental aquarium completely shut off from light, a large proportion of them would be found at rest in the morning when the light in the hood was again turned on. By removing the diaphragm (Fig. I, $H$ ), under the edge of which near the paraffine wall the worms were usually collected, it was possible without any mechanical disturbance to subject resting worms to sudden non-directive light after a prolonged period of complete darkness. This sudden stimulus rarely had an instantaneous effect. The interval of response was often several minutes and frequently non-directive light alone proved insufficient to start the worms into activity.

No sudden increase of intensity ever proved powerful enough to throw a gliding worm into the more rapid method of crawling. Pearl ('o3, p. 55 I) stated the same fact after subjecting planarians to much stronger intensities of light than were employed in the present experiments.

It was found that $\mathrm{P}$. gonocephala showed a decided responseeither some change in course or a wigwag motion of the anterior end-more frequently when suddenly subjected to dark than to light. By inserting a key into the electric circuit it was possible to control the light in the hood to a fraction of a second. Worms in complete darkness were by this means subjected to various intervals of sudden light and worms in light to intervals of sudden dark, the results being at once noted. While the worms were in the dark their behavior could not, of course, be directly observed, but by watching them closely just before the light was turned off and also the instant it was turned on again there was no great difficulty in determining whether a response had occurred during the interval. The results obtained from nearly a thousand trials are indicated in Table VIII.

It will be seen from this table that there are more responses than failures to respond and that the responses occur more fre- 
quently when the worms are suddenly subjected to dark than to light.

It may be further noted that the excess of the responses in the dark over those in the light increases with the interval of exposure, indicating that the worm's adjustment to a change in the light stimulus affecting it is not in all cases immediate.

The effect of previous exposure, whether to several hours of dark or light, is a factor in these results which will be considered more properly later on.

TABLE VIII

Percentage of the responses of $P$. gonocephala in various intervals of time when suddenly subjected to dark and to light of 39 c.m.

\begin{tabular}{|c|c|c|c|c|c|c|c|}
\hline Number of seconds exposed.... & 5 & 10 & 15 & 20 & 25 & 30 & Average \\
\hline Percentage of responses in light...$\ldots \ldots \ldots$ & $5^{\mathrm{I}}$ & 59 & 54 & 54 & 48 & $4^{6}$ & $5^{2}$ \\
\hline Percentage of responses in dark... & $6_{3}$ & 66 & 73 & 75 & $7 \mathbf{I}$ & $7 \mathrm{I}$ & 70 \\
\hline Excess of responses in dark. $\ldots \ldots \ldots \ldots \ldots \ldots$ & 12 & 7 & 19 & $2 I$ & 23 & 25 & 18 \\
\hline
\end{tabular}

It should be added that Bdelloura gives a remarkable response when enveloped in sudden darkness. It will frequently forsake its attachment under these circumstances and unattached in the water go through violent contortions. This striking response can be called forth by an exceedingly brief interval of dark, namely, the shortest time required to turn the electric light off and on. Nagel ('94, p. 387) speaks of animals thus affected by sudden shadow as "skioptic."

The relation of Bdelloura to light falls into a somewhat different category, however, than that of the fresh-water planarians, since Bdelloura is positive to light, while fresh-water flat-worms are negative.

\section{b Abrupt Changes of Light Intensity in Space}

Several devices were employed to test the behavior of planarians passing abruptly from an area of one intensity of non-directive light into another. The most successful device tried was that in which two lights of different intensities were mounted overhead 
in the hood of the apparatus already described in Fig. I, the mingling of their rays being prevented by the insertion of a vertical diaphragm (Fig. 3, C), which extended from the region between the lights down to the surface of the aquarium. In order to place the diaphragm in position it was, of course, necessary to remove the heat screen (Fig. I, $C$ ), the presence or absence of which, however, would not have affected the results sought since the water in the aquarium itself was nearly $2 \mathrm{~cm}$. deep and thus

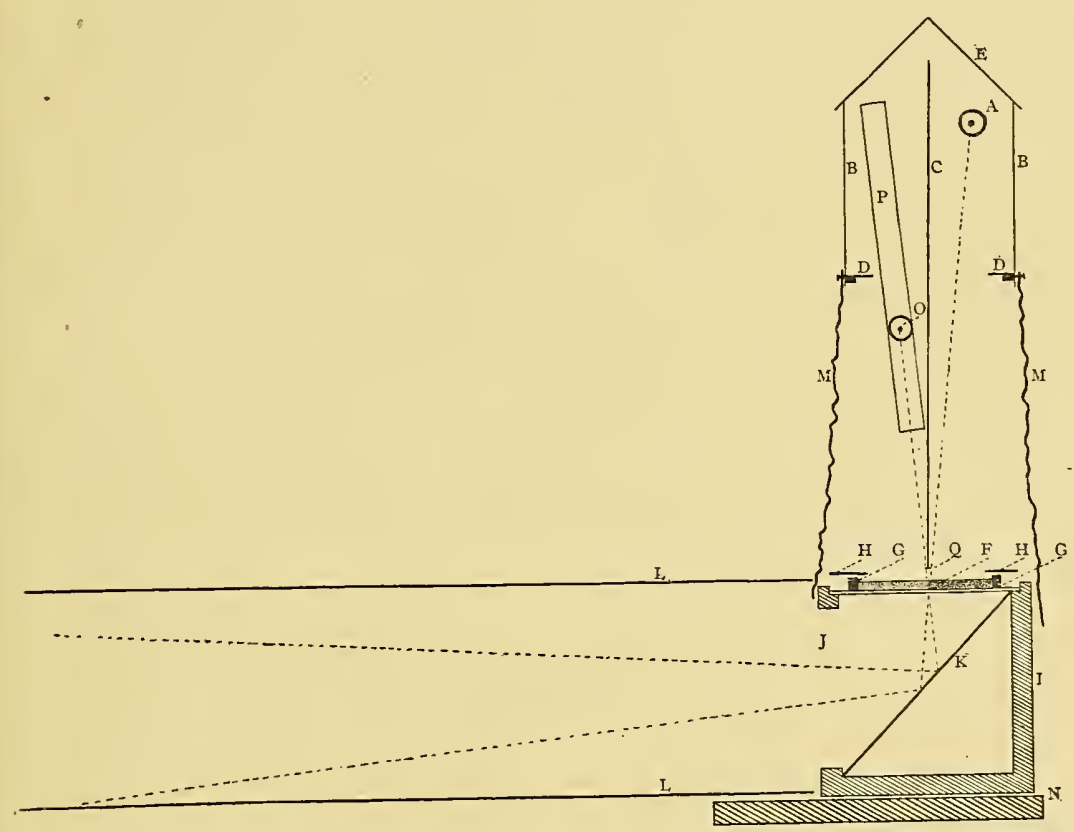

Fig. $3 A$, stationary light; $B$, sheet iron walls of hood; $C$, vertical diaphragm separating the two lights; $D$, horizontal diaphragm; $E$, sheet iron roof of hood; $F$, plate glass aquarium floor; $G$, paraffine wall of aquarium; $H H$, diaphragm to shut off refiections from wall of aquarium; $I$, wall of reflector box; $\mathcal{F}$, open side of bos; $K$, mirror; $L$, black tunnel; $M$, black draperies cutting off side light; $N$, table supporting reflector box and end of tunnel; $O$, movable light; $P$, track for movable light; $\mathcal{Q}$, narruw, horizontal diaphragm attached at right angles to the lower side of the diaphragm $C$, in order to prevent the light rays from the two sources of light, $A$ and $O$, from overlapping.

constituted an efficient heat screen. By keeping the hood stationary and causing one of the lights (Fig. 3, O) to slide up and down at will, it was possible to bring about various contrasts of 
intensity in the field below. The complete plan of the apparatus is given in Fig. 3 .

The principal variations in the behavior of Dendrocolum and Phagocata upon reaching the critical line separating the areas of two intensities are indicated diagrammatically in Fig. 4.

The dotted line represents the boundary separating two areas of different light intensities. The arrows represent the types of paths made by Dendrocœlum and Phagocata. For the sake of simplicity the worms are represented as going in one direction; that is, into one of the two contrasting intensities, but the same types of paths resulted as well when the opposite direction was

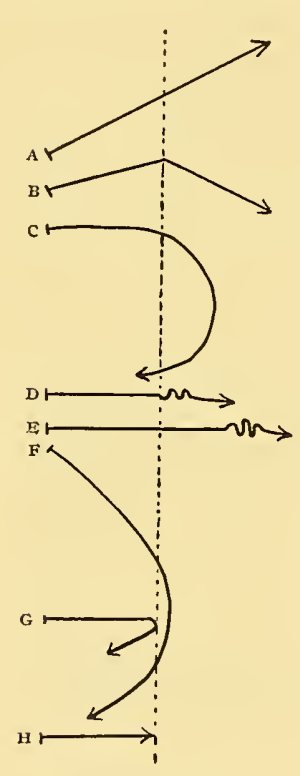

Fig. 4 taken. The angles made in crossing the critical line were also more varied than those represented in the diagram.

Type $A$ represents a passage without response; $B$, an angular change of course made at the critical line; $C$ and $F$, a loop-like return effected after a short excursion into the new intensity, and $G$, a sharp turning aside, while $H$ indicates a halt at the critical line, as if a barrier had been encountered. Finally $D$ and $E$ represent a temporary pause on the part of the worm accompanied by wigwag movements of the anterior end of the body. In the case of $D$ the wigwagging is immediate, but $E$ typifies a case when there occurred in the response an interval of such a nature that the significant movements were not made until the worm had advanced at least its own length into the new area.

Of these types all, with the exception of $A$, are to be regarded as reactions to differences in intensity encountered. The most questionable are the infrequent types $C$ and $F$, which may be otherwise explained as arcs in a curving course which might have occurred in a field of uniform intensity. By far the commonest type was $D$, plainly the least doubtful of the series. 
As a result of over 3000 observations on the manner in which the critical line separating the two intensities was passed, three facts become evident. First, responses were considerably more

TABLE IX

Kind and percentage of responses of Dendrocelum and Phagocata in passing from one intensity of nondirective light to another

\begin{tabular}{r|c|c|c|c|c|c}
\hline Character of course & $\begin{array}{c}\text { No } \\
\text { responses } \\
(\text { Type } A)\end{array}$ & $\begin{array}{c}\text { Wigwags } \\
\text { (Types } \\
\text { and } E)\end{array}$ & $\begin{array}{c}\text { Turn-backs } \\
\text { and full } \\
\text { stops } \\
(\text { Types } \\
G \text { and } H)\end{array}$ & $\begin{array}{c}\text { Loops } \\
\text { (Types } \\
C \text { and } F)\end{array}$ & $\begin{array}{c}\text { Angular } \\
\text { courses } \\
(\text { Type } B)\end{array}$ & $\begin{array}{c}\text { Total } \\
\text { responses }\end{array}$ \\
\hline $\begin{array}{r}\text { Going into greater intensity, } \\
\text { per cent................ }\end{array}$ & 79 & 11 & 6 & 2 & 2 & 21 \\
$\begin{array}{r}\text { Going into lesser intensity, } \\
\text { per cent....................... }\end{array}$ & 50 & 36 & 5 & 8 & 1 & 50 \\
Average responses, per cent. & 64.5 & 23.5 & 5.5 & 5.0 & 1.5 & 35.5 \\
\hline
\end{tabular}

frequent when the worms were passing into the lesser intensity than they were when entering the greater intensity. Secondly, lack of response is more frequent than a visible response of any kind since 64.5 per cent of the crossings made over the critical line were of the type $A$. Thirdly, the responses at the critical line were more frequent when the worm was upside down, $i$. e., moving on the surface film, than when it was on the floor of the aquarium. This latter point was illustrated most fully by Phagocata, which, being an active worm, takes quite readily to the surface film, so that it was possible with this species to get a series of observations in which the behavior when crossing the critical line on the bottom of the aquarium could be compared with that when the same line was encountered at the surface film. Table X contains the results of these observations.

The doubling of responses when the worm is on the surface film is probably not due to an unequal receptivity of light stimulus by the dorsal and ventral surfaces of the planarian as might at first thought seem possible. As will be shown further on, the worm's rate of locomotion on the bottom of the aquarium is nearly the same whether the light comes from below or from above, pro- 
vided the amount of light in both cases is equal. Planarians, as Pearl has emphasized, are strongly thigmotactic. Naturally, then, their response to contact is much greater when they are on the glass bottom of the aquarium than when they are suspended on the less resistant surface film. In other words, the less the worm is influenced by the stimulus of contact the freer it is to respond to the stimulus of light.

TABLE X

Percentage of the responses made by Phagocata at the critical line separating two intensities of non-directive light either on the bottom of the aquarium or on the surface fllm

\begin{tabular}{|c|c|c|c|}
\hline & $\begin{array}{l}\text { Number of } \\
\text { observations. }\end{array}$ & $\begin{array}{l}\text { No response } \\
\text { per cent }\end{array}$ & $\begin{array}{l}\text { Response } \\
\text { per cent }\end{array}$ \\
\hline 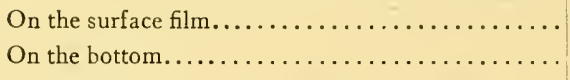 & $\begin{array}{r}740 \\
1664\end{array}$ & $\begin{array}{l}45^{\frac{1}{2}} \\
76\end{array}$ & $\begin{array}{l}54 \frac{1}{2} \\
24\end{array}$ \\
\hline Total................. & 2404 & $60_{4}^{3}$ & $39^{\frac{1}{4}}$ \\
\hline
\end{tabular}

Finally, a series of experiments was tried in which the contrast between two intensities was varied by raising or lowering one of the lights in the hood. It was found that the responses made by Phagocata under these circumstances increased with the increase in contrast between the two intensities as shown on the bottom line of Table XI, where these contrasting intensities are expressed in a ratio between the constant light taken as unity and the movable light.

The fact that responses by no means invariably occur when bright light and complete darkness are suddenly substituted for each other (see Table VIII) rendered a further extension of this series unnecessary. The contrasts here used form probably a much greater range of intensity contrasts than the worms ever encounter in nature.

Attention to the details presented in Table XI brings to light the fact that, although the number of responses is correlated in a general way with an increase in the contrast between the two illuminated areas, as shown in the bottom line of the table, yet the percentage of the responses is further influenced by the actual degree of the intensities employed. For example, when the two 


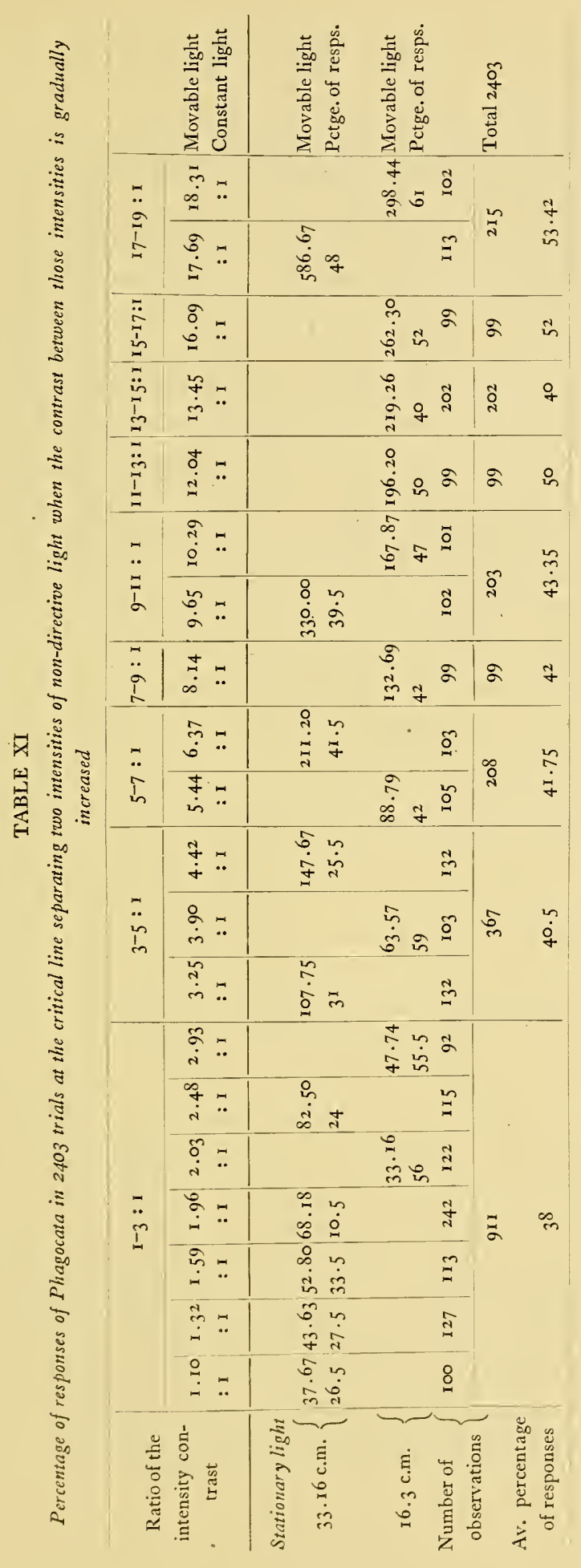


areas of light were respectively 33.16 and $68.18 \mathrm{c.m}$. the ratio was practically the same as when the two intensities were 16.3 and 33.16 c.m., yet the percentage of responses in the two cases is decidedly different, being 10.5 per cent in the former, and $5^{6}$ per cent in the latter case When the lesser of the two lights was 33.I6 c.m. there were invariably fewer responses than when the lesser light was I6.3 c.m. The latter intensity is undoubtedly nearer the planarian's optimum intensity, and the apparently inhibitive action of the higher intensities agrees perfectly with certain facts already detailed, as, for instance, that the activities of Planaria gonocephala were less pronounced at $43 \mathrm{I} \mathrm{c.m.} \mathrm{than} \mathrm{in} \mathrm{lesser} \mathrm{inten-}$ sities; and, again, that all planarians show more responses on going into a lesser than when going into a greater intensity.

Attempts were made in some other ways to subject planarians to areas of contrasted intensities and, although the results were less satisfactory in general than those obtained by the method of using two overhead lights of different intensities just described, yet certain facts were brought out that may be worth recording.

In the first of these attempts two concentric rings of white paper, each about two centimeters wide and having between them a space of a couple of centimeters, were fastened to the under surface of the aquarium floor. The white paper thus arranged reflected the light upward and made areas of gradually increased intensity as compared with the remainder of the aquarium floor through which the light passed without reflection. Worms placed in the center of these circles would consequently be obliged to pass from one intensity of light directly to another, whatever the direction of the radius they might be taking. When worms were actually tested, it was found that they exhibited considerable modification in their movements, particularly when approaching the edge of the paper backgrounds.

Owing to the considerable thickness of the plate-glass floor of the aquarium as well as to the fact that white paper is a surface which scatters the light falling upon it, it was found that there was formed, not a sharp line of demarkation between two intensities, but rather a penumbra-like margin of intermediate light. This apparatus was therefore abandoned as unsatisfactory. 
The difficulties presented by paper as a reflecting surface largely disappeared by the substitution of a plain mirror in its place, since the surface of a mirror is such that all the light striking it at right angles is reflected at right angles. When, therefore, an unmounted mirror was brought into contact with half of the under surface of the aquarium floor the whole field was thereby divided into two regions sharply separated from each other. Of these one was supplied with light from above only, while the other received the same light plus nearly an equal amount reflected from the mirror below. With the aid of this device an increase of I I per cent was gained over the responses obtained when white paper instead of a mirror was used as a reflector. Both Phagocata and Dendrocœlum were tried by this method. In 76 per cent of the trials made, $i$. e., in 125 cases out of 165 , the worms showed a visible modification in their behavior on reaching the boundary of the two areas of light. It was nevertheless decided that this method was an uncertain test of behavior, since the body of the worm, although fairly translucent, would by no means allow all the light that fell upon it to pass through and be reflected, and consequently the difference of the two intensities to which it was being subjected could not be easily estimated.

Summary. When sudden light or dark envelops planarians (Dendrocœlum, Phagocata and Planaria) the response, if any occurs, is often not immediate.

No one of the intensities of light which were employed in these experiments when introduced suddenly was sufficient to make the worms forsake gliding for crawling.

Sudden dark calls out more responses than sudden light, while the number of responses increases with an increasing interval of exposure to the stimulus. Bdelloura is decidedly "skioptic."

Worms encountering the edge of a reflecting area which increases the intensity of the light without introducing any other barrier, show a marked degree of response. The percentage of response is considerably larger when a mirror instead of white paper is used to produce the reflecting surface. If worms are allowed to pass from one intensity to another sharply separated from it, their responses are more frequent upon passing into the lesser intensity 
than when going into the greater. The average number of failures to respond to these contrasts of intensity reaches about two out of three.

Phagocata, at the critical line separating two contrasting intensities, responds oftener when on the surface film than when gliding over the bottom of the aquarium.

The number of responses increases with the increase in the contrast between the two intensities employed, but the percentage of response is greater, regardless of ratio, when one of the lights is of low intensity ( 13.6 c.m.) than when both are of higher intensity $(33+$ c.m. $)$

\section{PHOTOTAXIS}

The term "phototaxis" was introduced by Strasburger (' 78$)$ in a study of certain swarm-spores, to indicate movements which were parallel with incident light rays. The term has since been extended by several authors to include similar movements on the part of animals. Any organism is said to be positively phototactic when it moves toward the source of light in the direction of the rays and negatively phototactic when it goes in the opposite direction.

The purpose of this section is to consider the phototactic movements of planarians, as distinct from their photokinetic behavior, (A) when the light remains constant, (B) when the light is changed either (a) in intensity or (b) in direction, and (C) when phototaxis is combined with responses of a different kind.

\section{A In Constant Directive Light}

Orientation. With the exception of Bdelloura all the planarians studied are, under normal conditions, negatively phototactic so far as their first movements in directive light are concerned. To obtain quantitative data for this statement it was necessary to construct an apparatus in which the worms to be tested could be placed quickly and with as little mechanical disturbance as possible in the center of a unit circle with the long axis-at right angles to the direction of incident light. The circle was marked off into degrees so that by noting the place at which a worm made its exit a quan- 
titative measure of the amount of turning toward or away from the source of the light under the given conditions was obtained.

The apparatus finally utilized for this experiment was based upon a device employed by Parker and Burnett ('o) in testing the relative behavior of normal and eyeless planarians when subjected to directive light. Its arrangement is shown in Fig. 5 .

On the top of a table $(A)$ in the dark room was placed a rectangular aquarium $(B C D E)$, the ends of which $(B E$ and $C D)$ were

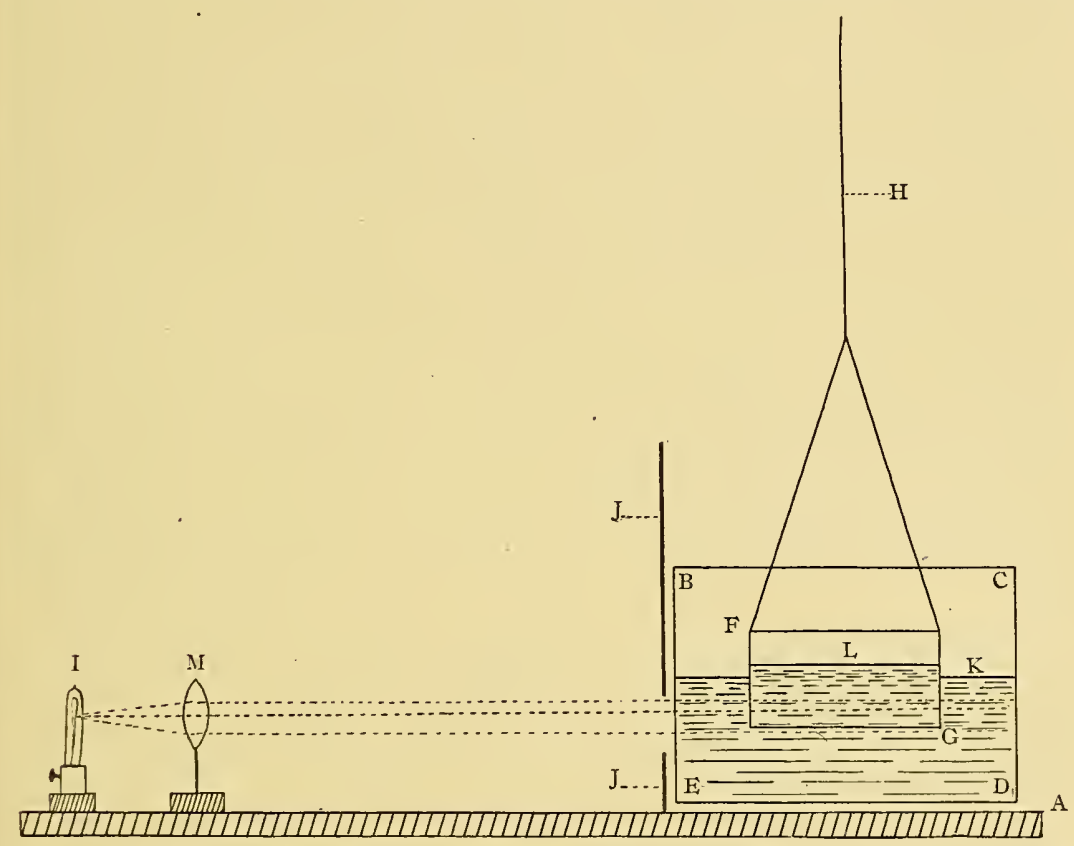

Fig. $5 A$, Top of table; $B C D E$, rectangular aquarium; $B E$, glass end; $F G$, round swinging aquarium; $H$, copper wire attached to ceiling and supporting the swinging aquarium $F G ; I$, movable light; $\mathfrak{F} \mathcal{F}$, diaphragm; $K$, surface of water in outer aquarium; $L$, surface of water in inner aquarium; $M$, lens.

made of glass while the floor and sides were of wood painted with camera-black. Within this aquarium a second cylindrical one $(F G)$, made entirely of thin glass and measuring $20 \mathrm{~cm}$. in diameter, was suspended from the ceiling by means of a fine wire $(H)$ attached to a swivel to allow turning. On the floor of the outer aquarium and directly beneath the inner one was drawn a circle 
Io $\mathrm{cm}$. in diameter and marked off plainly into arcs measuring 5 degrees each. An incandescent lamp (I), placed on the table at approximately the height of the inner aquarium floor, could be manipulated at any desired distance, while a diaphragm (f) prevented much of the light from reaching either the upper surface of the water contained in the two vessels or the floor of the outer aquarium whence itwould be reflected. A biconvex lens was then so interposed as to make the light rays practically parallel upon their emergence from it. Their course through the inner aquarium was kept parallel by means of the medium of water on both its inner and outer sides. A nearly uniform intensity over the entire floor of the swinging aquarium was thus obtained and the objection arising when the inner aquarium is used in air, viz: that it acts as a converging lens, was obviated. Side reflections were eliminated by enclosing the light $(I)$, together with the intervening space between it and the diaphragm, with black screens.

When a worm introduced into the inner aquarium began to glide, it could with slight mechanical disturbance be quickly rotated, by means of moving this inner aquarium, into any desired position with reference to the light, and then swung so as to bring its posterior end exactly over the center of the stationary circle below.

Various species of planarians were started in this manner at right angles to the light. Out of 386 cases, 37 , or 96 per cent, emerged from the $10 \mathrm{~cm}$. circle at a point farther away from the light than that toward which they were originally directed. This is taken to mean that 96 times out of a hundred the worms were negatively phototactic. If, however, the method of reckoning negativeness employed by Parker and Arkin ('or) on the earthworm is used, the foregoing per cent would be somewhat less. These authors assume ('or, p. 28) that the apparently positive responses of a normally negative animal, such as the earthworm, may be due to causes other than light, in which case an equal number of responses of like nature might be expected to occur on the negative side as well as on the positive. A number equal to the sum of these apparently positive responses should therefore be subtracted from the total of the apparently negative responses 
in order to obtain approximately the amount of unquestionable negativeness. By following this method in the case just given, the per cent of negativeness would be 92 instead of 96 , but since this method assumes that normally negative worms are never positive, which is contrary to the evidence to be given later, the most accurate estimate of negativeness would probably fall somewhere between these two percentages.

Bdelloura, on the other hand, behaves in the same way only three times out of ten, therefore showing itself to be positively phototactic.

This difference in orientation becomes more marked if the total number of degrees, that is, the amount of positiveness and negativeness of emergence from the circle is used as the basis of reckoning, instead of only the number of times of emergence. Such a quantitative computation is shown in Table XII.

TABLE XII

Amount and kind of orientation to directive light exhibited by various species of planarians in 396 trials

\begin{tabular}{r|c|c|c|c|c}
\hline & $\begin{array}{c}\text { Number of } \\
\text { trials }\end{array}$ & $\begin{array}{c}\text { Total de- } \\
\text { grees positive }\end{array}$ & $\begin{array}{c}\text { Total de- } \\
\text { grees negative }\end{array}$ & $\begin{array}{c}\text { Percentage of Percentage of } \\
\text { degrees neg. }\end{array}$ \\
\hline Negative worms (Dendroce- & & & & & \\
lum, Planaria, Phagocata). & $3^{86}$ & 566 & 10157 & $94 \cdot 7$ & $5 \cdot 3$ \\
Positive worms (Bdelloura)... & I0 & 397 & 50 & 11.2 & 88.8 \\
\hline
\end{tabular}

Although the actual number of trials for Bdelloura in this table is small, they are characteristic of what was observed in a large number of unrecorded instances.

The amount a planarian may deviate from the direction in which it is pointed, depends upon the direction of the light impinging upon it. A negative species deviates from a straight course least when headed away from the source of the light and most when headed toward it, while an intermediate degree of deviation occurs when the direction of the light is at right angles to the long axis of the worm. In the case of Bdelloura the converse is true, as shown in Table XIII.

Rate of Locomotion. In obtaining the rate of locomotion of worms subjected to directive light, the double aquarium apparatus 
just described was used. After the worm to be tested had been placed in the inner aquarium and had begun gliding, it was so oriented that the tip of its posterior end came precisely over the center of the subjacent circle $10 \mathrm{~cm}$. in diameter. The exact time of its departure from the center of the circle was then noted and the instant thereafter that the tip of the posterior end passed over the circumference of the circle was again taken and the worm's course plotted at once on a duplicate circle sheet. Each worm was given four trials in this manner, being started in four different directions, toward the light, away from the light, and with the long axis of the body at right angles to the light, first with one side to the light. and then with the other.

TABLE XIII

Amount of average deviation in 2400 trials expressed in degrees of a circle, exhibited by negative planarians,

(Dendrocolum, Planaria and Phagocata), and a positive one (Bdelloura) when pointed toward, away from, and at right angles to the source of light

\begin{tabular}{|c|c|c|c|}
\hline $\begin{array}{l}\text { Direction in which the worm was pointed with regard } \\
\text { to the light } \ldots \ldots \ldots \ldots \ldots \ldots \ldots \ldots \ldots \ldots \ldots \ldots\end{array}$ & At right angles & Towarủ & Away from \\
\hline Negative planarians, degrees....... & $4^{8 . I}$ & I28.7 & $27 \cdot 3$ \\
\hline Positive planarians, degrees........... & 49 . & $39 \cdot 3$ & 132.1 \\
\hline
\end{tabular}

The time of the worm's emergence from the circle was not taken with a stop-watch because the observer's hands were otherwise occupied. Instead a small clock, ticking half-seconds, was placed conveniently near. By counting the number of ticks during the interval of the worm's transit from the center to the circumference of the circle the time consumed could be determined within less than a half-second. After tracing the worm's course on a duplicate circle sheet and measuring the same by means of a map measurer, a unit of distance was obtained, which together with the known unit of time consumed in covering this distance, furnished all the data necessary for computing the rate of locomotion.

Ten representatives of Dendrocolum lacteum, Planaria maculata, Phagocata gracilis and Planaria gonocephala respectively were given four trials apiece by the method just explained. The results are presented in Table XIV. From the 160 records thus obtained it becomes evident that the average rate of locomotion 
is greatest when the worms are pointed toward the light, and least when they are pointed in the opposite direction, while an intermediate rate occurs when they are started at right angles to the light.

This result is at variance with the findings of Parker and Burnett ('oo, p. 38r), who incidentally reported that Planaria gonocephala when started away from the light traveled faster than when started toward the light.

\section{TABLE XIV}

Average rate of locomotion, expressed in $\mathrm{mm}$. per sec., of various species of planarians when started torward, away from, and at right angles to the source of directive light of 27 c.m. intensity.

\begin{tabular}{|c|c|c|c|c|c|}
\hline Species & $\begin{array}{l}\text { Dendrocœlum } \\
\text { lacteum }\end{array}$ & $\begin{array}{l}\text { Planaria } \\
\text { maculata }\end{array}$ & $\begin{array}{l}\text { Phagocata } \\
\text { gracilis }\end{array}$ & $\begin{array}{c}\text { Planaria } \\
\text { gonocephala }\end{array}$ & $\begin{array}{c}\text { Total } \\
\text { average }\end{array}$ \\
\hline $\begin{array}{r}\text { Direction in which the worm was } \\
\text { pointed with reference to the light }\end{array}$ & & & & & \\
\hline At right angles ............ & 0.855 & I. 475 & I. 445 & 0.980 & 1.19 \\
\hline Toward...... & 0.910 & I. 505 & $1.43^{\circ}$ & 1.205 & 1.26 \\
\hline Away from... & 0.795 & 1.440 & 1.310 & 1.090 & I. 16 \\
\hline
\end{tabular}

It was further found that, regardless of the direction in which the worms were started, there was a gradual decrease of the rate during the four successive trials. The order in which different worms were oriented during the four trials was arranged so as to neutralize the possible effect of the sequence in the direction started. In Table XV the data for 200 trials are arranged to express this slowing down of the rate.

TABLE XV

Average decrease in rate of locomotion for 50 planarians during four successive trials while subjected to directive light of $27 \mathrm{c.m}$.

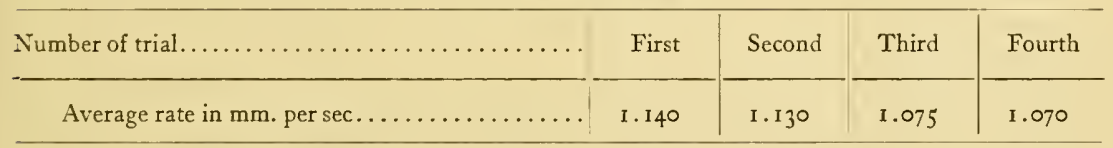

Various factors influencing the rate of locomotion, such as the intensity of light, the size and species of the worm, the amount of pigment present in the body and the general physiological state of the animal under experimentation, will be more suitably discussed in other connections. 
Change in Character of Course. When several specimens of Phagocata were placed in a square aquarium which received light solely from one side, their first movements were plainly negative, that is, away from the light. After a brief interval, however, it was seen that apparently as many worms were going toward the light as in the opposite direction. In fact an actual count showed that in a certain interval of time 43 worms passed a central point going toward the light while 44 passed the same point in the opposite direction. This apparent change in the character of the course was probably due, not to any change in the degree of negativeness of the animal, but rather to the fact that the impulse to keep moving in some direction is stronger than the impulse to negative phototaxis. Consequently when the limit of the aquarium in a negative direction is reached a worm, since it normally travels in straight lines or sweeping curves and does not turn around and around in one spot, continues its locomotion in the direction of least resistance, namely, back toward the light. It will be remembered that Loeb ('93b) has called attention to this fact by saying that planarians are not negatively "heliotropic" in a strict sense because they do not remain as far away from the source of light as they can get.

Among various observations made with other ends in view, there were numerous incidental cases of a normally negative worm making an unexpected positive response even from the first moment of being subjected to the light stimulus. This occasional positiveness is clearly apparent from the general fact already noted that four times out of a hundred the average negative planarian turns toward the light.

Two definite instances of a reversal in the character of response may be cited.

The first was the case of a Phagocata in the double aquarium, which became increasingly positive through twelve successive trials. Its average emergence from the circle for the first four trials was $45^{\circ}$, which is a normal negative result, since $90^{\circ}$ represents complete indifference. In the next four trials, however, the average was $100^{\circ}$, that is, slightly positive, and in the last four, $124^{\circ}$, which is decidedly positive, as shown diagrammatically in Fig. 6. 
In the other instance an individual worm, Planaria gonocephala, made the erratic average emergence from a circle of $145^{\circ}$, just $35^{\circ}$ short of absolute positiveness. This worm was carefully isolated and tested again four days later under identical external conditions when it was found to have returned to a normal negative condition by showing an average record of $56^{\circ}$.

Accuracy of Orientation. It was found to be frequently the case that when negative worms were subjected to directive light their first movement instead of being directly away from the source of light formed a path in a diagonal direction. This tendency to
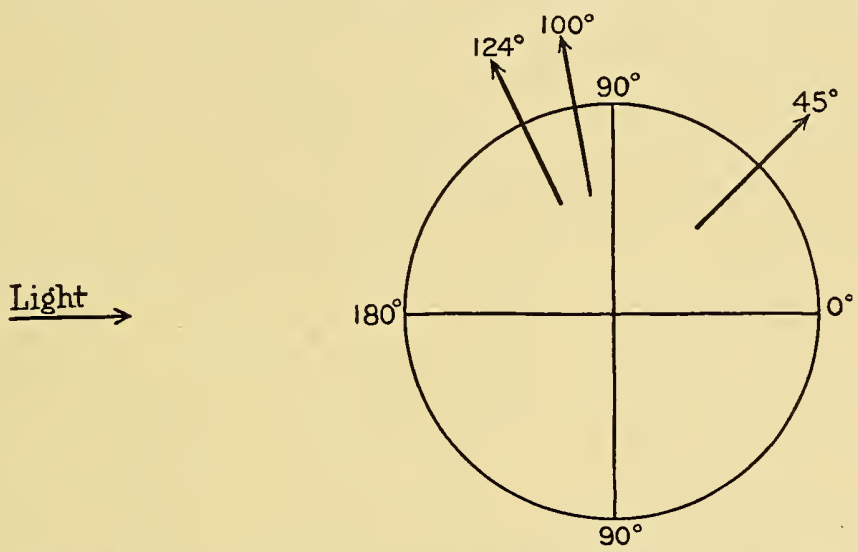

Fig. 6 The arrow at the left represents the constant direction of the light. In each of the three sets of trials each worm was headed successively toward $0^{\circ}$, the upper (in the diagram) $90^{\circ}, 180^{\circ}$, and the lower $90^{\circ}$. The point of average emergence for the first set of trials-supposing the records of the lower semicircle to have been transferred to the upper semicircle-was at $45^{\circ}$, of the second set, at $100^{\circ}$, and of the third set, at $124^{\circ}$.

travel diagonally away from the light has also been noted in the case of the earthworm by Smith ('o2, p. 469).

If the negative phototaxis of planarians is to be explained on the theory of tropisms, and if, moreover, the eyes, as Hesse ('97) maintains, are the principal organs which, when unequally illuminated, cause the directive response, it may be shown that possibly the arrangement of the crescentic pigment shields around the sensory cells of the eyes is such that equal stimulation of both eyes is just as certainly received by the worm when it is in a position diagonal to the light as when it is pointed directly away from the light. 
By reference to Fig. 7, in which the relative size of the eyes is somewhat exaggerated and made diagrammatic for sake of clearness, it will be seen that no more light reaches the sensory cells of either eye from position $A$, the diagonal position, than from position $B$, and that it is only when the light comes from some source more lateral than $A$ that the left eye receives more illumination than the right.

This view may furnish a possible explanation of the diagonal paths representing imperfect orientation among planarians, but it can in nowise apply to the case of earthworms since in them direction eyes are absent.

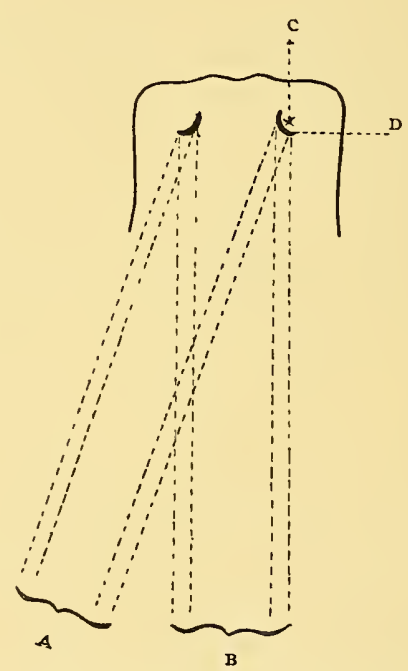

Fig. $7 A$, diagonal direction of light; $B$, posterior direction of light; $C$, location of sensory cells; $D$, pigment shield.

Degree of $W$ andering. The degree of wandering decreases with an increase of intensity. It may be found approximately through the degree of error in orientation in a unit space under different intensities of light, for perfect orientation signifies the minimum of random wandering and, conversely, the greater the error of orientation the greater the probable wandering.

The error of orientation expressed in percentages was computed as follows. With a negative worm emergence from the circle at 
a point directly opposite the light was reckoned as o per cent of error, whereas emergence at a point directly toward the light was reckoned as Ioo per cent, or a maximum of error in orientation. The orientation value at these two extremes having been established, the percentage of error which occurs when the worm emerges at any intermediate position on the circumference of the circle may be easily determined.

\section{TABLE XVI}

Average degree of error in orientation made by various species of planarians during 360 trials in directive light of different intensities

\begin{tabular}{|c|c|c|c|}
\hline \multirow{2}{*}{$=$} & \multicolumn{3}{|c|}{ Percentage of error in orientation } \\
\hline & $\begin{array}{l}\text { When started to- } \\
\text { ward the light }\end{array}$ & $\begin{array}{c}\text { When started } \\
\text { away from the } \\
\text { light }\end{array}$ & Average \\
\hline 3.3 candle meters $\ldots \ldots \ldots \ldots \ldots \ldots \ldots$ & 34 & II.5 & 22.7 \\
\hline 27.0 candle meters..................... & 32 & 12 & 22.0 \\
\hline 53.0 candle meters.......................... & 31 & 10 & 20.5 \\
\hline Average.. & 32 & II & \\
\hline
\end{tabular}

From this table it appears that there is three times as much wandering, or error of orientation, by worms headed toward the light, as by those headed away from it. This doubtless indicates that orientation is a more complicated process in the former case than in the latter.

Duration of Activity. Superficial observation is sufficient to establish the fact that different species of planarians when set into activity in directive light show decided differences with regard to the length of time they normally continue in motion before coming to rest. Among the forms experimented upon, Bdelloura came to a stand-still in light soonest and Phagocata latest.? Fatigue in itself is by no means the inevitable result of continued activity on the part of an organism. For instance, Hodge and Aikens ('95) observed a Vorticella continuously for 36 hours, during which time its regular ciliary and contractile movements continued uninterruptedly, while Rádl ('or) found that the eye of Daphnia when 
light was flashed upon it vibrated as vigorously after the experiment had been repeated $4 \mathrm{IO}$ times in close succession as it did at first.

An attempt was made with Planaria maculata to see how long activity would continue in a succession of trials in directive light. The worm was started on the middle of an aquarium floor and allowed to glide in any direction. As soon as it stopped and assumed the relaxed contour of the resting worm, the time required for the journey being noted, it was immediately returned to the starting point. Subjected to this treatment, the worm made 39 trips, which in general occupied an ever decreasing length of time, ranging from 18 minutes to $1 \frac{3}{4}$ minutes, or an average of 5 minutes and 53 seconds each. When returned to the starting point the fortieth time the worm refused to start. Although in this experiment, which lasted $4^{\frac{1}{2}}$ hours, the worm became gradually less responsive to the mechanical stimulus of the brush by means of which it was transferred to the starting point, its fatigue did not materially affect the negative character of its response to light.

Time Required to Leave a Unit Circle. In obtaining the data on this point, the apparatus and method already described (p. 73) were employed. It was found that when worms of different species were subjected to three different intensities in immediate succession the degree of intensity did not prove to be as important a factor as fatigue in determining the average number of seconds necessary for the worm's exit from a circle $10 \mathrm{~cm}$. in diameter.

During the series of experiments upon this point care was exercised so to vary the succession of intensities that the effect obtained could not be attributed to any cumulative increase or decrease of intensity. Thus, on one day the order of intensities was $\mathrm{I}, 2,3$, on the next 2, 3, I, and on the third, 3, I, 2. In Table XVII the data obtained are arranged on the left with reference to the actual intensities employed and on the right with reference to the succession of trials made upon the various species which are designated in the middle column. The averages in the table are each made up of four records.

It will be noted that Phagocata gracilis and Planaria gonocephala are, according to these figures, less subject to fatigue than Dendrocœlum lacteum or Planaria maculata. 
Manner of Coming to Rest. Loeb ('93b) and others have shown that planarians under the influence of directive light generally come to rest in regions of lessened intensity. A few experiments were made bearing on this point. By means of screens and backgrounds, both black and white, a rectangular glass aquarium was arranged so that the area of least intensity was plainly localized and could be varied in different ways. In Fig. 8 are shown (I) the places where worms (P. gonocephala) which had been started together in the middle of the dish finally came to rest; (2) the number of worms in each locality; and (3) the different combinations of backgrounds and screens used in each of the experiments.

\section{TABLE XVII}

Relative effect of fatigue (at right of table) and change in intensity of light (at left of table) as shown by the average number of seconds required for individuals of various species of planarians to leave a circle $10 \mathrm{~cm}$. in diameter

\begin{tabular}{|c|c|c|c|c|c|c|}
\hline \multicolumn{3}{|c|}{ INTENSITY } & \multirow{2}{*}{ SPECIES } & \multicolumn{3}{|c|}{ GROUPS OF TRIALS } \\
\hline $3 \cdot 3 \mathrm{c} . \mathrm{m}$ & $27.0 \mathrm{c.m}$ & $53.0 \mathrm{c} . \mathrm{m}$ & & First & Second & Third \\
\hline seconds & seconds & seconds & & seconds & seconds & seconds \\
\hline 63 & $6_{5}$ & 64 & Dendrocœlum lacteum & $54 \cdot 5$ & 63 & $72 \cdot 5$ \\
\hline 40 & 43 & $4^{I}$ & Planaria maculata & 37 & 42 & $45 \cdot 5$ \\
\hline 40 & $3^{8}$ & $4^{6}$ & Phagocata gracilis & $3^{8}$ & 44 & $4^{2}$ \\
\hline $5^{2} \cdot 5$ & 47 & 49 & Planaria gonocephala & $4^{6}$ & $5^{2} \cdot 5$ & $5^{\circ}$ \\
\hline 65 & 64 & 67 & Average & $5^{8} \cdot 5$ & 67 & 70 \\
\hline
\end{tabular}

Wherever shaded borders are indicated the aquarium was surrounded on five sides by black screens and likewise on the sixth side except for a narrow space admitting the light, the direction of which is indicated by arrows; in a similar fashion, where unshaded borders appear, light-reflecting screens enclosed five sides.

It will be seen at a glance that the great majority of the worms placed in directive light come to rest as far from the light as possible. That this is due to the directive power of light is at once apparent by comparing $A, B$ and $C$ with $D$, where the light was non-directive. The darkened area was selected whenever the directive force of the light did not prevent, as in $A, C$ and $D$. 
The five worms coming to rest on the lighter side of $D$ were carefully examined and found to be mutilated or fragmented individuals, while the same was not true of the others.

The reason why the worms in $B$ failed to arrive in the darkened area is probably that, being started near the middle boundary line, their first movements were normal, i. e., away from the light, and carried them into the area of greatest intensity, whence they were unable to escape. In this case the effect of the directive light seems to have more than counterbalanced the locomotive

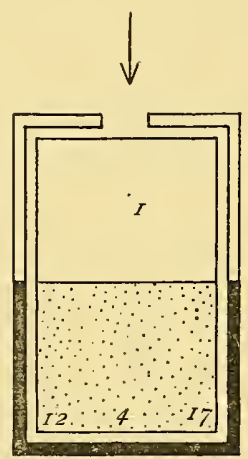

A

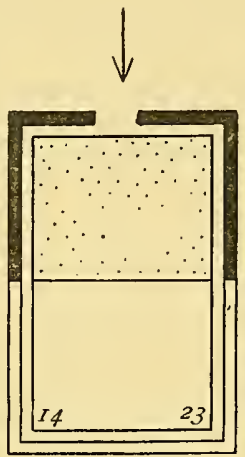

B

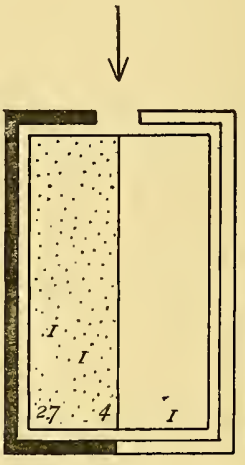

C
Light vertical

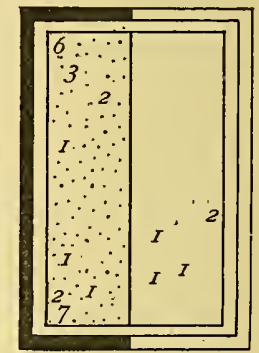

D

Fig. 8 Planaria gonocephala. The arrows represent the direction of the light. The dotted areas were surrounded by black backgrounds, except for a space on the side toward the light, and the clear areas similarly by white backgrounds. The figures represent the number of planarians that came to rest in any particular locality.

energy exerted by the worms. Had the species experimented upon been Phagocata gracilis, instead of Planaria gonocephala, the result might have been different, for in the former species, as already shown (p. 78 ), the phototactic response is secondary to the tendency to a general wandering.

It was frequently observed that worms when fatigued after a period of activity apparently lost their phototaxis, with the result that the final movements of a tired worm would sometimes be made toward the light. Such behavior is probably not to be considered as a reversal of phototaxis, but rather as indifference to 
photic stimuli, due to the worm's lowered physiological state and a chance turn toward the light. In fact the final position taken by 49 fatigued worms with reference to the source of light, showed that only five of them, or $10+$ per cent, pointed away from the light while $15(30+$ per cent $)$ were headed toward the light and 29 (59+ per cent) stopped indifferently at right angles to it. It is quite probable that among the external factors that influence a worm to come to a halt, light plays an exceedingly insignificant rôle, as compared with the stimulus of contact or some stimulus, probably chemical, given out by other worms in close proximity.

One curious instance was observed, however, in which light was apparently of more importance than contact or other stimuli in determining the place of coming to rest. A large crystallizing dish half full of water was left over night with a few planarians in

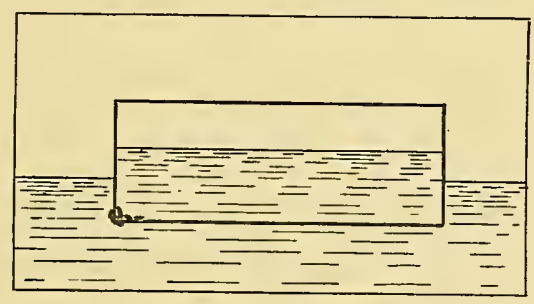

Fig. 9

it. Floating on the surface of the water in this dish was a small Petri dish, in which a few more planarians were isolated. In the morning the worms in both vessels were found grouped at the same region on the outside and inside of the smaller dish, as shown in Fig. 9.

This curious distribution on both surfaces of the Petri dish could not be due to chemical stimulus exerted by one group of worms on the other, and there seems to be no particular reason why a thigmotactic reaction should have caused them to assemble in such a way. The locality chanced to be one, however, where the intensity of the light was considerably reduced; this seems to offer a reasonable explanation of the observation.

Bdelloura in coming to rest shows an entirely different behavior. When left over night free to wander in an aquarium half of which 
had been previously covered with black cloth to exclude most of the light, this species was found in the morning in the light area, a behavior exactly the reverse of that shown by fresh-water planarians. Another peculiarity of this species is that individuals in coming to rest arrange themselves in compact rosettes with the anterior end of the body pointed toward the circumference of the rosette, while the sucker-like posterior end remains attached near the center of the group. They are so delicately responsive to mechanical stimuli that any slight disturbance of one member of such a rosette is sufficient to throw the whole group into activity. The advantage to the individual worm of such a habit of arrangement in coming to rest, is evident.

Finally, Bdelloura was repeatedly seen on taking the resting position to point directly toward the light with the anterior end of the body raised and the posterior end flattened out into a suckerlike expansion.

Summary. Fresh-water planarians (Dendrocœlum, Planaria and Phagocata) are negatively phototactic while Bdelloura is positively phototactic.

Negative planarians deviate most from the direction in which they are started if pointed toward the light and least if pointed away from the light, an intermediate deviation occurring when they are pointed at right angles to the light.

The rate of locomotion is greater when worms are headed toward the light than when they are headed away from it.

During successive trials the rate of locomotion decreases.

Negative planarians frequently take an apparently positive course because the impulse to move in any direction is greater than the phototactic impulse.

The normal negative phototaxis of a worm may change temporarily to positive by reason of some physiological state which is not obviously referable to external stimuli.

The greater the intensity of the light the less worms wander in their course. When they are headed away from the source of light, there is less error in the precision of their orientation than when they are started toward it.

Planarians frequently travel away from the source of light diagonally instead of directly. 
Bdelloura continues activity in the light for a much shorter time than Phagocata.

When subjected to successive trials the period of a planarian's activity decreases.

Change in the intensity of light is less important than the effects of fatigue in determining the time required for a worm to leave a unit círcle. When fatigued, worms often become indifferent to light, coming to rest less frequently in an oriented position with reference to the light than in an unoriented one.

Fresh-water planarians come to rest as far away from the source of light as possible and, if the directive stimulus does not prevent, in the region of least illumination.

Bdelloura candida, on the contrary, comes to rest in regions of greater rather than of less illumination; usually worms of this species arrange themselves in compact rosettes with the anterior ends pointed outward.

\section{B In Changing Directive Light}

The light acting upon planarians in their natural habitat must necessarily be a variable factor of great complexity, since its intensity changes constantly throughout the day, while the position of the sun relative to various surfaces which reflect light is also continually shifting.

The fact that planarians, to a great extent, keep out of the light, does not diminish the force of this statement, for whatever the part played by light in their behavior, it must always be an exceedingly varied and complex one.

Changes in the Intensity. When a worm is gliding away from a source of light it shows a more marked response to change of intensity when the change is made suddenly than when it is made gradually. In fact, it is possible by exercising patience and care to change the intensity of directive light to a considerable degree so gradually as to produce no corresponding response on the part of the worm, whereas a comparatively slight change, if abruptly effected, immediately results in the animal's performing some one or more of the acts in its repertory of behavior, such as halting, wigwagging, etc. 
In all the experiments made upon the effects of change of intensity in directive light, more responses were found to occur when the intensity was decreased than when it was increased. This is in agreement with the experiments already described relating to the critical region between two intensities, in which it was found that worms show a greater number of responses when going from a higher into a lower intensity than vice versa.

Bdelloura is particularly sensitive to changes in intensity. It is necessary to throw a shadow on a moving worm only momentarily to cause it to perform vigorous wigwag movements or to change the direction of its course.

Whitman ('99), writing of Clepsine, suggests that the extreme agitation of this animal when a shadow is thrown upon it may be the result of natural selection, since any sudden shadow cast upon it in its natural environment may be caused by a turtle swimming overhead, to which the leech, if it is quick enough, may become attached. It may be that Bdelloura, which is also an ecto-parasite, has developed this extreme responsiveness to sudden decrease of intensity in a similar way.

Changes in Direction. The precision with which all the planarians in a dish may be made to pass back and forth by shifting a directive light from one side to another is a striking phenomenon, which is sure to impress anyone who sees it. By careful manipulation of the light, it is possible even to make an individual planarian follow a predetermined path in the most undeviating manner. For example, when two lights, placed near the ends of an aquarium, are alternately turned on and off, the worm will zigzag across the field, at right angles to the direction of the lights, while under a moving light it may be made to turn around and around, almost as if its posterior end were a pivot, to trace figure 8's and curves of various patterns, or to turn abruptly at right angles an imaginary corner.

Unlike the changes in intensity previously described the degree of abruptness in any change in the direction of the light made no apparent difference in the quality of the reaction, since any change in direction, however gradual, met with an immediate response on the part of the worm. Indeed it was necessary to abandon an 
attempt to illuminate one side of the worm alone because the animal invariably turned faster than it was possible to regulate the light.

The quickness with which this delicate response to any change in the direction of the light occurred was found to increase upon successive trials. A square aquarium was arranged so that it could be illuminated instantly at either end, in a room otherwise dark. With one light on, a planarian was allowed to move until it had assumed the characteristic negative direction, whereupon the source of illumination was instantly changed $\mathrm{I} 80^{\circ}$ by turning this light off and the one at the other end of the aquarium on. The time required for the worm to become headed about was noted and then a reversal of lights repeated and the interval necessary for readjustment again recorded. In a typical experiment of this kind the number of seconds required by the worm, Planaria maculata, to accomplish re-orientation were for 16 successive orientations as follows: 260, 70, 100, 60, 65, i 10, 60, 85, 70, 105, 80, 60, 50, 40, 45,35 . The sum of the first eight is $8 \mathrm{ro}$ sec., that of the last eight, only $485 \mathrm{sec}$.

Summary. Planarians show a greater response to sudden change of intensity than to gradual change. This response is more pronounced when the intensity is lowered than when it is raised.

Bdelloura is particularly affected by sudden changes of intensity.

Planarians respond with great precision to changes in the direction of the light, and as promptly when the change is gradual as when it is abrupt.

The period required for re-orientation to changes in the direction of light, diminishes upon repetition.

\section{In Combination with Other Responses}

It is impossible to subject planarians to the influence of light alone. The best that can be done is to render extraneous factors as uniform as possible. For example, so long as a moving worm is kept upon a horizontal surface there can be no directive geotactic stimulation, because the worm is moving in a plane at right angles 
to the force of gravity. The moment the worm begins to glide up the sides of an aquarium, however, the relation of the axes of its body to the center of the earth changes and directive geotaxis results.

No systematic attempt was made to analyze compound stimuli, for such a study would overstep the boundaries set for the present inquiry. Nevertheless certain facts bearing on this point were incidentally noted and these may properly be detailed here.

Geotaxis. In a majority of cases, Planaria gonocephala seems, after several hours of exposure to the dark, to be positively geotactic, and after several hours of exposure to light, negatively geotactic, as shown in the following series of observations.

A cylindrical aquarium jar $20 \mathrm{~cm}$. in diameter and $40 \mathrm{~cm}$. high. was placed before a moderately lighted window and stocked with a freshly obtained supply of about 300 worms. No stones, sand, or water-weeds, which would afford places of concealment, were introduced. At intervals during the next ro days the distribution of the worms was recorded and these records are brought together in Table XVIII.

TABLE XV̈III

The distribution of about 300 planarians (Planaria gonocephala) in an aquarium, as observed forenoons and afternoons during 10 days. The figures express percentages

\begin{tabular}{|c|c|c|c|c|c|c|}
\hline \multirow{2}{*}{$\frac{\text { Place in the Aquarium }}{\text { Time of day }}$} & \multicolumn{2}{|c|}{ Top } & \multicolumn{2}{|c|}{ Sides } & \multicolumn{2}{|c|}{ Воттом } \\
\hline & a. $\mathrm{m}$. & p. m. & a. $\mathrm{m}$. & p. m. & a. m. & p. m. \\
\hline April 26... & & $5^{I}$ & & II & & $3^{8}$ \\
\hline April $27 \ldots \ldots \ldots \ldots$ & $6 \mathrm{r}$ & & 13 & & 26 & \\
\hline April $28 \ldots \ldots \ldots \ldots \ldots \ldots \ldots \ldots \ldots$ & 74 & 3 & II & .15 . & 15 & 82 \\
\hline 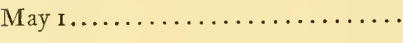 & 72 & 29 & 6 & 7 & 22 & 64 \\
\hline May $2 . . . . .$. & 63 & 39 & 12 & 20 & 25 & 41 \\
\hline May $3 \ldots \ldots \ldots \ldots \ldots \ldots \ldots \ldots \ldots$ & 43 & & 16 & & 41 & \\
\hline May $4, \ldots \ldots \ldots \ldots \ldots \ldots \ldots \ldots \ldots \ldots \ldots$ & $5^{\circ}$ & & 16 & & 34 & \\
\hline May $5 \ldots \ldots \ldots \ldots \ldots \ldots \ldots \ldots \ldots$ & & $3^{1}$ & & $r_{3}$ & & $5^{6}$ \\
\hline Average. & 60.5 & 30.6 & $12 \cdot 3$ & $13 \cdot 2$ & $27 \cdot 2$ & $5^{6.2}$ \\
\hline
\end{tabular}

The forenoon census was taken about 8 o'clock, when the worms were re-arranging themselves after the darkness of the night, while the afternoon records were made about 4 o'clock, when the worms 
had been all day in the light. The average at the bottom of the table indicates, first, that an approximately equal percentage of worms was found on the sides of the aquarium at both times of day, which may therefore be left out of the reckoning, and, secondly, the occurrence of a significant migration during the interval between 8 a. m. and 4 p. m., demonstrated by the distribution of the worms at the top and bottom of the jar respectively. According to the data obtained, at least 30 per cent of the worms in the top group must have become positively geotactic and gone to the bottom during the day.

A later set of experiments in which an aquarium was kept swathed in black cloth during the day showed less migration. The conclusion naturally follows that geotaxis is more likely to occur in the presence of light than in its absence. Whether there is a regular diurnal vertical migration among planarians in nature, as Birge ('97) and Schouteden ('02) found to be true for freshwater entomostraca, and various authors ${ }^{4}$ for different forms in marine plankton, remains unknown. It is probable, however, that planarians ordinarily remain quiescent on the under sides of stones or in other shaded places for considerable intervals of time, coming under the influence of light only when started into activity through some other stimulus.

A worm placed in an aquarium with square sides and left free to travel undisturbed on the bottom or the sides occupies the sides more frequently than the bottom.

In a trial to test this point, an aquarium was used, the bottom area of which measured approximately five times that of the sides. The course pursued in this aquarium by one worm ( $\mathrm{P}$. gonocephala) in directive light and covering $1340 \mathrm{~cm}$., was plotted and the percentage of distance traveled on the sides was found to be practically equal to that traveled on the bottom, notwithstanding the fact that the animal was started in the middle of the bottom, where it had five times as much available territory to travel over as on the sides. Other things being equal, therefore, this worm showed itself five times as ready to travel on the sides of the aquarium as on the bottom.

${ }^{4}$ Groom and Loeb ('9o), Loeb ('93a), and Parker ('o2). 
The existence of such a decided geotactic tendency should not be forgotten when trying to determine the part light plays in planarian behavior.

Again, it was found that there was less accuracy of orientation to directive light while the planarians were on the sides of the aquarium in a position parallel to the light rays than while they were on the bottom.

Their behavior in the former case was the resultant of at least two known stimuli, gravity and light, whereas gravity was practically eliminated when they glided on the floor of the aquarium. In the experiment cited under the preceding paragraph 92 per cent of the distance traversed by the worm on the bottom of the aquarium was in a direction in general away from the light, as contrasted with only 79 per cent when it was traveling on the sides of the aquarium. This difference of I 3 per cent may represent roughly the necessary correction for geotaxis, in order to ascertain the influence of light alone.

Thigmotaxis. Contact with the substratum is an almost constant condition of planarian activity. Occasionally worms may be seen dangling free at the end of a mucus-thread, as commonly occurs among many fresh-water snails; sometimes they may fall helplessly from the surface-film to the bottom, but definite contact with something firm is the rule during their ordinary locomotion.

A change in the degree of this contact, and consequently a production of thigmotactic stimulation, may come about in two ways: the surface on which the animal glides may present irregularities, such as increased roughness or a different degree of solidity, or the worm itself may vary in the extent of body-surface which it brings into contact with the substratum. This latter method of causing thigmotactic stimulation applies especially to Bdelloura, which has the habit of frequently alternating a leech-like looping movement with ordinary gliding, thus changing its contact relations and probably producing a thigmotactic stimulus in consequence.

As already mentioned, Bdelloura, when subjected to sudden dark, usually detaches itself from its support and wriggles vio- 
lently in the water. It is uncertain how far this behavior is attributable to light alone or to some combination of light and thigmotaxis.

This phenomenon of compound stimulation occurs in a less pronounced way whenever a change of light intensity results in the "wigwagging" response common to planarians. The same uncertainty prevails as to how far the subsequent behavior of the worm may be due to the direct stimulation of light and how far to thigmotactic stimulation primarily and to light stimulation secondarily. It is evident, then, that under any circumstances there is such a close interrelation of stimuli that an accurate analysis of the consequent behavior is difficult.

Further evidence of the close relation between different kinds of stimuli is afforded by the fact that planarians are more responsive to the mechanical stimulus of a slight jar when the entire ventral surface of the body is in contact with the substratum than when the anterior end is lifted up and waving about. Apparently the greater the degree of contact the greater is the effect of a jarring mechanical stimulus.

This point was demonstrated by means of a small aquarium mounted on a turntable, such as is used in "ringing" microscopic slides, in such a way that it could be rotated with great ease and delicacy. A light from one direction only was projected upon the single planarian placed in the aquarium. Any attempt to change the angle of light by rotating the aquarium ever so slightly resulted instantaneously in a momentary halt on the part of the worm, provided it happened to be gliding with its ventral surface entirely in contact with the floor of the dish. If, however, the rotation was made when the anterior end of the worm was lifted, the halt did not so readily occur. This response was of such delicacy that with a little practice it was possible to halt the anterior end of a worm without disturbing the continuous progress of the posterior end! That this halting was due to thigmotaxis rather than to any rheotaxis induced by the movement of the animal against the relatively stationary water particles, is shown by the fact that the reaction was more pronounced when the anterior end of the body was held flat than when it was raised and so brought more under the possible influence of a water current. 
Finally, it may be recalled that in a preceding section data were given (Table X, p. 68) to show that there is more response to light while worms are upside down on the surface-film than when they are in contact with the bottom of the aquarium, a difference probably referable in large measure to the different thigmotactic relations in the two cases.

Goniotaxis. Goniotaxis is a term introduced by Pearl ('o3, p. 56I) to define a particular kind of thigmotactic response in which the "different parts of the body are brought into such positions that they form unusual angles with each other," as when a planarian occupies the angle formed between a side and the bottom of an aquarium.

There is no doubt that the peculiar movements resulting from the goniotactic stimulus directly modify the phototaxis of the worm. Once in the angle of an aquarium a planarian becomes increasingly indifferent to light. In one series of records, showing how a considerable number of planarians came to rest, it was found that the majority came to rest in an "angle" and that out of this number 78 per cent failed to orient to the light. The stimulus of the "angle" was greater apparently than the stimulus of light.

Furthermore, it is to be noticed that goniotaxis is always more effective if the worm is in a lowered rather than in a heightened physiological state, for whenever a planarian is freshly introduced into an aquarium and is in an aroused condition on account of the mechanical stimulation necessarily given it in transference, it will pass over angles and crevices with total indifference, all the while responding plainly to light. As soon as it has become fatigued, however, if its path chances to cross an angle or crevice it exhibits goniotaxis at once by slowing down and remaining in the new situation, as if caught in a trap, with complete disregard of the continued action of directive light.

Chemotaxis. Pearl has made an extensive study of this phase of planarian behavior and suggests that the well-known planarian habit of collecting in groups may be explained on the supposition that a resting planarian is surrounded by a halo of chemical ema- 
nations which serve as a direct stimulus to other planarians, attracting them and causing them to come to rest in groups.

In this connection it is worth mentioning that several times when Dendrocolum lacteum was put in an aquarium with other species of planarians, the individuals of this species would later be found gathered into a separate group by themselves. This manner of isolation was also repeatedly noticed in examining on the under sides of stones taken from the pond at Falmouth, Mass. A similar segregation of species in the case of $\mathrm{P}$. alpina and $\mathrm{P}$. gonocephala, was noted by Collin ('9I). He says ('9I, p. I80) "Iijima fand diese beiden Arten zusammenlebend, während sie im Harz stets getrennt vorkamen; auch in der Gefangenschaft schien die P. alpina die grössere $\mathrm{P}$. gonocephala in demselben Behälter zu meiden und ihr ängstlich auszuweichen." It would be difficult to explain how these planarians avoid each other so as to fraternize in this fashion, except on the basis of some delicate chemotactic response which caused them to halt when they entered the chemical halo of their own kind, but not to do so in the different chemical halos of other species. As in the case of goniotaxis, the manifestations of phototaxis may be entirely superseded by the effect of feeding (Chemotaxis). When once a hungry planarian, driven by directive light into the neighborhood of a crushed snail, becomes subjected to the chemical stimulus arising from the fluids of that object as they are disseminated through the water, it seems to become suddenly indifferent to the light, owing to the greater influence of the chemical stimuli.

The same inhibition of the influence of light by a chemotropic response to food has been observed by Parker ('o3) on the mourning-cloak butterfly, Vanessa antiopa L. He says ('o3, p. 457) "when a butterfly alights on a bough, it orients in the sunlight with the usual precision. Should the sap be running from a near stem, the insect is very soon attracted to the spot, begins feeding, and moves about from that time on with no reference to the direction of the sun's rays. Thus, when feeding or near food the butterflies do not respond phototropically." Furthermore Darwin ('8I, p. 23) observed that earthworms are less disturbed by light while feeding or during copulation than at other times. 
The foregoing examples illustrate only a few of the many modifications of light responses due to the interference of some other stimulus.

Summary. In judging the effect of any stimulus upon an animal it is necessary to have constantly in mind the accelerating or inhibiting effects of other stimuli which may be influencing the organism at the same time. In the case of planarians some of the responses known to be intimately connected with phototaxis are geotaxis, thigmotaxis, goniotaxis and chemotaxis.

Planaria gonocephala shows itself to a certain extent negatively geotactic after several hours of dark and positively geotactic after a similar interval of light.

When given horizontal and vertical surfaces of equal extent, worms travel more on the vertical surfaces.

Their accuracy in orienting themselves to light while subjected to geotactic stimulus on a vertical surface is less than when they are traveling on a horizontal surface, where the directive geotactic stimulus is eliminated.

Thigmotactic stimulus may result either from an environmental change in the substratum, or a change in contact caused by the worm itself whereby its relation with the substratum is varied.

There is a close interdependence of the various stimuli which may be acting on an animal at the same time.

Behavior may be the direct consequence of light or the indirect result of light combined with the direct effect of a thigmotactic stimulus indirectly brought about by some change in the intensity of the light.

The greater the degree of contact with the substratum the more responsive a planarian becomes to the mechanical stimulus of jarring, but the less to the stimulus of light, as shown by comparing the behavior of worms on the surface film with their behavior on the aquarium floor.

Goniotaxis has an inhibitive effect on phototaxis; this effect becomes more apparent as the worm reaches a condition of fatigue, phototaxis meanwhile becoming less apparent.

Dendrocœlum lacteum exhibits a remarkably delicate response (Chemotaxis?) in frequently coming to rest in the neighborhood of its own kind. 
Hungry planarians in the presence of food have their phototaxis entirely obscured.

\section{KINDS OF BEHAVIOR}

In the two preceding sections, treating of Photokinesis and Phototaxis, respectively, animal behavior, as illustrated by the effect of light upon planarians, has been taken up from the point of view of the stimulus. In the two following sections, on the other hand, the reactions of planarians will be dealt with from the standpoint of the animal rather than from that of the stimulus.

To this end a classification of the behavior of planarians in light is here presented based upon (A) generic and specific differences, and $(B)$ individual differences.

That there are morphological differences which fall naturally within the lines of this classification has long been recognized, indeed, the criteria used in classification by systematists are based almost exclusively upon such differences, while relatively little importance has been attached to differences in the behavior of animals.

As already mentioned in the historical review, Loeb ('94), in dealing with the differences of behavior which characterize the two genera, Planaria and Thysanozoön, pointed out that decided physiological variation may appear in forms closely related morphologically. The same fact had been previously emphasized for the case of the pulmonates by Willem ('gr). Obviously such physiological variations do not furnish reliable criteria for the systematist, since they are so largely dependent upon environmental causes, and furthermore the work of the systematist is usually done upon dead animals. Nevertheless some interesting relations between behavior and systematic position await the student who approaches the study of animal behavior from this direction.

Strictly speaking, all behavior is individual behavior. In this sense it is manifestly incorrect to speak of the behavior of a genus or of a species per se.

The behavior of individuals may, nevertheless, be classified into responses which are characteristic of all the members of a genus, 
or again into responses which are characteristic of only one species of a genus and not necessarily of other species of the same genus, and, finally, into those peculiar to the individual as such, which may not in all particulars be shared by other representatives of the species to which the individual in question belongs. It is in this sense of the terms generic, specific and individual, that behavior will be taken up in the present section.

\section{A Generic and Specific Behavior}

In the present inquiry a basis for generic comparisons is afforded by a study of the behavior of individuals of four different genera, namely, Planaria, Dendrocœlum, Phagocata and Bdelloura, while some idea of specific differences is made possible by comparing the behavior of individuals of the two species Planaria maculata and Planaria gonocephala. In the cases of Dendrocœlum, Phagocata and Bdelloura it is obvious that the conclusions drawn are based in each instance upon the behavior of representatives of a single species under each genus. The question may be properly raised as to how far such conclusions indicate generic behavior and how far specific behavior. Conceding that from the data obtained exact deductions may not be drawn, the fact still remains that the three species, Dendrocœlum lacteum, Phagocata gracilis, and Bdelloura candida, are separated from each other by generic gaps, such that the differences exhibited by these species may be regarded as generic in degree. The point unestablished, then, is whether other species of the genera in question if examined might not show that the behavior, which in these single representative species seems generic in nature, is not characteristic of other species of the same genus as well.

It will be convenient to present the data of both generic and specific behavior at the same time.

Percentage of Negativeness. The manner of obtaining this criterion of behavior has been explained in the section on Phototaxis (p. 72). It will be remembered, too, that in Table XII a comparison was made between positive and negative worms, showing the degree of their orientation to directive light. The 
data there used are rearranged for the present purpose in Table XIX.

\section{TABLE XIX}

Percentage of generic and specific negativeness in worms started at right angles to incident light, as determined at the circumference of a circle Io $\mathrm{cm}$. in diam. by the average amount of their deviation from the directions in which they were started

\begin{tabular}{|c|c|c|c|c|c|c|}
\hline & \multicolumn{4}{|c|}{ Generic Differences } & \multicolumn{2}{|c|}{$\begin{array}{c}\text { SPECIFIC } \\
\text { DIFFERENCES }\end{array}$} \\
\hline & $\begin{array}{l}\text { Dendro- } \\
\text { cœlum }\end{array}$ & $\begin{array}{c}\text { Phago- } \\
\text { cata }\end{array}$ & Planaria & Bdelloura & $\begin{array}{l}\text { Planaria } \\
\text { maculata }\end{array}$ & $\begin{array}{c}\text { Planaria } \\
\text { gono- } \\
\text { cephala }\end{array}$ \\
\hline Number of observations.......... & 78 & So & 158 & IO & 78 & 80 \\
\hline Total number of degrees positive... & I 55 & 238 & 165 & 397 & 5 & 160 \\
\hline Total number of degrees negative. . & 2112 & 1964 & 4070 & 50 & 2102 & 1968 \\
\hline Percentage of negativeness........ & $93 \cdot \mathrm{I}$ & 89.6 & 96.1 & II & $99 \cdot 9$ & 84.6 \\
\hline
\end{tabular}

Comparing the figures given in this table, a greater range of difference is seen to obtain between the two species of Planaria (P. maculata and P. gonocephala) than between the genus Planaria and either of the other negative genera, namely, Dendrocœlum and Phagocata. Although not indicated in this table, similar results appear when the number of times the worms went in a negative direction is used as a basis of comparison, instead of the total number of degrees of negative deviation.

Character of the Course in Directive Light. When worms were placed on the middle of a rectangular aquarium floor and subjected to a directive light their movements showed both generic and specific differences. By experimenting with one worm at a time it was possible to plot on a sheet of paper with sufficient accuracy for general comparison the entire course of the worm during a considerable period. This was done many times and typical records of such observations are given in Figs. IO-I4. In such instances the worm was exposed to a light of approximately I $47 \mathrm{c.m}$., placed so as to correspond to the right side of the figures. The central rectangular area bounded by the broken lines indicates the limits of the floor of the aquarium, while the smaller exterior adjacent areas represent its vertical sides so rotated as to 
bring them into the plane of the floor. The course taken by a planarian is indicated by the tortuous line. The full line shows the course taken on the solid surface of the aquarium; the dot-

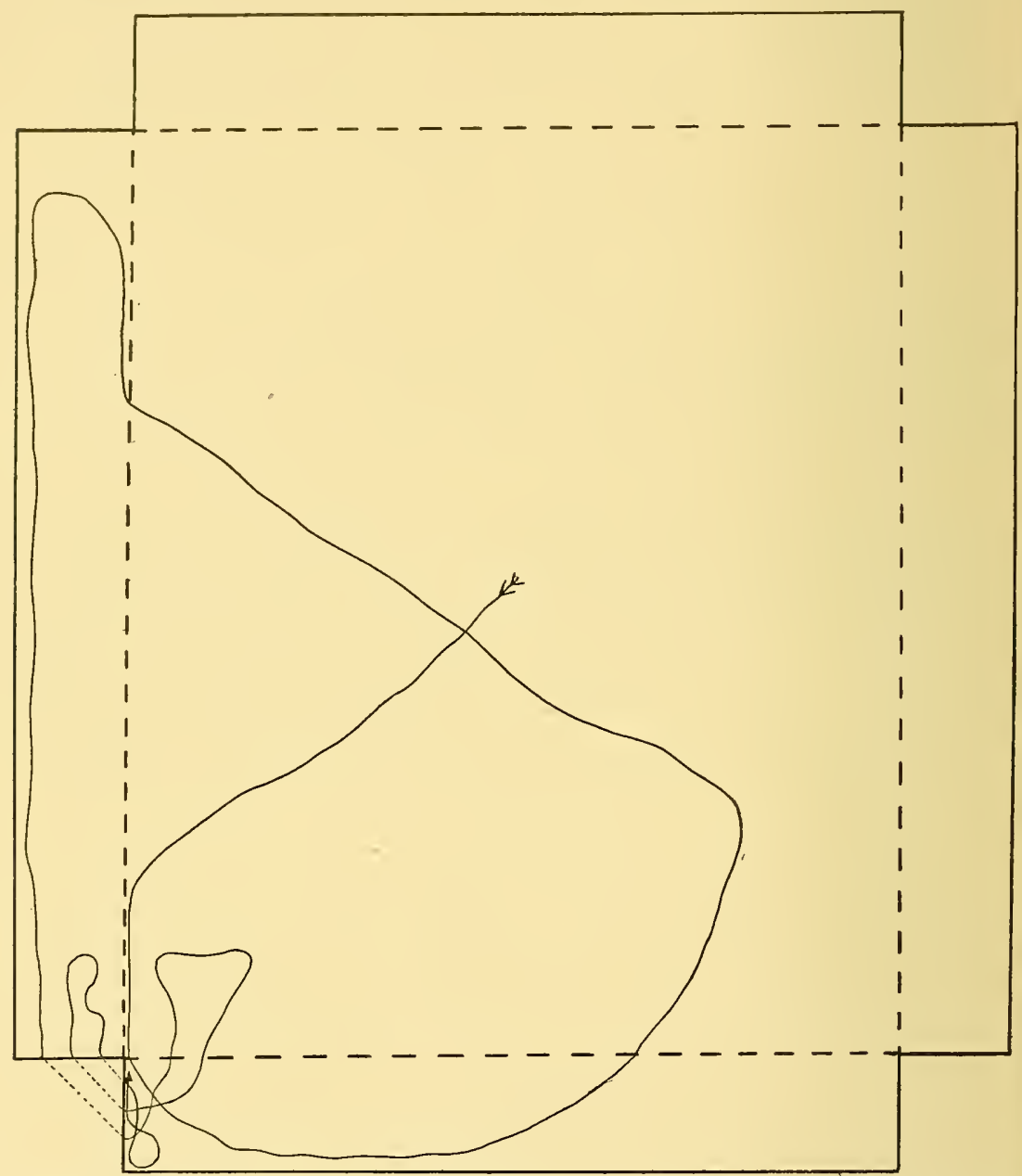

Fig. Io Dendrocœlum lacteum. The shortness of the path shows comparatively little persistence in locomotion, and the direction, considerable indifference to the source of light.

and-dash lines, the course of the worm on the surface film. The dotted line indicates a hiatus in the path, made necessary by the attempt to represent on a flat surface a continuous line which traverses vertical as well as horizontal surfaces. A succession of 
abrupt kinks in the line signifies that at that point the worm executed decided wigwag movements with its anterior end. The figures are reduced in size from the original records.

In Fig. Io is given a specimen record of a Dendrocœlum which

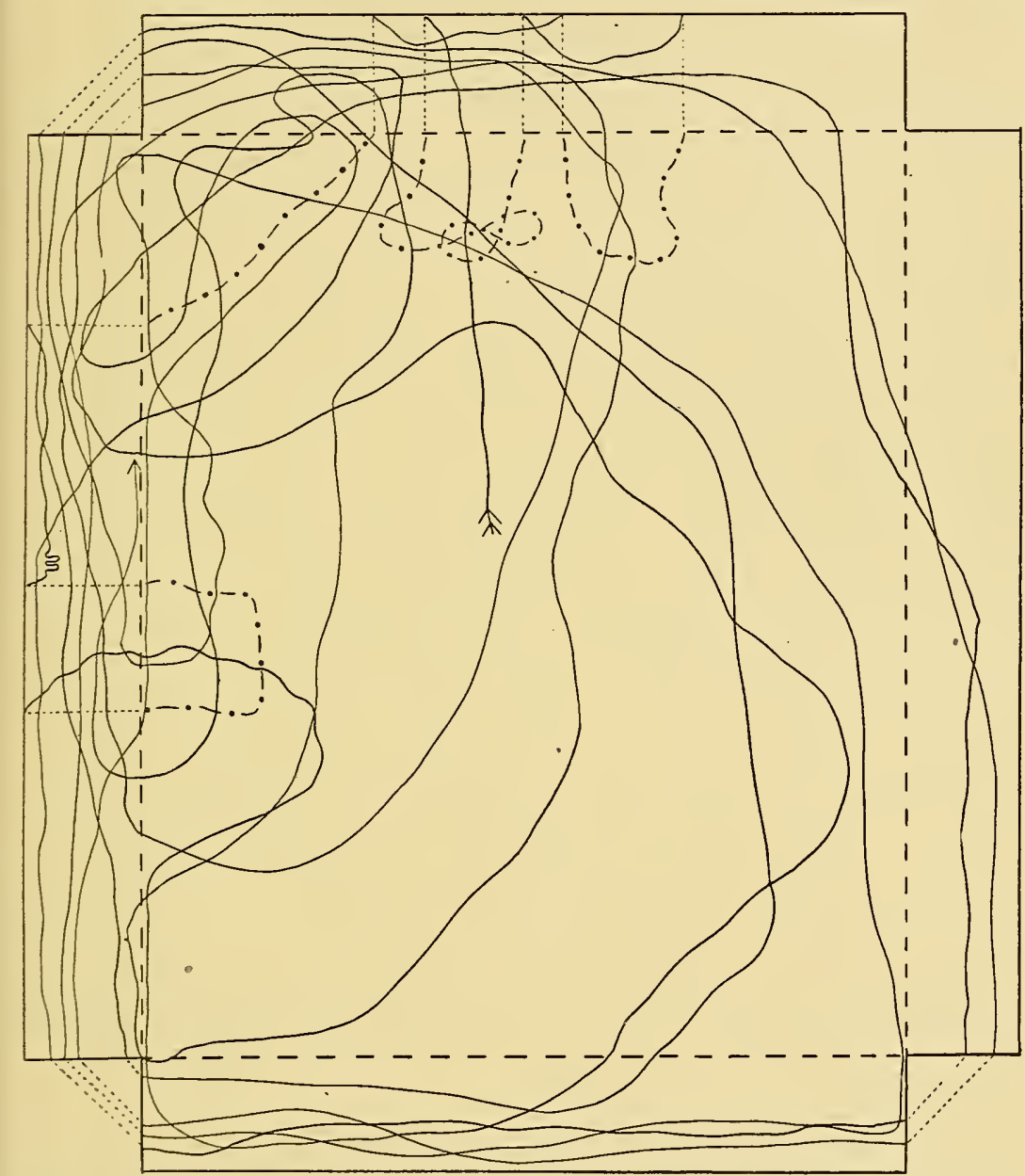

Fig. II Phagocata gracilis. This path shows great activity on the part of the worm, and, although it is mostly laid down away from the source of the light, it shows that the worm experienced no great difficulty in moving toward the light.

came to a standstill after I8 minutes of locomotion. The first movement of this worm was diagonally away from the light, but it soon came back toward the light traversing almost the entire 
width of the aquarium and in doing so showed considerable indifference to the directive influence of the light. Its susceptibility to goniotactic stimulus is plainly shown by its behavior upon reach-

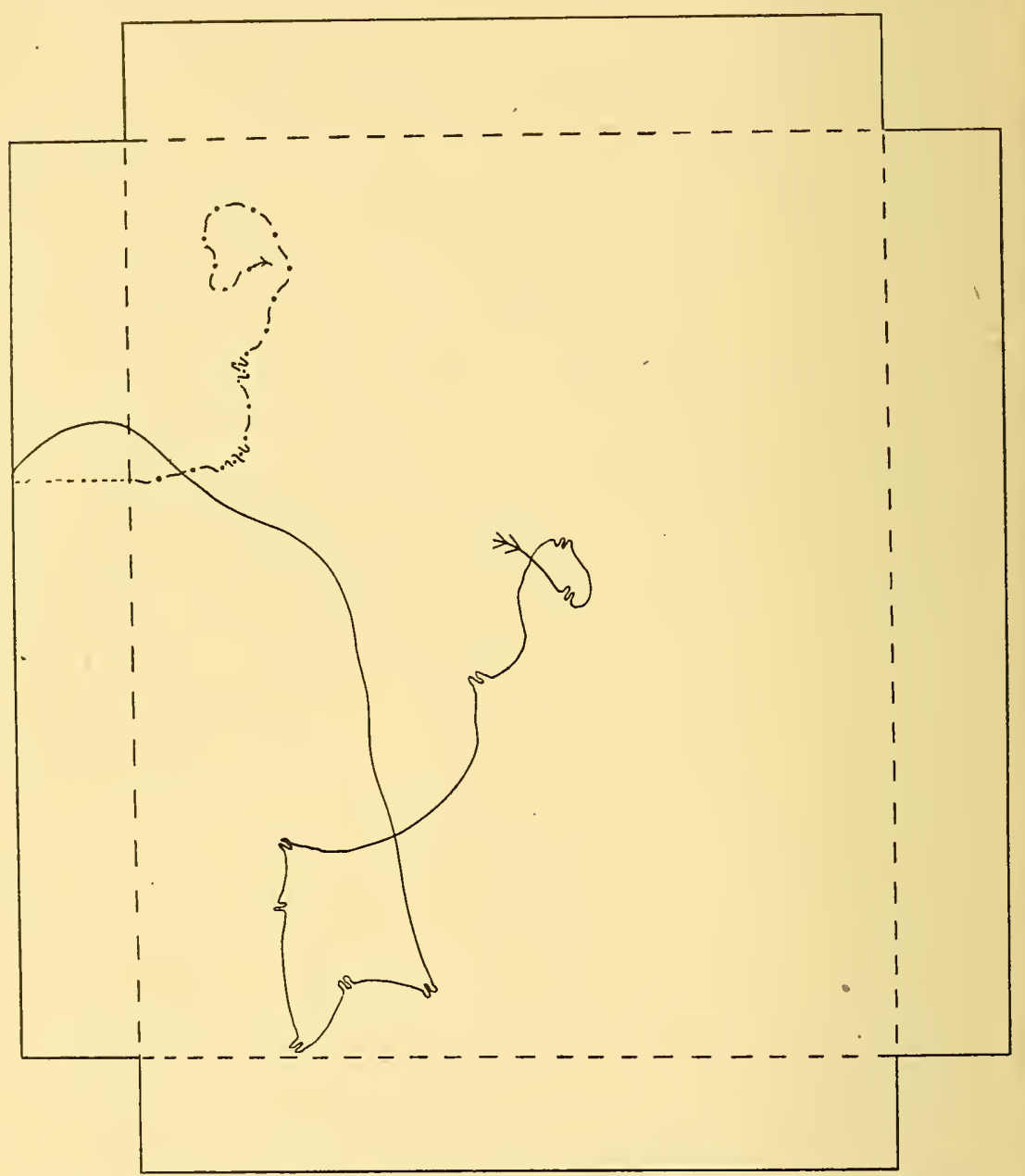

Fig. I2 Bdelloura candida. This path was traversed with much "wigwagging;" there was indifference to the source of light and locomotion was not of long duration.

ing the angle formed at the junction of the sides and floor of the aquarium, as well as by its manner of finally coming to rest.

A typical Phagocata (Fig. I I), on the other hand, exhibited 
almost no goniotaxis, although the worm repeatedly crossed the line of the angle. The response to the directive influence of the light, too, was in this case even less than that of the

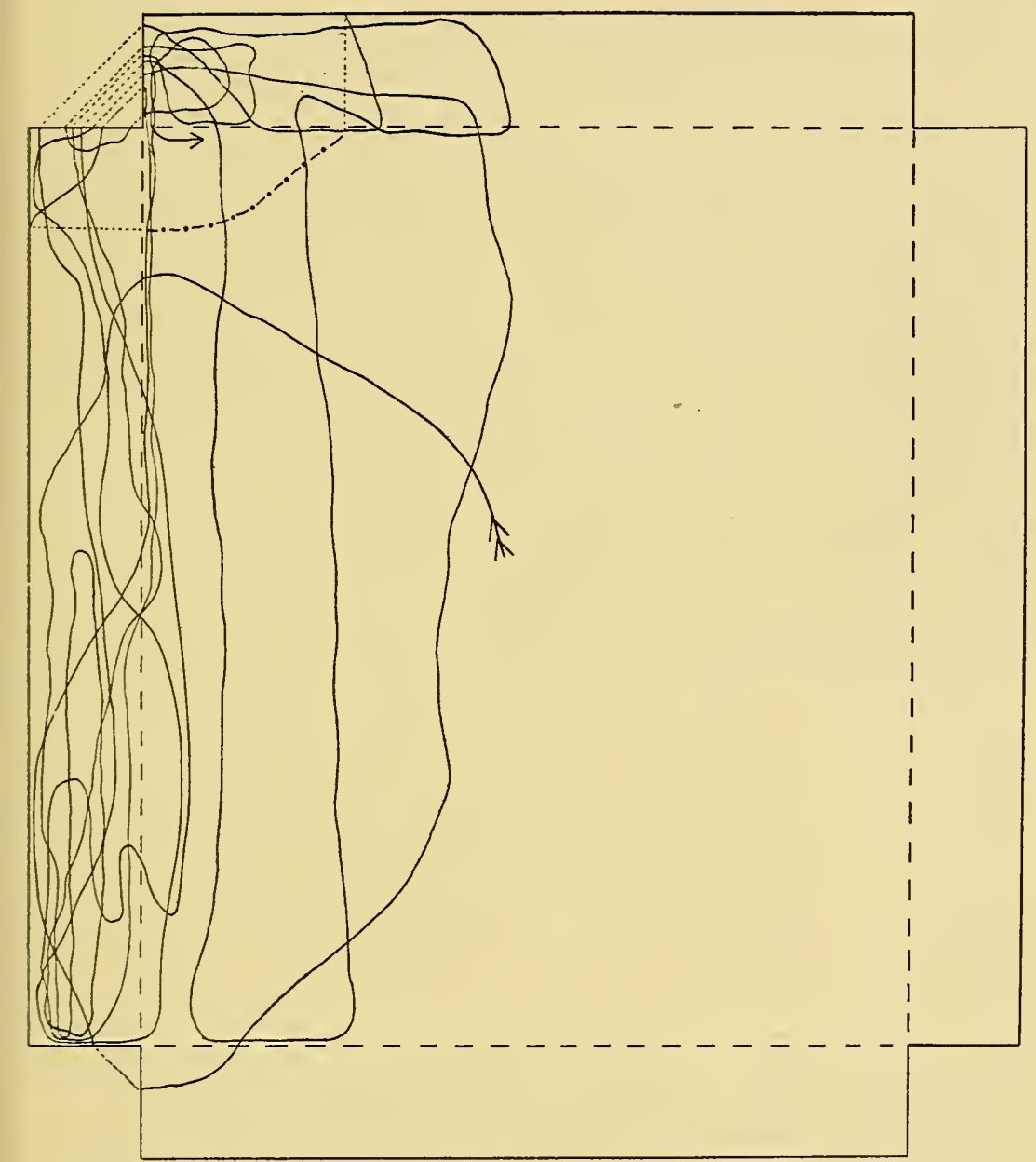

Fig. 13 Planaria maculata. Considerable activity was shown over this course and a decided inability to approach the source of the light beyond about the middle of the aquarium.

Dendrocœlum just described, as is evident from the general wandering character of the course. Although the Phagocata in question frequented both sides of the aquarium-that which was toward 
the light, as well as the opposite side-its wanderings were in the main on the side away from the light. An hour's activity is chronicled in the record, at the close of which the worm was apparently as energetic as ever.

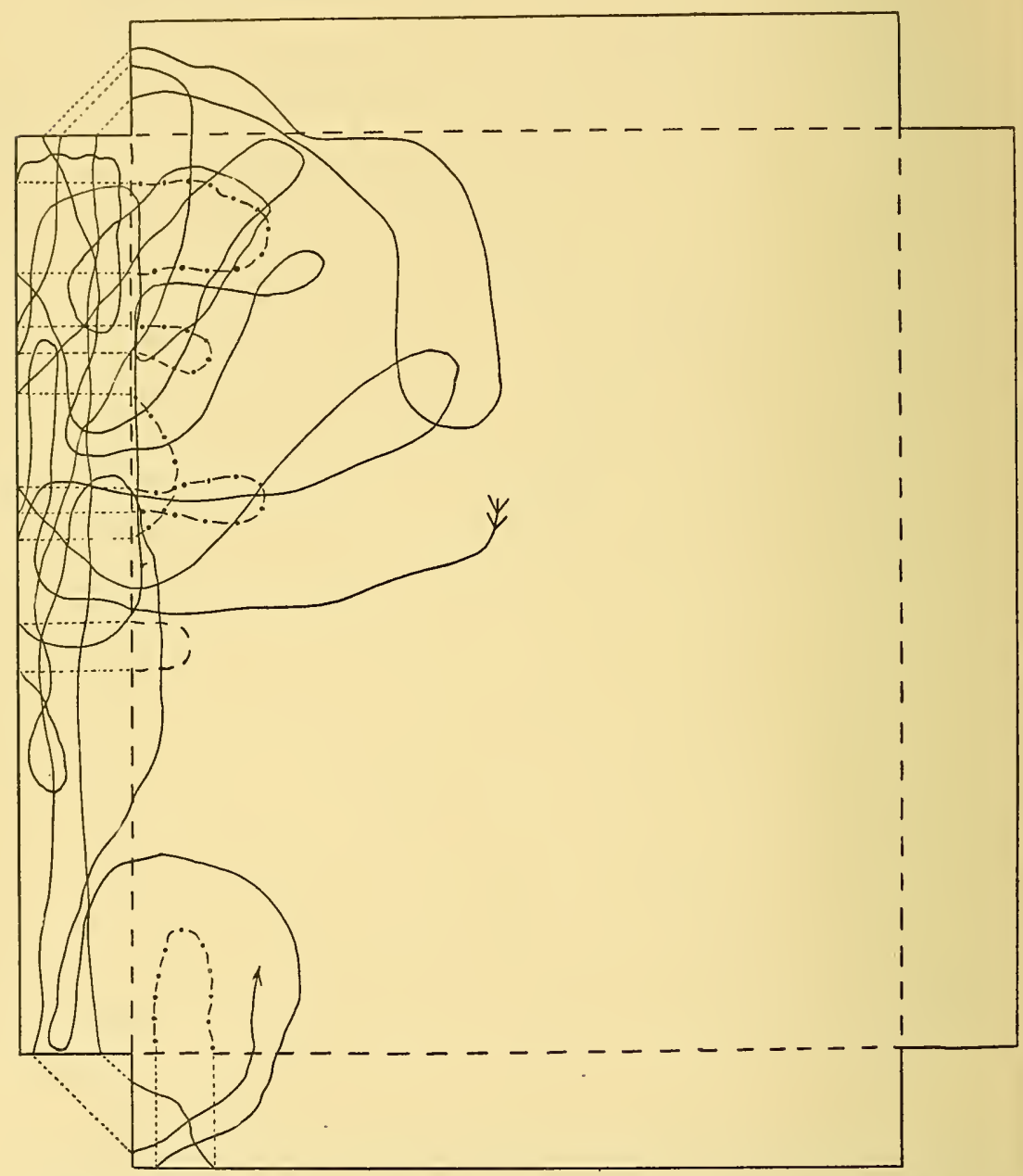

Fig. I4 Planaria gonocephala. The path is of the same generic type as with Planaria maculata (Fig. 13), and is easily distinguishable from those of Dendrocœlum, Phagocata and Bdelloura.

Fig. I 2 gives a characteristic record of the way in which Bdelloura behaves. The first movement of this specimen was more 
toward than away from the source of the light, but very soon wigwagging motions set in, and after every exercise of these movements, which were apparently in the nature of explorations, a change in the direction of the course was effected. As might be expected, such abrupt changes in direction were more difficult of execution when the worm was on the surface-film.

Characteristic movements of individuals of the genus Planaria are shown in Figs. $\mathrm{I}_{3}$ and I4. From these two typical records it would be difficult to select any diagnostic points which would distinguish the behavior of $\mathrm{P}$. gonocephala from that of $\mathrm{P}$. maculata. There is no doubt, however, that taken together the behavior of representatives of these two species presents a distinct (generic) difference from that of the representatives of the other genera studied. The most striking feature of the Planaria records (Figs. I3 and I4) is the high degree of response exhibited by members of this genus to the directive action of light. Although many attempts were made by the individual worms to penetrate the half of the aquarium nearer the light, yet they seemed as unable to keep to that direction as they would have been had a solid barrier been interposed between them and the light. This characteristic responsiveness to directive light helps to explain why (as shown in Fig. 8, $B$, p. 84) P. gonocephala was unable to comej to rest in the area of lessened illumination as it would naturally have been expected to do.

From the cases cited in this section, at least, it may be affirmed that the generic differences are so pronounced that one could take a miscellaneous, unidentified assortment of such records and correctly assign the great majority of them to the proper genera.

Duration of Movement. When worms of different genera are subjected to the same light intensity there is considerable variation in the time required to bring them to a standstill. Bdelloura is usually the first to stop, followed in order by Dendrocœlum, Planaria and Phagocata. Of the two species of Planaria, P. gonocephala, although averaging somewhat smaller in size, usually keeps in motion for a longer time than P. maculata. The individual records of the duration of movement given in Figs. IO-I4 may be taken as a typical set of records. They were as follows: 
Fig. Iо. Dendrocolum, is min.

Fig. I I. Phagocata, $60 \mathrm{~min}$. (still moving).

Fig. I2. Bdelloura, $15 \mathrm{~min}$.

Fig. I3. Planaria maculata, $47 \mathrm{~min}$.

Fig. I 4. Planaria gonocephala, 60 min. (still moving).

Woodworth ('97) in contrasting the activity of Planaria maculata, P. gonocephala and P. dorotocephala states that individuals of the latter species remain in motion longer than individuals of the other two-an observation confirmed by Pearl ('o3).

Degree of $W$ andering. If a worm is started at the center of a circle parallel to the direction of the light and pointing away from its source, then the more devious its course the more it may be said to wander. Both generic and specific differences were obtained bearing upon this phase of behavior. Selected instances of such differences are given in Table $X X$, expressed in average degrees of deviation upon emergence from a circle $10 \mathrm{~cm}$. in diameter.

\section{TABLE XX}

The average generic and specific differences between individuals of four genera and two species of planarians expressed in degrees of deviation upon leaving a circle $10 \mathrm{~cm}$. in diam. In every instance the worm was started away from the source of the light

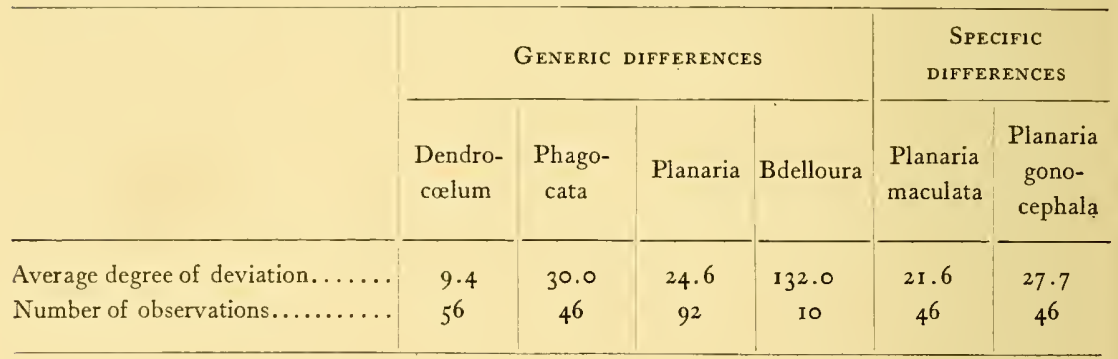

The remarkably large deviation shown by Bdelloura is due to the fact that it is a positive worm. When pointed toward the light its deviation was only $39 \cdot 3^{\circ}$, a number which would perhaps be more justly comparable with the other records in this table. But even so, it will be seen that Bdelloura, of all the forms observed, is the least oriented by directive light. Specific differences in the degree of wandering are in general less marked than the generic differences, according to the records in Table XX. 
Rate of Locomotion. As regards rate of locomotion the records of specific differences exhibit a wide range, although not as great as that of the generic differences existing between Dendrocolum and Phagocata.

TABLE XXI

The average rate of locomotion expressed in millimeters per second

\begin{tabular}{|c|c|c|c|c|c|}
\hline & \multicolumn{3}{|c|}{ GENERIC DIFFERENCES } & \multicolumn{2}{|c|}{$\begin{array}{c}\text { SPECIFIC } \\
\text { DIFFERENCES }\end{array}$} \\
\hline & $\begin{array}{l}\text { Dendro- } \\
\text { cœelum }\end{array}$ & Phagocata & Planaria & $\begin{array}{l}\text { Planaria } \\
\text { maculata }\end{array}$ & $\begin{array}{c}\text { Planaria } \\
\text { gonocephala }\end{array}$ \\
\hline Rate in $\mathrm{mm}$. per sec..... & 0.850 & I $\cdot 395$ & 1.272 & I. 470 & I. .075 \\
\hline Number of observations............ & 40 & 40 & 80 & 40 & 40 \\
\hline
\end{tabular}

It is interesting to note in this connection that Parker and Burnett ('oo, p. 385) give the average rate for Planaria gonocephala as I.08 mm. per sec., while Pearl ('o3, p. 546) records for P. maculata $\mathrm{I} .48 \mathrm{~mm}$. per sec. in the case of a worm II $\mathrm{mm}$. in length and $1.23 \mathrm{~mm}$. per sec. for one $6 \mathrm{~mm}$. in length. An average of these two records, that is, $1.355 \mathrm{~mm}$. per sec., might perhaps be comparable with the average (I.272) given in Table XXI, since an equal number of large and small worms from each genus formed the basis on which these averages were calculated.

Time Required to Leave a Unit Gircle. If planarians invariably took a straight radial path in going from the center to the circumference of a circle, the time required to leave a unit circle might be used in computing the rate of locomotion. Such a path, however, is not taken. Nevertheless, records of this kind, although untrustworthy for purposes of accurate calculation, furnish a reliable criterion for the comparison of generic and specific behavior. The differences in behavior in the representatives of three genera and two species are given in Table XXII. Bdelloura failed so frequently to emerge from the circle that it is excluded from the list. Each genus and species was tried an equal number of times in light of three different intensities. 
As might be expected, Table XXII presents a close parallel to Table XXI. The only difference in the relative values of behavior, expressed by the averages of rate and time in these two tables, appears in the case of P. maculata. This species, though first in the scale as regards actual rate of locomotion, is second as regards the time required to leave a unit circle, a condition indicating relatively more wandering on its part than was shown by any of the other worms.

\section{TABLE XXII}

The average time in seconds taken in passing from the center to the circumference of a circle Io $\mathrm{cm}$ in. diameter in directive light

\begin{tabular}{|c|c|c|c|c|c|}
\hline & \multicolumn{3}{|c|}{ GENERIC DIFFERENCES } & \multicolumn{2}{|c|}{ SPECIFIC DIFFERENCES } \\
\hline & $\begin{array}{l}\text { Dendro- } \\
\text { cœlum }\end{array}$ & Phagocata & Planaria & $\begin{array}{l}\text { Planaria } \\
\text { maculata }\end{array}$ & $\begin{array}{c}\text { Planaria } \\
\text { gonocephala }\end{array}$ \\
\hline Average number of seconds... & 62 & 40 & 54 & 47 & 60 \\
\hline Number of observations...... & 120 & 120 & 240 & I 20 & I 20 \\
\hline
\end{tabular}

The Effects of Fatigue. To obtain an idea of generic and specific differences in the effects of fatigue, two sets of averages have been combined. First the average rate of ten worms of each kind, when subjected to four successive trials, was first ascertained and the difference between the first and the fourth rate was then expressed as a percentage of increase or decrease in rate, as the case might be. Secondly, the time required to leave a unit circle in twelve successive trials was next recorded and the average percentage of increase or decrease in time of the last four trials, as compared with the first four trials, was computed. By combining these two kinds of percentages the relative differences in the effects of fatigue upon the individuals of the various genera and species, are clearly brought out.

If the results of this computation be compared with the conclusions reached in another way under the preceding paragraphs on "duration of movement," it will be seen that there is a complete agreement in the relative behavior of the different genera and species. That is, the worms most subject to fatigue are the 
first to come to rest and those least affected by fatigue continue longest in motion

TABLE XXIII

The average generic and specific difference in fatigue

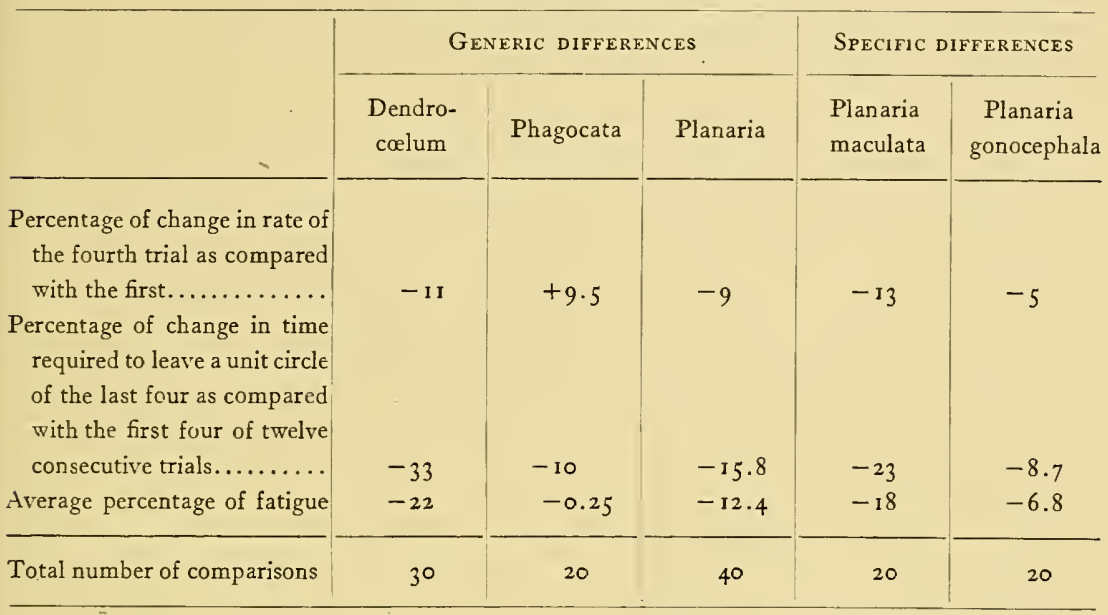

Responses to Changes in Intensity. When worms in non-directive light pass from a given intensity to one $2 \frac{1}{2}$ times as great, decided differences appear in their behavior, the generic differences being plainly of wider range than the specific.

\section{TABLE XXIV}

Average differences in response at the critical line separating two areas of non-directive light of which one $(82.50 \mathrm{c.m}$.$) is approximately 2 \frac{1}{2}$ times as great as the other $(33.16 \mathrm{c.m}$.

\begin{tabular}{|c|c|c|c|c|c|}
\hline & \multicolumn{3}{|c|}{ GENERIC DIFFERENCES } & \multicolumn{2}{|c|}{ SPECIFIC DIFFERENCES } \\
\hline & $\begin{array}{l}\text { Dendro- } \\
\text { colum }\end{array}$ & Phagocata & Planaria & $\begin{array}{l}\text { Planaria } \\
\text { maculata }\end{array}$ & $\begin{array}{c}\text { Planaria } \\
\text { gonocephala }\end{array}$ \\
\hline Number of observations...... & 45 & 202 & 206 & 50 & ${ }_{15}^{6}$ \\
\hline Percentage of responses....... & 17 & 37 & $5^{2} \cdot 5$ & 55 & $5^{\circ}$ \\
\hline $\begin{array}{l}\text { Percentage of failures to re- } \\
\text { spond................... }\end{array}$ & 83 & 63 & $47 \cdot 5$ & 45 & 50 \\
\hline
\end{tabular}

In this table Dendrocolum is shown to respond in only $\mathbf{I} 7$ per cent of its passages across the critical line separating the two different intensities of light, while Phagocata responds in 37 per cent 
and Planaria in 52.5 per cent of the cases. These are differences in degree of response that are great enough to be of unquestionable significance. When, however, Planaria maculata and Planaria gonocephala are compared in the same way, only a slight difference in the degree of response, namely, that between 55 per cent and 50 per cent, is to be observed.

Manner of Coming to Rest. Although little attention was paid to this point during the series of observations taken up for the present study of planarian behavior, still a few indications of generic difference in the manner of coming to rest appear from the foregoing data. Bdelloura, it will be remembered, has a distinctive manner of coming to rest in close rosettes within an area of increased illumination, while Dendrocolum shows a considerable tendency to collect in exclusive companies during periods of inactivity. With regard to the two species of Planaria studied, nothing at all definite was observed in this connection which could be called a true specific difference in behavior. Between Dendrocœlum and P. gonocephala, however, a decided generic difference seems to exist, as several series of records on orientation in directive light show. Dendrocœlum according to these records came to rest in an unoriented position in 70 per cent of the cases observed, while $P$. gonocephala failed to take up an oriented resting position in only 59 per cent of the observations. In other words, P. gonocephala is more liable to come to rest in a position oriented with reference to the light than Dendrocœlum.

Summary. The essential points brought out in the foregoing section are condensed for the sake of brevity and clearness in Table XXV.

In certain instances, namely, in changes in the character of the course (2), the influence of fatigue (7), and the percentage of responses to change in light intensity (8), specific behavior shows a more intimate correlation than generic behavior, otherwise the range between the behavior of $\mathrm{P}$. gonocephala and $\mathrm{P}$. maculata is greater than the generic differences separating Planaria from the other genera under observation.

It might be expected a priori that generic differences would exhibit a greater range than specific differences and that similarly, 
specific behavior would include more phases of action than individual behavior.

In the present series of records hardly enough representatives of different genera and different species were under consideration to establish any convincing generalization on this point.

TABLE XXV

Comparisons in behavior, generic and specific

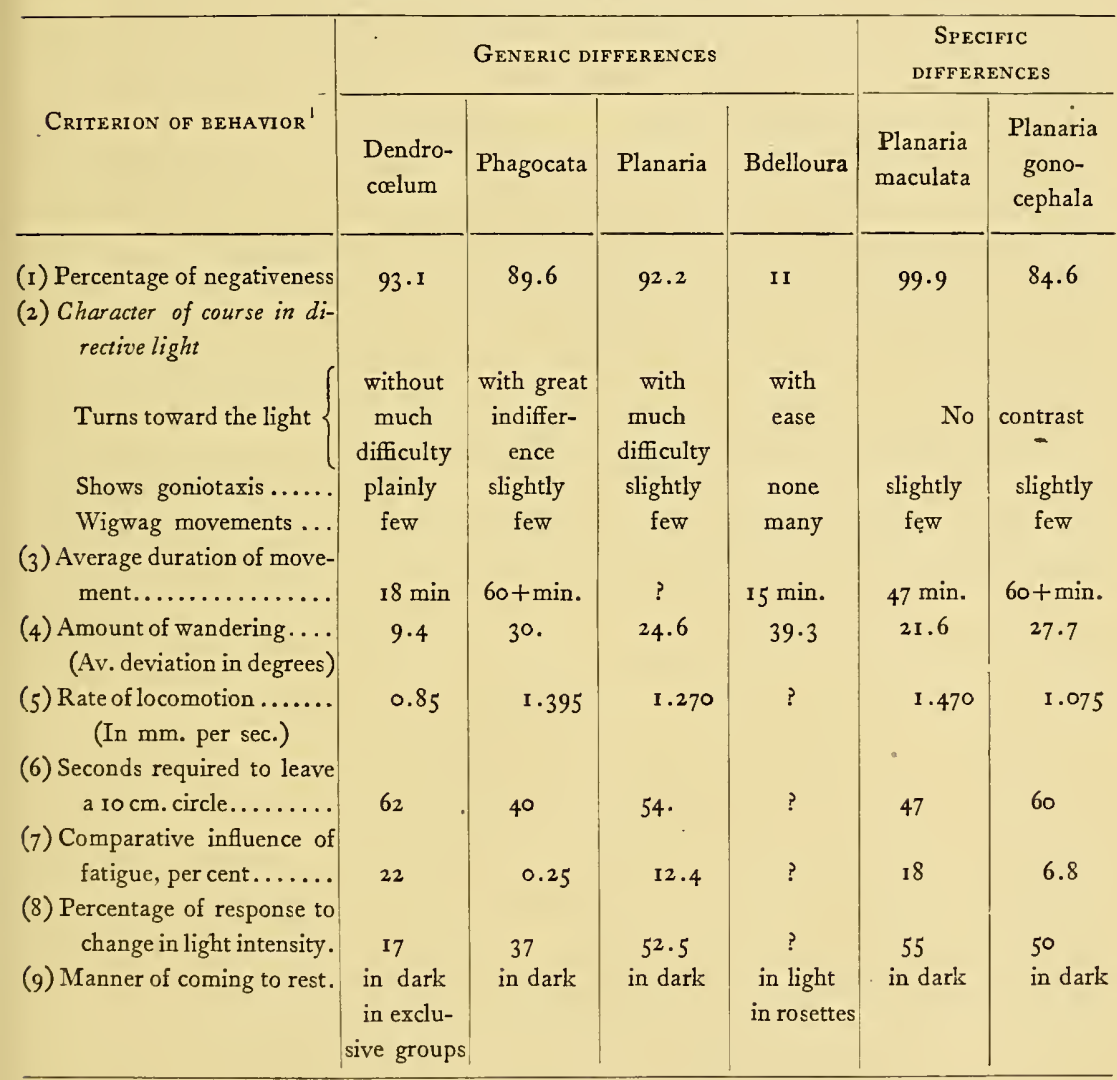

\section{B Individual Behavior}

The analysis of specific behavior leads to the study of individuals, since it is the average activity of different individuals that makes up the behavior typical of the species. In biological litera- 
ture animal behavior, particularly among the lower forms, is ordinarily referred to in its specific or even generic aspect. The - distinctive actions of individuals, as such, it seems, have usually been outside of the purpose of the observer. ${ }^{5}$

Individuals, however, even among such comparatively. simple forms as planarians, do not always act with machine-like uniformity. Until it is possible to predict with exactness what behavior will result under any given set of conditions, an accurate knowledge of the behavior of any kind of organism must be based upon repeated observations of individuals as such rather than as representatives of species and genera.

Individual variations in behavior constantly appeared throughout the course of the present investigation. It will be sufficient, however, for the purpose of making clear their importance to cite only a few instances of such variations.

It should be noticed that whenever "exceptions to the rule" of behavior occur, as in the case of negative planarians coming to rest in the light or becoming positively phototactic for a time (see the two cases cited on p. 78), they are ordinarily simply abnormal cases of individual behavior standing out against the background of average specific or generic behavior. Exceptional cases of this kind, however, are not so typical of what really constitutes individual behavior as the less aberrant actions making up the majority of the movements which the animal performs.

The main point to be recognized, then, is that the individual presents unknown factors, which, even in the simplest forms of life, where the range of variation is least, have never yet been reduced entirely to chemico-physical terms, a fact which impairs somewhat the conclusions of those writers who would draw a complete parallel between an organism and a machine.

Rate on Successive Days. When the rate of locomotion of certain isolated individuals is averaged from four trials, for example, and the same experiment is repeated on the following day with the same individuals, thereby eliminating the effects of fatigue, under as nearly identical conditions as possible, the two sets of figures

Frandsen ('or), who was impressed by individual differences in the phototaxis of Limax, and Smith ('o2), who worked with the earthworm, are exceptions to this generalization. 
thus obtained show more variation than would be expected if the organisms experimented upon responded in a machine-like way. If not all, at least a part of this variation may, then, be due to differences in individual behavior.

\section{TABLE XXVI}

The differences among isolated individuals of different species in the average rate of locomotion, based on 4 trials each on each of two different days, expressed in $\mathrm{mm}$. per sec.

\begin{tabular}{|c|c|c|c|c|}
\hline & $\begin{array}{c}\text { Dendrocœlum } \\
\text { lacteum }\end{array}$ & $\begin{array}{c}\text { Phagocata } \\
\text { gracilis }\end{array}$ & $\begin{array}{r}\text { Planaria } \\
\text { maculata }\end{array}$ & $\begin{array}{c}\text { Planaria } \\
\text { gonocephala }\end{array}$ \\
\hline First day & $\mathrm{I} \cdot 5^{2}$ & 1.22 & I. 76 & 0.67 \\
\hline Second day $\ldots . . . \ldots \ldots \ldots \ldots$ & 0.70 & 0.96 & I. II & 0.73 \\
\hline
\end{tabular}

The Relative Value of Individual Behavior. In the three following tables individual behavior will be compared with light intensity with respect to (I) rate of locomotion, (2) range of rate and (3) manner of turning.

First, the individual behavior of ro worms belonging to the species Planaria gonocephalá under all intensities of non-directive light showed greater range in the rate of locomotion than the average behavior of the same ten worms showed under any single intensity of non-directive light.

\section{TABLE XXVII}

The relative effect on rate of locomotion of individual behavior and light intensity. The averages are expressed in $\mathrm{mm}$. per sec.

A Variation of Individual Behavior

\begin{tabular}{|c|c|c|c|c|c|c|c|c|c|c|c|}
\hline \multicolumn{3}{|c|}{ Identification number of worm $\ldots \ldots \ldots \ldots \ldots$} & I & 2 & 4 & 5 & 6 & 7 & 8 & 9 & 10 \\
\hline \multicolumn{3}{|c|}{ Average rate in all the intensities given in $\mathrm{B} \ldots .}$. & 0.790 & 0.570 .70 & 0.64 & $0.83 \circ$ & 0.70 & 0.72 & 0.60 & 0.49 & 90.62 \\
\hline \multicolumn{12}{|c|}{ Range $=0.34\left[0.8_{3}(\right.$ No. 5$)-0.49($ No. 9) $]$} \\
\hline \multicolumn{12}{|c|}{ B Variation in Different Light Intensities } \\
\hline Light in candle meters $\ldots . . .$. & $\circ$ & 0.94 & 11 & 39 & 78 & I 2 & 26 & 155 & 217 & 7 & $43^{1}$ \\
\hline $\begin{array}{l}\text { Average rate of the Io worms given } \\
\text { in } A \ldots \ldots \ldots \ldots \ldots \ldots \ldots \ldots\end{array}$ & 0.57 & 0.66 & 0.69 & 0.75 & 0.64 & 0.6 & 65 & 0.69 & 0.7 & 70 & 0.63 \\
\hline
\end{tabular}

Range $=0.18[0.75$ (39 c.m.) -0.570 (o c.m.) $]$ 
Secondly, the range between the maximum and minimum rates of ten individuals in all intensities of non-directive light was greater than the average range of rate of the same individuals under different intensities of non-directive light.

\section{TABLE XXVIII}

The relative effect of individual behavior and light intensity on the range of rate of locomotion, expressed in $\mathrm{mm}$. per sec.

A Variation of Individual Behatior

\begin{tabular}{ll|l|l|l|l|l|l|l|l|l|l} 
Identification number of worm............. & I & 2 & 3 & 4 & 5 & 6 & 7 & 8 & 9 & 10 \\
\hline
\end{tabular}

Maximum rate in all intensities given in B...2.58 1.672.001.672.172.08 2.20 1.78 1.82 1.58 Minimum rate in all intensities given in B.... $0.920 .670 .920 .83 \quad 1.030 .420 .670 .280 .280 .75$

Range of rate............... I.66 I.00 I.080.84 I.I4 I.66 I. 53 I. 50 I.540.83

$$
\text { Range } \circ 8_{3}=\left[1.66(\text { No. I or } 6)-0.8_{3} \text { (No. 10) }\right]
$$

B Variation in Different Light Intensities

\begin{tabular}{|c|c|c|c|c|c|c|c|c|c|}
\hline Light in candle meters ........ & $\circ$ & 0.94 & II & 39 & 78 & 126 & I 55 & 217 & $43 \mathrm{I}$ \\
\hline $\begin{array}{l}\text { Maximum rate for all worms given } \\
\text { in } \mathrm{A} \ldots \ldots \ldots \ldots \ldots \ldots \ldots \ldots \ldots \ldots \ldots \\
\text { Minimum rate for all worms given } \\
\text { in } \mathrm{A} \ldots \ldots \ldots \ldots \ldots \ldots \ldots \ldots \ldots\end{array}$ & $\begin{array}{l}\text { I. } 5^{8} \\
0.71\end{array}$ & $\begin{array}{l}\text { I.93. } \\
\text { I.07 }\end{array}$ & $1.9^{2}$ & I. 77 & $\begin{array}{l}1.92 \\
0.77\end{array}$ & $\begin{array}{l}1.79 \\
0.62\end{array}$ & $\begin{array}{l}\text { I. } 87 \\
\text { I. } 15\end{array}$ & 2.00 & $\begin{array}{l}\text { I. } 55 \\
0.79\end{array}$ \\
\hline Range of rate $\ldots . . . \ldots$ & 0.87 & 0.86 & I. 18 & 0.73 & I. 15 & 1.17 & 0.72 & 0.97 & 0.76 \\
\hline
\end{tabular}

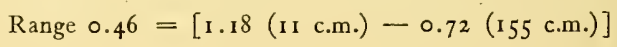

Thirdly, with respect to clockwise or contra-clockwise turnings, individual factors were found to be of more importance than differences of intensity of non-directive light in determining the direction of turning.

It should be added that the ten worms concerned in the three preceding tables were as similar in size and external appearance as it was possible to select.

$A$ Cave Planarian. This specimen came from an Indiana cave, where it probably had always lived in darkness up to the time of its capture. When first made the subject of experiment, it could be briefly described as a white worm, about $6 \mathrm{~mm}$. in 
length, devoid of any dark pigment except in the two eye spots. Although most nearly resembling Dendrocœlum lacteum in color, it showed some differences from this species in the contour of its body and particularly in its behavior. It was thought probable, therefore, that this was a representative of some species peculiar to a dark habitat. The absence of sexual organs made its exact identification impossible. In the present connection it will be referred to simply as "the cave worm." As a unique subject for the study of individual behavior, it proved to be very

TABLE XXIX

The relative effect of individual behavior and light intensity on the direction of turning, expressed in a ratio of contra-clockwise to clockwise movements

A Variation of Individual Behavior

\begin{tabular}{|c|c|c|c|c|c|c|c|c|c|c|}
\hline Identification number of worm........... & I & 2 & 3 & 4 & 5 & 6 & 7 & 8 & 9 & IO \\
\hline $\begin{array}{l}\text { Ratio of contra-cluckwise to clockwise turn- } \\
\text { ings in all the intensities given in B } \ldots .\end{array}$ & $\begin{array}{c}\mathbf{I} \\
\text { to } \\
\text { I }\end{array}$ & $\begin{array}{c}1 \\
\text { to }\end{array}$ & $\begin{array}{c}\mathbf{I} \\
\text { to }\end{array}$ & $\begin{array}{c}\text { I } \\
\text { to }\end{array}$ & $\begin{array}{c}\text { I } \\
\text { to }\end{array}$ & $\begin{array}{l}\mathbf{I} \\
\text { to }\end{array}$ & $\begin{array}{c}\text { I } \\
\text { to }\end{array}$ & $\begin{array}{c}I \\
\text { to } \\
4.02\end{array}$ & $\begin{array}{c}\text { I } \\
\text { to } \\
0.8\end{array}$ & \\
\hline
\end{tabular}

$$
\text { Range }=\text { I to } 3.60[\text { I to } 4.02 \text { (No. 8) - I to } 0.42 \text { (No. } 3 \text { ) }]
$$

B Variation in Different Light Intensities

\begin{tabular}{|c|c|c|c|c|c|c|c|c|c|}
\hline Light in candle meters ........ & $\circ$ & 0.94 & II & 39 & 78 & 126 & 155 & 217 & $43^{I}$ \\
\hline $\begin{array}{l}\text { Average ratio of contra-clock- } \\
\text { wise to clockwise turnings of } \\
\text { the } 10 \text { worms given in A... }\end{array}$ & $\begin{array}{c}\mathbf{I} \\
\text { to } \\
\mathbf{I}\end{array}$ & $\begin{array}{c}\text { I } \\
\text { to } \\
\text { I. IO }\end{array}$ & $\begin{array}{c}\text { I } \\
\text { to } \\
\text { I. } 24\end{array}$ & $\begin{array}{c}\text { I } \\
\text { to } \\
\text { I. } 65\end{array}$ & $\begin{array}{r}I \\
\text { to } \\
I\end{array}$ & $\begin{array}{c}\text { I } \\
\text { to } \\
0.93\end{array}$ & $\begin{array}{c}\mathbf{1} \\
\text { to } \\
\mathbf{I} \cdot 32\end{array}$ & $\begin{array}{c}\text { I } \\
\text { to } \\
I .40\end{array}$ & $\begin{array}{c}\text { I } \\
\text { to } \\
\mathbf{I} \cdot 5^{8}\end{array}$ \\
\hline
\end{tabular}

$$
\text { Range }=1 \text { to } 0.72[\mathrm{I} \text { to } \mathrm{I} .65 \text { (39 c.m.) }-\mathrm{I} \text { to } 0.93 \text { (I } 26 \text { c.m.) }]
$$

interesting. A comparison of its activities with those of other planarians is given in Table XXX, where it will be seen that this cave worm was considerably more active than any other kind of worm under observation, both with respect to locomotion and to the average time required for it to leave a unit circle. Regarding the degree of negativeness which it presented, no new feature appeared, though its average in this point was rather higher than that of all the other worms studied. However, its degree of wandering quite exceeded anything shown by planarians which had been reared in the light. 
If the relationship of an animal could be determined by behavior alone, there need be no hesitancy in saying that this unidentified planarian should not be classified under the species Dendrocœlum lacteum, since in all the criteria mentioned in the foregoing table it stands at an opposite extreme to Dendrocœlum. In point of fact its behavior more closely resembled that of Phagocata gracilis, a species which, according to Dr. A. M. Banta, who kindly furnished the cave planarian for this study, is common in the streams in the vicinity of the cave where the latter was found.

TABLE XXX

The behavior of a cave planarian compared with that of planarians accustomed to light.

\begin{tabular}{|c|c|c|c|c|c|c|}
\hline \multirow{2}{*}{ Criteria OF BEHAVIOR } & \multicolumn{2}{|c|}{$\begin{array}{l}\text { ThE CAVE } \\
\text { PLANARIAN }\end{array}$} & \multicolumn{4}{|c|}{ OTHER PLANARIANS } \\
\hline & $\begin{array}{l}\text { Number } \\
\text { of trials }\end{array}$ & $\begin{array}{l}\text { Average } \\
\text { record }\end{array}$ & $\begin{array}{l}\text { Average } \\
\text { record }\end{array}$ & $\begin{array}{l}\text { Maxi- } \\
\text { mum }\end{array}$ & $\begin{array}{l}\text { Mini- } \\
\text { mum }\end{array}$ & Range \\
\hline $\begin{array}{l}\text { Average amount of negativeness, expressed } \\
\text { in the percentage of deviation upon leav- } \\
\text { ing a circle } 10 \mathrm{~cm} \text {. in diameter when } \\
\text { started at right angles to incident light }\end{array}$ & 70 & $99 \cdot 6$ & $9^{91.8}$ & $\begin{array}{l}99.9 \\
\text { delloura }\end{array}$ & $\begin{array}{c}84.6 \\
\text { omitted) }\end{array}$ & $15 \cdot 3$ \\
\hline 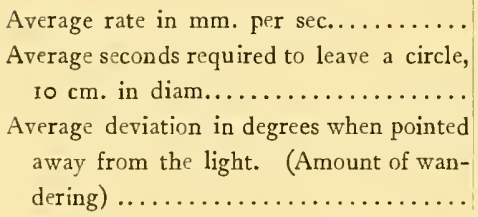 & 60 & 2.00 & 1.203 & $\begin{array}{l}\text { I. } 473 \\
62.2\end{array}$ & $\begin{array}{l}0.853 \\
39 \cdot 7\end{array}$ & $\begin{array}{l}0.62 \\
22.5\end{array}$ \\
\hline
\end{tabular}

Summary. Average individual behavior constitutes typical specific behavior. Variations in individual behavior make accurate predictions of responses to stimuli under given conditions, impossible. The rate of locomotion of the same individuals varies from day to day even under apparently identical conditions. Individual variations in the rate of locomotion, in the range between maximum and minimum rates, and in the percentage of clockwise turnings, are more variable than the average behavior in these particulars under different light intensities.

An unidentified cave planarian showed greater activity and more inclination to wander than any of the other planarians under observation. 
CONTRIBUTIONS FROM THE ZOÖLOGICAL LABORATORY OF THE MUSEUM OfF COMPARATiVE ZOÖLOGY AT HARVARD COLlege. E. L. MARK, Director. No. 193 .

\title{
THE REACTIONS O'F PLANARIANS TO LIGHT
}

BY

\author{
HERBERT EUGENE WALTER \\ With Fourteen Figures \\ (Concluded) \\ 4 BASIS OF BEHAVIOR
}

In the sections on Photokinesis and Phototaxis certain conditions of illumination were shown to be variable factors in influencing the movements of planarians. Following this treatment of the subject an attempt was made under "Kinds of Behavior" to classify the effects of light according to the way in which the responses of planarians become manifested in a generic, a specific or an individual sense. It now remains to consider the nature of the factors which cause different individuals to present characteristic differences in behavior. There are at least three ways of approaching the matter. These may be roughly indicated as the point of view of the morphologist, the physiologist, and the psychologist.

\section{A Morphological Basis of Behavior}

The structure and shape of a planarian, its muscular and ciliary equipment, together with the kind and distribution of its lightreceiving apparatus, are some of the morphological factors definitely restricting the kind and range of its reactions to light. These morphological factors may be grouped into, first, those which determine the general form of the body and consequently influence the animal's activities in a broad sense, and, secondly, those directly concerned with the reception of the light stimulus, the photoreceptors.

The. Journal of Experimental Zoölogy, vol. v, no. 2. 


\section{a General Form of the Body}

A normal, full-grown planarian may be expected to give typical reactions to any stimulus. Fragments of a planarian, on the other hand, whether occurring from natural or artificial causes, would not be expected to behave as perfectly developed worms do, and observation shows that they do not.

As previously mentioned, Loeb ('94), and later other investigators, established the fact that planarians with eyes and brain removed are still able to give characteristic reactions to light, while Lillie ('OI) found that any fragment capable of regeneration would respond to light.

In all cases of mutilated worms, however, the response to light is slower and less precise than that exhibited by normal individuals, and therefore different in degree if not in character from that of the latter. It has been repeatedly observed that worms mutilated unilaterally perform circus movements regardless of the light. This seems to be a plain case of morphological limitations on the part of the crippled animal, whereby the cilia and musculature of one side, on account of injury, are less efficient than those on the other side. Since it is practically impossible in nature to select at random a dozen planarians of which at least one specimen does not show some sort of mutilation, the modified behavior of morphologically imperfect animals becomes a factor of considerable importance in any general analysis of planarian activities.

Again, with regard to the general form of the body, it seems reasonable to suppose that a mature planarian loaded down with sexual products, or one gorged with food, must encounter mechanical difficulties in responding to light, so far at least as locomotion is concerned, which the same animal when unencumbered would not experience. A few experiments were performed to test this supposition, in which a comparison of the behavior of large and small worms was attempted. Pearl ('o3, p. 546), it will be recalled, has shown that in the case of Planaria maculata, a worm I I mm. long travels at a faster rate than one $6 \mathrm{~mm}$. long. This experiment was repeated with a confirmatory result but, as will be seen 
upon examining Table XXXI, the same result did not occur when Dendrocœlum lacteum was used.

\section{TABLE XXXI}

The average rate of locomotion in $\mathrm{mm}$. per sec. of 5 small and 5 large individuals of each of four species, subjected to identical light conditions

\begin{tabular}{|c|c|c|c|c|}
\hline \multirow[b]{2}{*}{ SPEcies } & \multicolumn{2}{|c|}{ LARGE } & \multicolumn{2}{|c|}{ SMALL } \\
\hline & $\begin{array}{l}\text { Size } \\
\mathrm{mm} .\end{array}$ & $\begin{array}{c}\text { Average } \\
\text { rate }\end{array}$ & $\begin{array}{l}\text { Size } \\
\mathrm{mm} .\end{array}$ & $\begin{array}{c}\text { Average } \\
\text { rate }\end{array}$ \\
\hline Dendrocœlum lacteum (first trial)... & II & 0.695 & 4 & I.OI \\
\hline Dendrocœlum lacteum (second trial . & II & 0.74 & 4 & 0.77 \\
\hline Phagocata gracilis............... & 9 & I. $5^{8}$ & 4 & 1.21 \\
\hline Planaria maculata $. . . \ldots \ldots \ldots \ldots \ldots \ldots \ldots . . .$. & 13 & I. 57 & 8 & $1 \cdot 37$ \\
\hline Planaria gonocephala.................. & 10 & I. 17 & 5 & 0.98 \\
\hline
\end{tabular}

The worms selected for the experiments detailed in Table XXXI were carefully chosen as to length and did not vary more than a millimeter in any case from the size recorded in the table. The result obtained with Dendrocœlum was so unexpected that the same ten individuals were put aside and tried a week later under as nearly identical conditions as possible. As will be seen by the table, the result of the second experiment was in general the same, though not so pronounced, as that obtained in the first set of trials. In the cases of Phagocata gracilis, Planaria gonocephala and Planaria maculata, the larger worms traveled faster than the smaller ones. Why the factor of size should give a different result in the case of Dendrocœlum lacteum from that common to the dark-pigmented planarians is by no means clear. It is conceivable that a planarian with undeveloped sexual organs or one whose size was reduced through starvation might have a better ciliary equipment in proportion to its mass than a normally adult animal and that in consequence it could travel faster. This supposition explains the behavior of Dendrocœlum lacteum, but it does not throw light on that of the other species, of which the smaller individuals, instead of traveling faster than their larger associates, moved at a slower rate. It is possible that in the case of the dark-colored worms reduction in size is accompanied by a 
corresponding reduction in the photoreceptive elements, which, according to the experiments of Loeb ('94) and of Parker and Burnett ('o) seem to be in some degree at least distributed over the entire body. If this is true, there would result less stimulation from the light and consequently a slower rate. That Dendrocœlum lacteum when reduced in size does not suffer a similar reduction of its photoreceptive apparatus is probable. The work of Lillie ('or), wherein he showed the inability of headless individuals of Dendrocœlum lacteum either to regenerate or to respond to light, suggests that the photoreceptive apparatus of this species is not scattered over the entire body, but is rather concentrated anteriorly, in all probability consisting of the eyes only. If this is true, a reduction in the size of the body would not necessarily cause a proportionate reduction in the photoreceptors, and, indeed, the proportion of the light-receiving elements as compared with the mass of the body might increase as the worm became smaller. In this connection it is interesting to note that Gissler ('82) pointed out that in the case of Bdelloura candida increasing size of the body is accompanied by a decrease in the size of the eyes, and so far may this inverse ratio be carried that the eyes sometimes disappear entirely in large individuals. If there actually exists some such inverse ratio between the size of the photoreceptors and the mass of the body in the case of Dendrocœlum lacteum, it is easy to see why the smaller worms travel faster than the larger ones.

By another series of experiments it was found that the smaller worms of all four species, with the possible exception of Dendrocœlum lacteum, orient with less accuracy than the larger worms under the same external conditions. In these experiments, as in the previous ones already described dealing with orientation, each worm was placed at the center of a circle $10 \mathrm{~cm}$. in diameter and headed successively toward, away from, and at right angles in both directions, to the incident light. The average amount of deviation at the circumference of the circle from the direction in which the worms were started, reckoned in degrees, gives a criterion of their accuracy in orientation. The averages of behavior obtained are indicated in Table XXXII. 
The lessened accuracy in orientation among the smaller worms, as compared with the larger ones, helps to support the hypothesis that reduction in size entails proportionate reduction in the photoreceptive apparatus. The fact that Dendrocœlum lacteum forms an apparent exception to this general rule may also be taken as evidence that in this case the photoreceptive apparatus is more localized than in the other worms studied and conse-

\section{TABLE XXXII}

The average deviation (expressed in degrees), at the circumference of a circle $10 \mathrm{~cm}$. in diameter, of large and small worms, each lot consisting of 5 individuals. Each worm was headed successively toward, away from and at right angles in both directions to incident light. The actual sizes of the worms were the same as in Table XXXI

\begin{tabular}{|c|c|c|c|c|c|c|c|}
\hline \multirow[b]{2}{*}{ SIZE OF WORMS } & \multicolumn{3}{|c|}{ DENDROCELUM LACTEUM } & \multicolumn{2}{|c|}{ Planaria } & \multirow{2}{*}{$\begin{array}{c}\text { Phagocata } \\
\text { gracilis }\end{array}$} & \multirow{2}{*}{$\begin{array}{c}\text { Total } \\
\text { average }\end{array}$} \\
\hline & First trial & $\begin{array}{c}\text { Second } \\
\text { trial }\end{array}$ & Average & maculata & $\begin{array}{c}\text { gono- } \\
\text { cephala }\end{array}$ & & \\
\hline Large, degrees... & 67 & 70 & 68.5 & 57 & 64 & 63 & 63 \\
\hline Small, degrees... & 57 & $85 \cdot 5$ & 68.5 & $6 I$ & 69 & 72 & $67 \cdot 4$ \\
\hline
\end{tabular}

quently does not suffer a proportionate decrease when the size of the body becomes less. It is furthermore quite possible that a sexually mature planarian may on that account behave differently in light than an immature one. For instance, Yerkes ('o3) states that in the case of the hydromedusa Gonionemus murbachii, the sexually mature individuals are the ones most sensitive to light, and Schouteden ('O2) found the young of Daphnia positive, while the adults were negative to light.

Finally, Harper ('05) has shown that in the case of the earthworm the degree of sensitivity to light depends upon the degree of contraction or expansion of the body, since the photoreceptor cells - which in the earthworm lie interstitially at the bases of the epithelial cells-are more exposed to stimulation when the worm is expanded and conversely more shielded when it is contracted. It is more than likely that planarians offer a parallel instance and that their comparative indifference to light stimulation when in the relaxed resting position is due to the fact that then they present a more rounded contour and consequently their photoreceptors 
are more deeply buried from the light than when they are in the expanded position assumed while gliding.

\section{b Photoreceptors}

What is the photoreceptive apparatus of the planarian? Is it made up of the eyes only, or partly of nerve-endings or of some special morphological elements homologous perhaps to the photoreceptor cells in the integument of the earthworm as described by Hesse ('96). Or does the central nervous system, the ciliary apparatus, or the musculature receive the stimulus directly without the mediation of special sense organs?

Although these questions were not made the subject of particular investigation in the present study of planarian behavior, certain facts incidentally appear from the observations made for other purposes which bear directly upon these inquiries and may serve as a basis for a brief discussion of the nature and location of the photoreceptive apparatus of planarians. The presence of eyes in the anterior part of the body, together with the wigwag movements which often take place in the same region when a variation occurs in the light conditions, point directly to the conclusion that the anterior end of the worm is more responsive to light than the posterior end. The fact that many planarians continue to react to light with considerable definiteness after the whole anterior end of the body is removed, indicates that this region does not necessarily contain the entire photoreceptive apparatus. Decapitated individuals of the species Dendrocœlum lacteum, it should be noted, seem to be exceptional in this respect since, according to Lillie, they fail to react to light.

In further support of the supposition that the anterior end of the planarian is the portion most sensitive to light it was found that the skioptic response of Bdelloura candida is confined not only to the anterior end but particularly to the region directly including the eyes. Observations repeatedly showed that if Bdelloura was allowed to come to rest in a field illuminated from above only, a sharp narrow shadow thrown across its body produced no visible response unless the shadow included the eyes. 
The moment, however, that the eyes were in shadow the worm would elongate and frequently begin strikingly active movements.

It has already been shown (Table XIV, p. 77) that all the different species of planarians u pon which experiments were made, traveled at a faster rate when they were started with the anterior end pointed toward directive light than when away from it. A reason may be offered for this characteristic increase in rate on the ground that the anterior end was plainly subjected to stronger stimulation when directed toward the light than when pointed away from the source of the stimulus. In the latter instance it was not only turned away from the source of the stimulus but was shielded alșo from the light to a considerable extent by the shadow formed by the posterior part of its own body.

Again, when a small beam of sunlight passing through a pinhole in an opaque screen was directed locally to different parts of a gliding Planaria maculata, it was found that tropic response would occur in case one side of the anterior end was illuminated, and that it was not necessary for the eye itself to be included in the illuminated area to obtain such responses. However, when the middle of the body or the posterior end was similarly stimulated the worm could not be made to turn.

From the foregoing observations it seems probable that the photoreceptive apparatus of planarians is mainly but not exclusively located in the anterior end of the body and that considerable specific or generic difference may exist with respect to the extent of the distribution of additional light-receiving organs over other parts of the body. It is interesting to note in passing that Gamble and Keeble ('O3) found that in the case of the green rhabdocole Convoluta roscoffensis the sensitiveness to light was at the anterior end of the body only.

Concerning the relative sensitiveness to light of the dorsal and ventral surfaces of planarians, a set of experiments was performed on Planaria gonocephala in which the results show an absence of any marked differentiation in this regard. It is well known that in the matter of response to a thigmotactic stimulus the dorsal and ventral surfaces of a planarian show a very striking difference. Indeed, the dorsal surface is negatively thigmotactic to 
such a degree that it is practically impossible to make a worm remain with its dorsal surface in contact with any surface, while its ventral surface is just as strongly positive in its thigmotaxis.

In contrasting the receptivity of these two surfaces to light stimulation a field of two adjacent intensities, similar to that used in the experiments on abrupt spacial changes in light intensity (Fig. 3, p. 79), was arranged in such a way that, in the first instance the source of the two lights was below, and in the second above, the field in which the worms were placed. The intensities of the light in each case were approximately 66 and $33 \mathrm{c.m}$. By this means the responses of the worms could be tabulated as they glided from one intensity of light to another and those given when the light impinged on the dorsal surface compared with similar responses made when the light struck directly on the ventral surface. It will be seen in Table XXXIII that the results do not indicate any particular difference for the dorsal and ventral surfaces with respect to the distribution of the photoreceptors. This condition of affairs, however, may be largely due to the translucency of the planarian's body, which would render light-receiving organs accessible from whatever direction the light primarily comes.

\section{TABLE XXXIII}

A comparison of responses made by Planaria gonocephala to a change in light intensity, tabulated with reference to the source of the light and its relative degree of stimulation upon the dorsal and ventral surfaces of the worm respectively

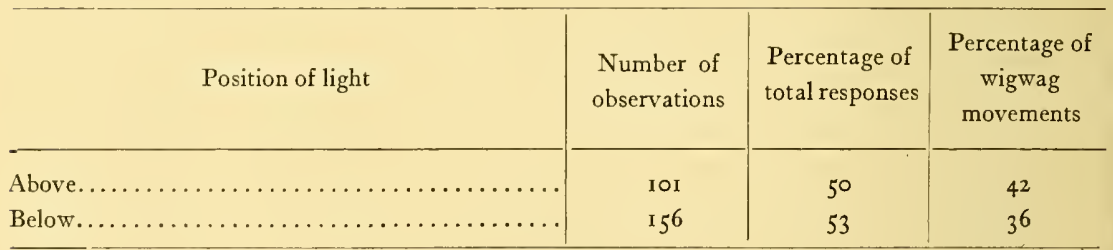

An exact determination of photoreceptors other than the eyes was not made. Both Iijima (' 84, p. 438) and Carrière ('82, p. I67) in their histological researches upon planarians found "Nebenaugen" frequent and these occasional accessory eyes have also been described by Jäninchen ('96, p. 259). Such structures may 
possibly be interpreted as the connecting link between undifferentiated light-receiving organs and the normal eyes of the planarians.

The part that pigment plays in the reception of light is not as yet clearly defined. It is not probable that pigment in itself constitutes a photoreceptor, though it is usually found associated with sensory cells which are directly concerned with light reception. That it is not an essential factor of a photoreceptor is evident, inasmuch as it is absent from the eyes of albino animals. The secondary rôle of pigment in the reception of light by organisms is admirably pointed out and discussed by Beer ('or).

The presence of pigment in a planarian may, however, modify the animal's response to light stimulation by shielding the sensory cells from light, and since its distribution in general is near the exterior, it may afford some clue to the relative receptivity of internally and externally situated photoreceptors. In other words, if pigmented and non-pigmented worms, for example, exhibited the same behavior in light, it might reasonably be assumed that the photoreceptors were not located internally, since they would be partially shielded from light in the case of the pigmented forms and consequently would give rise to a different response.

It is of interest, therefore, to contrast the behavior of darkpigmented worms with those in which the dark pigment is absent except in the eyes. This is done in Table XXXIV, but it by no means follows that the contrasts there given between the behavior of dark and light worms are due to the presence of dark pigment in the one case and its absence in the other. Other factors than pigment may very probably have been influential in bringing about variations in the light reactions tabulated. Furthermore, it is inaccurate to refer to a white worm as being non-pigmented, since in that case it would be entirely transparent. The question, then, so far as planarians are concerned, is confined not to differences between pigmented and non-pigmented but to differences between dark-pigmented and light-pigmented forms.

It will be seen from Table XXXIV that when subjected to light stimulation dark-pigmented worms in general show more activity than light-pigmented forms. A single exception to this rule occurred in the case of the cave planarian experimented upon. 
This marked difference in behavior might possibly be explained on the hypothesis that the direct effect of light on the deeper lying nervous system is inhibitive; that is, so excessive as to produce a sort of light rigor. Thus the more the central nervous system is shielded from light by pigment the less the inhibitive effect becomes apparent. Certain it is that Bdelloura candida, which has dark

\section{TABLE XXXIV}

The behavior of dark-pigmented worms contrasted with that of worms not possessing dark pigment distributed over the body. The number of observations in each case is not given since the details of this table have already appeared elsewhere

\begin{tabular}{|c|c|c|c|c|c|c|c|c|}
\hline & \multicolumn{4}{|c|}{ DARK PIGMENTED } & \multicolumn{4}{|c|}{ Light Pigmented } \\
\hline & 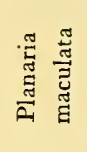 & 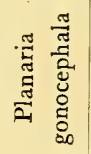 & 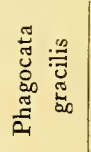 & 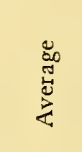 & 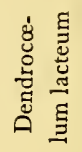 & 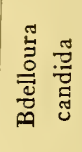 & 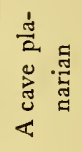 & 总 \\
\hline $\begin{array}{l}\text { Duration of movement in a typ- } \\
\text { ical set of experiments, minutes }\end{array}$ & 47 & $60+$ & $60+$ & $5^{6+}$ & I8 & I5 & & $16+$ \\
\hline $\begin{array}{l}\text { Percentage of orientation to light } \\
\text { upon coming to rest.......... }\end{array}$ & & 4I & & $4 I$ & 30 & & & 30 \\
\hline $\begin{array}{l}\text { Wigwag responses at the critical } \\
\text { line separating two intensities } \\
\text { of non-directive light, per cent }\end{array}$ & & 39 & & 39 & $8 \cdot 5$ & & & 8.5 \\
\hline $\begin{array}{l}\text { Average number of seconds re- } \\
\text { quired to escape from a circle } \\
10 \mathrm{~cm} \text {. in diameter } \ldots \ldots \ldots \ldots\end{array}$ & $4^{8.8}$ & 59.6 & 39.6 & $49 \cdot 3$ & 62.2 & & 27.6 & 44.9 \\
\hline Precision of response & & & & & & & & \\
\hline $\begin{array}{l}\text { Deviation in degrees upon emerg- } \\
\text { ing from a circle ro } \mathrm{cm} \text {. in dia- } \\
\text { meter when headed away from } \\
\text { the light................. }\end{array}$ & 24.4 & $25 \cdot 3$ & $29 \cdot I$ & 26.3 & IO. I & & I I. 4 & 10.7 \\
\hline $\begin{array}{l}\text { Rate of locomotion in mm. per } \\
\text { sec......................... }\end{array}$ & I .47 & I. .075 & I. 395 & I .28 & 0.85 & & & 0.85 \\
\hline
\end{tabular}

pigment in its eyes only, may be brought to a standstill very readily by means of light stimulation. With the exception of the eyes it may be possible that the photoreceptive apparatus is not differentiated to such an extent that it could fairly be said that any part of the translucent planarian body is entirely free from the direct stimulation of light. The relation of pigment to light reactions 
is, however, by no means settled in the foregoing observations. This matter should be finally tested by comparisons in the behavior of different individuals of the same species showing variation in pigmentation or of identical individuals at different times when their phases of pigmentation are unlike, rather than upon individuals of different species.

It has proven impossible to include such a consideration in the present paper, but the preliminary steps toward attempting an analysis of the function of pigment with reference to light reactions have already been made and it is expected that a discussion of this phase of planarian behavior will be presented later. It may be stated here that when Planaria maculata is fed with a drop of human blood, a decided increase in pigmentation makes its appearance within a few days, due probably to the oxidation of the hæmoglobin in the blood corpuscles with which the planarians have become gorged. This single observation suggests an experimental means for controlling the amount of pigment in a single individual and it may reasonably be supposed that tests of behavior before and after excessive pigmentation will contribute direct evidence upon the part played by pigment in reactions to light.

Summary. Mutilated planarians in general respond to light with less accuracy than normal individuals.

Small worms move more slowly than large ones in the case of those species whose photoreceptive apparatus is not solely confined to the anterior end of the body. In the case of Dendrocolum lacteum, whose photoreceptive apparatus is relatively greater in small individuals than in large, the rate of locomotion is faster among the smaller than among the larger.

Small worms orient with less accuracy than large ones. Planarians in the relaxed, resting position are less responsive to light than when they are stretched out in the act of gliding, a result probably of the greater exposure of the photoreceptors to light in the latter instance.

The anterior end of the body is the chief photoreceptive region and in certain worms, such as Dendrocoelum lacteum and Bdelloura candida, the anterior end is apparently the exclusive seat of this function. 
No marked difference in response to light is shown between worms stimulated on the ventral surface and those equally stimulated on the dorsal surface.

Aside from the eyes, which form at least a part of the photoreceptive apparatus, no definite light-receiving organs were recognized.

Planarians possessing dark-colored pigment distributed over the body show in general greater activity when subjected to light than forms in which there is no dark pigment except in the eyes.

The central nervous system, as well as the more exterior parts of the planarian, may possibly be stimulated directly by such light as passes through the translucent body.

\section{B The Physiological Basis of Behavior}

The continually changing adjustment in any organism between the incoming and the outgoing energy gives rise to varying phases of metabolic balance, which may be designated as different "physiological states." Such physiological states form a noticeable factor in the behavior of any animal, a fact to which Jennings ('o 4 b, p. I09) in particular has called attention.

That the difference between such states is great may be readily demonstrated. A planarian's response to directive light when it is in a relaxed, quiescent condition is plainly different from that exhibited after it has been vigorously disturbed by a brush. In fact, it is extremely difficult to get two animals that are in precisely the same physiological condition, or the same animal in precisely the same state at two different times, since the exact adjustment of physiological states is too delicate a matter to be controlled by the present gross experimental methods.

The attempt is ordinarily made to eliminate from experiments, so far as possible, the disturbing element of changing physiological conditions, that is, to keep constant all the factors except the one which is being subjected to test, and those results are counted as most successful in which such disturbance is reduced to a minimum.

It is the purpose of this section first, to give a possible classification of the different physiological states in which a planarian may 
be, and, secondly, to pass briefly in review some of the many ways in which light may change the physiological state of such a worm.

\section{a Classification of Physiological States}

It is by no means easy to define even a simple physiological state, since the subtle changes form a continuous series of conditions which pass imperceptibly into each other.

An arbitrary classification for convenience may, however, be made as follows:

I Relaxation, or rest.

2 Slight activity, without locomotion.

3 Normal activity.

4 Violent activity.

5 Rigor.

6 Exhaustion.

In the first of these states there is a minimum expenditure of energy caused by the ebb of the katabolic processes.

The second and fourth states indicate what are often referred to as conditions of low and high "tonus," but as this term has a technical significance with reference to muscle reactions, it will not be used in this classification. The third state, that of normal activity, is the average condition; it is the most desirable one to maintain in testing the animal's responses to different stimuli. By rigor is understood a state wherein there may be an excessive outgo of energy, but unaccompanied by movement, while under exhaustion is included the condition when energy is not being released because there is none to release.

That excessive or continuous light stimulation may go beyond the point producing rigor or exhaustion and may actually cause death, has been repeatedly proven in the case of bacteria by a long line of observers. ${ }^{6} \quad$ The inhibitive effect of excessive light upon other organisms than bacteria has been pointed out by Berger ('oo) with reference to Cubomedusæ; by Pearl and Cole

\footnotetext{
"Tyndall ('78), Downes and Blunt ('77, '78), Jamieson ('82), Duclaux ('85a,'85b,"',o), Arloing ('87a,'87b), Roux ('87), Dandrieu ('88), Raum ('89), Pansini ('89), Janowski ('9o), Buchner ('92), and Ward ('0,4).
} 
('O2) in the case of various infusoria as well as Hydra, Hyallela, Clepsine, Stichostema and Physa; by Yerkes ('o3) for Gonionemus and by Carpenter ('05) for Drosophila.

\section{b Changes in Physiological States Induced by Light}

A variety of stimuli besides light may cause an animal to pass from one physiological state to another. For example, the sense of phototaxis was reversed through mechanical stimulation by Towle ('o) in Cypridopsis and by Holmes ('OI, 'O5b) in Orchestia and Ranatra.

The following typical illustration of the manner in which changes from one physiological state to another succeed each other is offered as a basis of comparison with the responses to light itself, which are about to be described. In the absence of mechanical stimuli a planarian may be in a state of relaxation. Very gentle mechanical stimulation causes the worm to lift its anterior end and move it cautiously about, bringing the animal into a state of slight activity without locomotion. If, now, the mechanical stimulus is prolonged or increased in intensity, enough energy is released to put the animal into gliding locomotion, when it may be fairly said to have passed into the state of normal activity. Provided the stimulation is made still more pronounced, the worm can next be forced to forsake gliding for crawling or humping, so passing into the state of violent activity. Further, it is possible by vigorous shaking to throw the worm, temporarily at least, into a condition of inactivity through excessive stimulation, during which the animal would remain quiet, not because it is failing to release any energy, but because it is unable for the time to set free its energy in the form of locomotion. In other words, it is in the state of rigor. Last of all, if mechanical stimulation is repeatedly applied a condition of exhaustion will appear when the worm has no more available energy and so is unable to move at all.

Effect of Different Intensities. As already pointed out, no intensity either of directive or non-directive light was found sufficient to change the condition of normal gliding into crawling. 
Moreover, light of any intensity or direction frequently proved ineffective in arousing a quiescent worm into any state of apparent activity, particularly if the worm had but recently passed into the state of rest after a prolonged period of exercise.

Effect of Excessive Light. In the experiments with non-directive light it appeared that Planaria gonocephala, when subjected to an intensity of $43 \mathrm{I} \mathrm{c.m.,} \mathrm{showed} \mathrm{somewhat} \mathrm{less} \mathrm{activity} \mathrm{than} \mathrm{at}$ lower intensities, both with respect to rate of locomotion (Table III, p. 57) and to the number of turnings made (Table VI, p. 59); yet, so high a degree of intensity of the light stimulus was apparently not sufficient to cause a change into the physiological state of light rigor. It was comparatively easy, on the other hand, to transform Bdelloura candida by means of excessive light from the state of normal activity into that of light rigor.

Effect of Sudden Change in Light Conditions. A sudden change in light intensity either by increase or decrease is more effective in producing a new physiological state than an equal gradual change. The sudden withdrawal of the lamp to a considerable distance, for example, is usually sufficient to throw a worm from a normal state into violent activity, that is, from a gliding movement into a disturbed state in which the anterior end is waved actively about. But if the light is gradually withdrawn the same distance the worm will usually not pass into a different physiological condition.

The sudden introduction of complete darkness was never found sufficient to reduce an active worm more than temporarily to the resting position. Sudden dark might temporarily halt a moving worm, but it would not cause it to come to rest and assume the relaxed contour. In Bdelloura candida sudden dark, instead of checking the animal's movements, threw it into violent activity.

Effect of Continued Exposure to Light. Continuous exposure to light results in fatigue, which finally causes planarians to change from the state of normal activity to that of relaxation. The tendency toward such a change is shown in Table XXXV, where the responses of a number of wormis newly subjected to light stimulation are contrasted with the responses made by the same worms after they had been moving about for several hours in the light. 
The fresh worms show more activity than the fatigued worms do. Otherwise expressed, the worms have a tendency to change into a lowered physiological state upon continued exposure to light.

\section{TABLE XXXV}

Fatigue effects due to continuous exposure to non-directive lights forming adjacent fields of different intensities, as shown in the behavior of Phagocata gracilis

\begin{tabular}{|c|c|c|c|c|c|c|c|c|c|}
\hline $\begin{array}{c}\text { Ratio of THE TWO } \\
\text { INTENSITIES }\end{array}$ & & I. $96:$ I & & & $13.45: 1$ & & & Average & \\
\hline $\begin{array}{l}\text { Percentage of the re- } \\
\text { sponses at the crit- } \\
\text { ical line separating } \\
\text { the two intensities }\end{array}$ & $\begin{array}{l}\text { Going } \\
\text { into } \\
\text { greater } \\
\text { intensity }\end{array}$ & $\begin{array}{l}\text { Going } \\
\text { into } \\
\text { lesser } \\
\text { intensity }\end{array}$ & 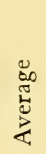 & $\begin{array}{l}\text { Going } \\
\text { into } \\
\text { greater } \\
\text { intensity }\end{array}$ & $\begin{array}{l}\text { Going } \\
\text { into } \\
\text { lesser } \\
\text { intensity }\end{array}$ & 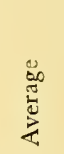 & $\begin{array}{l}\text { Going } \\
\text { into } \\
\text { greater } \\
\text { intensity }\end{array}$ & $\begin{array}{c}\text { Going } \\
\text { into } \\
\text { lesser } \\
\text { intensity }\end{array}$ & 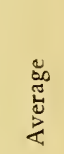 \\
\hline $\begin{array}{l}\text { Fresh worms... } \\
\text { Fatigued worms }\end{array}$ & $\begin{array}{r}10.5 \\
2.5\end{array}$ & 21 & $\begin{array}{r}16 \\
6\end{array}$ & $45 \cdot 5$ & $47 \cdot 5$ & $46 \cdot 5$ & 28 & $34 \cdot 4$ & $3^{I+}$ \\
\hline F atigued worms & $2 \cdot 5$ & $9 \cdot 5$ & b & $3^{2} \cdot 5$ & $33 \cdot 5$ & 33 & $17 \cdot 5$ & $21 \cdot 5$ & $19 \cdot 5$ \\
\hline
\end{tabular}

It may be incidentally noted in Table XXXV that, as has already been pointed out in another connection, the percentage of responses is greater when the contrast between the light intensities is greater, and that both fresh and fatigued worms respond oftener upon going into the lesser intensity than when going into the greater intensity.

The time required for a worm placed in directive light to come to rest; that is, to run the gamut from the state of normal activity to that of rest, becomes gradually shorter with continuous exposure. As fatigue increases the worm shifts down the scale of physiological states in less time than when freshly subjected to directive light. A specific case of this kind has already been described in the paragraph on "duration of movement" (p. I05), where in 39 consecutive trials the change from normal activity to relaxation was first made in 18 minutes, but the thirty-ninth time in $\mathrm{I}_{4}^{3}$ minutes, while the fortieth time even mechanical stimulus failed to arouse the exhausted worm from the resting position.

Effect of Previous Exposure to Dark. Worms kept several hours in complete darkness make a larger percentage of responses to changes in their light environment than those which previous to experimentation have been several hours in light. Individuals removed from the stimulus of light for any consider- 
able time are more responsive when subjected to it, for the reason that they are in a physiological state farther removed from fatigue than those worms which have remained a long period in the light. This point is brought out in Table XXXVI.

\section{TABLE XXXVI}

Percentage of reactions of two worms, Planaria gonocephala, to a sudden change in light intensity both when previously kept several hours in the dark and also when previously exposed for several hours to light

\begin{tabular}{l|c|c}
\hline & Percentage of responses & Number of observations \\
\hline After several hours in the light.......................... & 54 & 100 \\
After 48 hours in the dark....... & 66 & 100 \\
\hline
\end{tabular}

Summary. Physiological states grade imperceptibly into each other, but may be tentatively divided into: $\mathrm{I}$, relaxation; 2 , slight activity; 3, normal activity; 4 , violent activity; 5 , rigor; 6, exhaustion.

Various stimuli besides light may induce a change from one physiological state to another.

No light intensity lower than $43 \mathrm{I} \mathrm{c.m}$. is sufficient to throw a worm into a higher state than that expressing normal activity, nor is the absence of light sufficient to bring a planarian to rest.

Excessive light intensity shows a tendency to carry Planaria gonocephala from a state of normal activity to one of rigor. Bdelloura candida is easily changed into a condition of rigor by light.

A sudden change of light intensity acts more immediately than a gradual change in causing planarians to pass from one physiological state to another.

Continuous exposure to light induces fatigue, finally resulting in the passage of the worm into a state of continuous relaxation, in which condition it becomes practically indifferent to light. Repeated trials of the time required in constant light to come to rest show that a progressively shorter interval occurs between the state of normal activity and that of relaxation until a point of complete inactivity is reached, the worm finally remaining in the latter state for a prolonged period. 
Planarians kept for some time in darkness pass into a state in which they are more responsive to light than individuals exposed for a similar length of time to light.

\section{Psychological Basis of Behavior}

Among the first questions that naturally arise concerning the behavior of planarians in light are those which approach the matter from a psychological point of view. How much can planarians actually see, and can they, by repeated experience, "learn" to adapt themselves to changes in the light surrounding them?

To this kind of inquiry it is most difficult to give a satisfactory answer, for the reason that it is impossible to go beyond conjecture and inference in judging what any animal, aside from man, can see or know or experience. It is only possible to state, in more or less definite terms, the responses which animals make to light, since it is beyond man's power ever to experience how animals "feel" under any circumstances.

\section{a. How Much Can Planarians See?}

Broadly speaking it may be said that planarians can distinguish light from darkness. The experiments described on pp. 84, et seq., relating to planarians placed in aquaria so surrounded by backgrounds as to produce regions of different light intensity, point to this conclusion, since when subjected to such differential environments the worms come to rest in the darkened areas.

Again, the numerous responses made at the critical line separating two light intensities may be regarded as evidence of some power of discrimination on the part of the worm between diferent intensities of light.

It is probable, furthermore, that planarians can distinguish a moving object when that object is of sufficient size and contrasts with its surroundings in its degree of illumination, for the reason that a moving object from which light is reflected, means the same to a worm coming into the vicinity of the object as any other change. in the direction of light, such as might be caused by moving a 
lamp from one position to another. To changes in directive light planarians are known to respond very definitely, and consequently they may be said to distinguish the motions of objects.

With regard to true seeing, however, in the sense of distinguishing the forms of objects, it is safe to assume that planarians have almost no power whatever, since their eyes are optically unable to form images even if the central nervous system were highly enough developed to interpret images when formed. In the case, therefore, of Planaria alpina, which, according to Collin ('9r, p. I80), "shuns" Planaria gonocephala when the latter has been put into the same aquarium with it, seeking "strenuously to escape" from its larger relative, the conclusion does not necessarily follow that P. alpina sees an enemy and experiences the sensation of fear. As previously pointed out (p.95), the whole matter is probably explainable on the basis of negative chemotaxis alone. To attribute fear, therefore, or any other similar complex sensation, to an organism whose responses are so plainly of a simple reflex nature, is to go quite beyond the evidence.

In the performance of the two great life processes of nutrition and reproduction, light is apparently in no way a direct aid to planarians, since they thrive in situations from which light is entirely excluded, as in caves, and since they habitually frequent places where this factor is reduced to a minimum. Light cannot, then, be regarded as a directly essential factor in the life of planarians.

That light is not essential to the activity of protoplasm has more than once been demonstrated. Engelmann ('79), for example, showed that the streaming protoplasm of plant cells occurs normally in darkness, while Maupas ('87) found ciliates multiplying as rapidly in the dark as in the light.

\section{b Are Planarians Able to "Learn"?}

With regard to the ability of these worms to acquire upon repetition an abbreviated form of response; that is, to "learn," a few suggestions may be drawn from experiments already described in other connections.

It will be remembered (p. 93) that when a small aquarium 
was delicately mounted upon a turntable, such as is used in "ringing" microscopic slides, a very slight rotation was sufficient to bring to a halt momentarily a gliding worm in this aquarium. It was possible to control this momentary response to such a point of nicety that the anterior end of the worm could be made to halt for an instant without interfering with the onward locomotion of the posterior end. If this slight rotation was repeated at intervals of a second it was found that the worm under observation halted with less and less certainty, until after a dozen or more trials it continued to glide on without halting at all. In ordinary phraseology the worm had learned by experience not to be alarmed by a sudden mechanical shock. The lesson, however, was always very soon forgotten, for after an interval of less than a minute, during which the aquarium remained stationary, the worm responded exactly as it did at first, whenever a slight rotation was made. In a similar way the skioptic response of Bdelloura candida became less pronounced upon repetition, until it was possible to throw a shadow upon the animal without obtaining any response at all.

Again, when worms were placed in a field of non-directive light, parts of which were of two different intensities, the number of wigwag responses made at the critical line separating the two intensities grew less after the animals had repeatedly crossed the line. At first the new condition of sharply contrasted light intensities in the worm's field of locomotion called out a large percentage of wigwag responses. Later, however, by repeated experiences the worm became familiar with this feature of its environment and made fewer wigwag motions. A definite instance of such a decrease in response is given in Table XXXVII.

TABLE XXXVII

Responses of Planaria gonocephala on crossing the line separating two intensities of non-directive light

\begin{tabular}{|c|c|c|c|}
\hline & Wigwag movements & No response & Percentage of response \\
\hline First 25 crossings...... & $2 I$ & 4 & 84 \\
\hline Second 25 crossings..... & 19 & 6 & 76 \\
\hline Third 25 crossings..... & 12 & I3 & $4^{8}$ \\
\hline Fourth 25 crossings ..... & 8 & 17 & $3^{2}$ \\
\hline
\end{tabular}


It will be seen that when Planaria gonocephala was first introduced into a field of contrasted intensities, it made the wigwag response at the critical line marking a change of light intensity, in $8_{4}$ per cent of the first 25 crossings, while during the second, third and fourth sets of 25 crossings, the per cents uniformly decreased until at the fourth 25 crossings the number of wigwag responses fell to 32 per cent. It may be objected that the instances thus far cited in this section find a more reasonable explanation upon the hypothesis of fatigue, but the same surely cannot be said of the following case.

It was found that Planaria maculata oriented itself to directive light at successively shorter intervals when the position of the light was suddenly changed. To produce such a series of responses there was placed in the dark room a shallow aquarium with an electric lamp at either end, under the control of the right and left hand, respectively, of the experimenter. A planarian was placed in the middle of the aquarium and the right-hand light turned on. As soon as the worm was fairly oriented to this light and gliding away from it, the right-hand light was turned off and at the same instant the left-hand light turned on. The time in seconds required for the worm to orient to the new light; that is, to turn $180^{\circ}$ and begin to glide away, was recorded. On p. 89 a typical series of records of such responses is given, in which the number of seconds required for re-orientation when the source of light was reversed, varied from 260 seconds, at first, irregularly down to 35 upon the sixteenth trial. It will be seen from this series that the worm acquired by experience some degree of facility in adapting itself to certain variations in its environment which it would never be liable to encounter in nature, and that this adaptation cannot be explained as due to fatigue. Davenport and Cannon ('97, p. 32) found similarly that "Daphnias respond more quickly and accurately to light after having made several trips to it."

It is quite certain, however, that any educative attainment which a planarian may experience, or which a planarian may acquire, is exceedingly evanescent and also that there is no evidence that the worm emerges from reflex behavior into responses connected with consciousness. 
Summary. The existence of feeling or consciousness among planarians is a matter of pure conjecture.

From their responses it may be inferred that they are able to distinguish dark from light, as well as objects in motion, but it is not clear that they can distinguish the forms of objects.

The knowledge which planarians have of objects in their immediate environment, such as food, enemies, etc., depends largely upon chemical and tactile means. They are, therefore, as well able to go through the entire range of their activities in the dark as in the light.

Upon repetition planarians may in some instances become accustomed to, or acquire greater facility in, responding to stimuli, but this result of experience is almost instantly lost, so that it is doubtful whether these animals possess more than the merest rudiments of the primary criterion of consciousness, namely, the ability to learn.

\section{General Conclusions}

Probably the questions which have occupied the greatest share of attention throughout the literature dealing with the reactions of organisms to light, are the following:

I Is the direction or the intensity of light of more importance in orientation?

2 Which theory best explains orientation and phototaxis, the theory of trial and error or that of the tropisms?

3 How far is behavior with respect to light, adaptive?

\section{DIRECTION OR INTENSITY}

Before the part played in the behavior of planarians by either the direction or the intensity of light can properly be discussed, it will be necessary to present a brief historical résumé of certain general conclusions reached by investigators along this line.

\section{A Historical}

Cohn ('53), Strasburger ('78) and Loeb ('90, '93a) attributed the directive effect of light to the action of the rays. In a later 
paper Cohn ('64) abandoned his first position and came to regard intensity as the important element in light, a position also maintained by Famintzin ('67), Engelmann ('83), Oltmanns ('92), Verworn ('or) and even by Loeb ('93b) in the case of Planaria torva, which he found came to rest in accordance with the intensity, and regardless of the direction, of the light. Davenport and Cannon ('97) modified this point of view by attempting to show that direction and intensity may each operate independently, producing, respectively, "phototaxis" and "photopathy." Holt and Lee ('Or) followed with an excellent summary of the whole controversy, emphatically maintaining, in opposition to Davenport and Cannon, that intensity alone is the only possible operative factor in light stimulation and that direction of the rays has no effect whatsoever except in determining a greater intensity of light with reference to one part of an organism as compared with other parts.

Among more recent investigations Holmes ('o3), experimenting with the same organism that led Oltmanns to ascribe the greater importance to intensity, namely, Volvox, declares himself in favor of direction, while Zeleny ('05), on the other hand, gives an instance of Serpulid larvæ going both toward the source of the light and away from it; that is, moving regardless of direction, in order to arrive in regions of increased intensity.

Carpenter ('05) found that the pomace fly, Ampelophila drosophila, will orient to the direction of light after it has first been sufficiently aroused by the intensity of the light, while both Yerkes ('99) and Towle ('oo) maintain that direction and intensity are by no means mutually exclusive, and that each may play a part simultaneously in determining the behavior of an organism.

Lastly, it has been made clear by Parker ('o3) that, besides direction and intensity of light, the size of the source of illumination may determine the orientation. This theory explains why butterflies alight upon a patch of reflected sunlight which produces a large but faint retinal image instead of flying toward the sun itself, which forms only a small but intense retinal image. In the case of planarians, however, this phase of light stimulation is not operative, since the eyes of these animals are incapable of forming retinal images. 


\section{$B$ Conclusions with Reference to Planarians}

The behavior of planarians may in general be more satisfactorily explained by regarding, with Loeb, the intensity rather than the direction of the light as the principal operative factor in light reactions. At the same time there is much evidence that the intensity utilized by the organism, is intimately associated with, and powerfully modified by the direction of the light. As a basis for these conclusions the following points will be considered. First, the distinction between direction and intensity; secondly, the way in which directive light modifies the intensity with reference to planarians; thirdly, the action of intensity without the modifying effect of direction, and finally, modifying effects of factors other than light.

\section{a. The Distinction Between Direction and Intensity}

Theoretically it is plain that light per se with respect to any fixed point, may be regarded in two distinct aspects, namely, that of intensity and that of direction. The intensity of light under ordinary circumstances varies inversely as the square of the distance and is independent of the position of the source of light. That is to say, at any points equidistant from its source, light has the same intensity, but the more remote the less is the intensity at any given point. The direction of light, on the contrary, is dependent solely upon the position of the source of the light and in no way upon the distance. When intensity and direction are considered with reference not to a fixed point but to an organism presenting three dimensions and made up of differentiated protoplasm, the basis of light relations becomes more complex. Light cannot here be treated as a phenomenon per se but must be considered in relation to a differentiating organism.

It is true that intensity in the case of the organism, as in the case of a fixed point, varies with the distance from the source of the light. A decided difference, however, appears in the case of the organism inasmuch as, owing to its structure, the intensity received by it varies also in accordance with the position of the light. This 
second form of variation in intensity is directly due to the fact that the organism has a solid form and is not homogeneously photoreceptive.

The direction of light with reference to the organism, presenting as the latter does a structurally diversified form, is influential only as regards the position of the source of light, just as in the case of a fixed point.

Any change in the position of the source results, then, in a redistribution of the intensities falling upon the organism, so that again the intensity received varies in accordance with the position of the light.

It is this factor of position in light that has been termed the directive influence of light and it is seen to be due to variations in the intensity of light with reference to the organism, and not to any peculiar property of light iself. By "non-directive light," on the other hand, is understood those conditions which secure for the organism equalized or symmetrical intensity with respect to the parts stimulated. If this interpretation is correct there can be no response, strictly speaking, to the direction of light exclusive of intensity although the factor of intensity may be continually modified by that of direction in the light relations of organisms.

\section{b The Modifying Influence of Direction}

It is undeniable that the planarians experimented upon exhibited without exception a definite characteristic phototaxis, that is to say, they habitually go either toward or away from the source of light according as they are respectively positive or negative. In analyzing this phototaxis it seemed desirable to eliminate so far as possible the factor of intensity, but the attempt to do this was only partially successful owing to physical limitations. A step was made, however, toward subjecting worms to directive light without at the same time exposing them to a variation in intensity by inserting a biconvex lens between the source of the illumination and the aquarium, thus making the diverging rays of light parallel throughout their course in the aquarium. By this means was formed a field equal in its amount of illumination at 
the two ends of the aquarium, the one opposite and the one next to the source of light, with the exception that there was a slight difference at the two ends due to the fact that light in its passage through water is partially absorbed. But modification of light in any degree results in producing less intensity at the farther end of the aquarium, though this difference is less pronounced when a lens is employed. Therefore, although worms placed in this apparatus went with considerable precision in the direction of the propagation of the light, there is no certainty that their behavior was not due simply to differences in intensity. Worms which are thus apparently traveling directly in accordance with the direction of the light, are meantime being subjected to different intensities at the anterior and posterior ends of the body, for the reason that the anterior end is more or less shadowed by the rest of the body, since the latter cuts out a certain portion of the light received at the posterior end.

That direction of light is a factor by no means to be disregarded, even if it cannot be proven to be the immediate cause of phototaxis, is apparent when it is recalled that slight changes in direction call out corresponding changes in the course of the gliding planarian, whereas considerable changes in intensity when the direction remains constant and particularly when such changes are gradually made, may fail entirely to produce corresponding changes in the worm's behavior. 'This is due to the fact that slight changes in direction may cause considerable changes in the asymmetry of illumination. When a worm, for example, is receiving horizontal light from behind, its head is more or less in shadow, the sides of its body being at the same time equally illuminated. The moment the light is shifted in even a small degree to one side, one entire side of the animal may receive an increase of illumination and the opposite side be thrown into shadow. Thus a slight change in position initiates a fundamental change in the distribution of intensity over the planarian's body.

\section{c Instances of Behavior Due to Intensity Alone}

The effect of intensity as a separate factor from the directive influence of light is clearly demonstrable in certain phases of 
light reactions. To isolate intensity by excluding the possibility of directive light; that is, to secure equalized intensity with reference to the organism, is not difficult and the manner in which this was done, with non-directive light falling upon a horizontal field from above, has been sufficiently detailed in the body of the paper.

It may be briefly recalled that planarians experimented upon by this method showed a certain unmistakable degree of response which could be referable only to differences in equalized intensity. For example, the rate of locomotion was found to be faster in any non-directive intensity up to $43 \mathrm{I} \mathrm{c} . \mathrm{m}$. than in darkness, although light in itself was not always sufficient to start a worm into activity, nor was its absence sufficient to check an animal already in motion. Again, though no close correlation between behavior and the degree of intensity was found to exist, there appeared certain general results which were plainly referable to intensity differences only. Instances of such results are the behavior of Planaria gonocephala (which was modified in several particulars at 43 I c.m. as compared with its behavior at lower intensities); the coming to rest in regions of diminished intensity of individuals of all species except Bdelloura; and the increase of wigwag responses corresponding to an increase of intensity differences when a field of contrasted intensities was used.

It is interesting to observe that increase in the intensity of nondirective light, and continued exposure to non-directive light of constant intensity, both tend to produce the same behavior that would result in directive light. Under any of the three conditions just mentioned there resulted by actual experiment fewer turnings, fewer "indefinite changes" and more nearly straight paths on the part of planarians than occurred when the worms were (I) placed in non-directive light of lower intensity, (2) subjected a short time to non-directive light of constant intensity, or (3) left in darkness. Now, fewer turnings, fewer "indefinite changes," and more nearly straight paths are ordinarily characteristic results of directive light, so that here is a case of reactions, which if resulting from the employment of directive light would be termed phototaxis, occurring in non-directive light as the result of intensity alone. Mast ('o3) experimenting upon the reactions of planarians to thermal 
stimuli obtained a similar result. He observed that apparently "negative" as well as "positive" responses resulted when the animals were subjected to non-directive thermal stimuli.

Another noticeable phenomenon with reference to responses to intensity is, that more wigwag responses occurred at the critical line separating two different intensities when the lesser of the two intensities was I6 c.m. than when it was 33 c.m. (Table XI, p. 69). Similarly responses were more frequent when planarians were subjected suddenly to dark than when they were flooded suddenly by light, and, throughout a large number of series, responses were invariably more frequent when the worms were passing into a region of diminished intensity than when they were entering an area of increased intensity. It is to be inferred that all these phases of behavior are due to the probable fact that the lower intensities compared are nearer the worm's optimum as regards light than the higher ones, since the latter apparently have a tendency to inhibit activity.

Lastly, the relative part played by intensity of light varies decidedly in different species of planarians. The relative intensity in different parts of an aquarium, when no lens is used to lessen the contrast, has comparatively little influence upon Phagocata gracilis, as its extensive wanderings (typically reproduced in Fig. I I) toward and away from the source of light, indicate. Planaria maculata and Planaria gonocephala, on the contrary (Figs. I3 and I 4 ), notwithstanding their ability to come toward the light in the direction of the "rays" throughout the farther half of the dish, seemed invariably to encounter an impassable barrier as soon as they approached within a certain intensity, thereby showing a more delicate responsiveness to intensity differences.

\section{d The Modifying Effect of Other Factors}

In attempting to analyze the relative bearing of the intensity and of the direction of light upon the behavior of planarians there must be constantly kept in mind two general sources of error which are always present when these factors of light are in operation. These 
are (I) the physiological state of the organism at the time of observation, and (2) the simultaneous effect of other stimuli.

A physiological state may be directly traceable to known causes, such as previous exposure to other stimuli or the condition of metabolic balance in which the animal chances to be at the time of observation, or, again, it may be the result of factors at present unknown, which consequently, although in active operation, are not susceptible of analysis. In any case it is certain that the uncontrolled factors comprehended under the ter $m$ " physiological state" prove individual planarians to be not identical mechanisms, but organisms possessing a more or less definite individuality. Moreover, it has been shown that differences in physiological state play a greater part in the determination of behavior than do intensity differences in the light stimulus. When a planarian is approaching a state of fatigue, for example, it becomes indifferent to differences of intensity.

With regard to the simultaneous effect of other stimuli acting in conjunction with light, it has already been pointed out that behavior is the resultant of all the factors, external as well as internal, which may be acting upon an organism at a given time, and that consequently the effect of any one of the operating factors, such as that of light, for example, cannot be determined unless the value of the other factors involved is also taken into account. In support of this view, which is so self-evident, it will be recalled that some of the ways in which the responses of planarians to light may be modified by geotaxis, thigmotaxis, goniotaxis and chemotaxis, were touched upon.

Summary. Direction and intensity are separable qualities of light. Direction is dependent upon the relative positions of the light and the organism, whereas intensity depends upon the distance between the light and the organism as well as the initial intensity of the light.

When applied to living organisms intensity may act independently of direction, or in conjunction with it. Direction cannot act independently of intensity upon organisms, since the latter possess definite form and consequently cannot receive the light at a single point. 
With reference to an organism, directive light is resolvable into unequalized intensity and non-directive light into equalized intensity.

Asymmetrical intensity in directive light is largely due to the partial shadowing of that part of the body farthest away from the source of the light. Slight changes in the position or direction of the light may cause considerable changes in the symmetry and the degree of the shadow effects and consequently in the relative intensity of the light on different regions of the body of an organism.

To different degrees of equalized or symmetrical intensity planarians show considerable response, but the correlation between their behavior and the degree of intensity is not so close as it is in the case of asymmetrical intensity.

Increase in intensity of non-directive light, continued exposure to non-directive light of constant intensity, and change from darkness to non-directive light, all tend to bring about apparent phototaxis similar to that occurring in directive light.

Responses are more frequent on the part of planarians in intensities approaching the optimum than in higher intensities, where there is a tendency to inhibition.

Relative differences in responses to various intensities are due to specific differences between planarians.

The physiological state of an organism together with the influence of known stimuli other than light are constant sources of error in estimating reactions to light. These factors taken together play a more important part in planarian behavior than light stimulus.

Finally, the action of light upon planarians is a function of its intensity, which, under certain conditions, is emphasized by the direction of the light.

\section{TRIAL AND ERROR OR TROPISM?}

It is apparent from the preceding section that light may have two effects upon organisms. Of these, one is a kinetic effect, arising from the intensity of the stimulus and resulting in a gen- 
eral activity termed photokinesis, while the other, connected indirectly at least with the direction from which light impinges upon an organism, is called phototaxis. In the case of planarians these two phases of light stimulation have been shown to be intimately associated and both operative. Carpenter ('05) pointed out in the case of the pomace fly that phototaxis occurs only when preceded by photokinesis or some other reaction, and such an interrelation of the two is undoubtedly of wide occurrence. The object of this section is to inquire into the causes underlying phototaxis. Loeb ('93b) has shown that phototaxis is the result of orientation. It does not necessarily follow, however, that orientation invariably results in phototaxis. In fact Dearborn ('o) found that crayfishes would orient to an electric light introduced into the water near them without making any considerable locomotor movements in consequence. ${ }^{7}$

To the question of how orientation of organisms to light is caused, three possible explanations may be presented: I, Chance result of photokinesis; 2, reflex response to directive stimuli; 3, voluntary action. Since the first hypothesis seems entirely inadequate to account for the uniformity of orientation in planarians, and the third alternative is out of the question with reference to these animals, a consideration of the reflex responses to directive stimuli may be taken up at once.

There are two general theories which attempt to explain the way in which orientation occurs through reflex responses to stimuli. These theories are first, the trial and error theory of Jennings and Holmes, and secondly, the tropism theory of Verworn and Loeb. By the trial and error theory orientation, with its consequent phototaxis, is interpreted as the result of repeated attempts on the part of an organism to become adjusted to any given stimulus. Those attempts which fail to result in adjustment to the stimulus are "errors," and as such are followed by other attempts until finally some one secures the necessary adjustment. Trials of this kind may be made in different ways according to the organism

7 Throughout the following discussion orientation will be understood as a position assumed with reference to the light while phototaxis will be made to include motion toward or away from the source of the light. 
in question. Among the infusoria and rotifera, as Jennings has shown in a masterly series of papers, ${ }^{8}$ such attempts at orientation are made by means of a "motor reflex," consisting in (I) a sudden withdrawal from the stimulus, (2) a rotation toward a structurally defined side of the asymmetrical organism, and (3), lastly, an advance in a new direction.

In the case of organisms which do not possess marked asymmetry the trial and error method, as pointed out by Holmes ('05a), resolves itself into a series of "random movements;" that is, a number of apparently experimental movements are made, which finally result in the best adjustment to the stimulus.

In both of these methods the organism acts as a unit and not in response to localized stimulation received asymmetrically.

The tropism theory, on the contrary, is based upon asymmetrical action as the result of asymmetrical stimulation. If an organism receives a stronger stimulus on one side of its body than on the other, the result, whether direct or indirect, is that it moves in such a way that this asymmetrical stimulation becomes symmetrical. In other words, orientation occurs.

It is unfortunate that the tropism theory was made to apply to the behavior of the infusoria, since it has been shown beyond doubt by Jennings that exact observation of the behavior of these organisms and an analysis of its details does not admit of the tropic interpretation, but is, on the other hand, explained by the trial and error theory of motor reflexes. It is also to be regretted that the unquestionable rout of the tropism theory, as applied to certain protozoa and other asymmetrical forms, should have led to an attempt to exclude it from the remainder of the animal kingdom.

In a paper on the tropism theory Jennings ('O4a) names as an essential criterion of tropism the direct unilateral stimulation of the motor organs. After showing how inadequate such an assumption is to explain the orientation of animals, particularly that of Infusoria, he continues ('O4a, p. 104), "We should perhaps con-

\footnotetext{
${ }^{8}$ See bibliography in Contributions to the Study of the Behavior of Lower Organisms. Carnegie Inst. of Washington. Publication No. 16. ${ }_{2} 5^{6}$ pp. 1904.
} 
sider here a modification of the original form of the tropism theory that has been proposed by some authors. This is in regard to the assumption that the stimulating agent acts directly on the motor organs upon which it impinges. For this it is sometimes proposed to substitute the view that the action of the stimulating agent is directly on the sense organs of the side on which the stimulus impinges and only indirectly on the motor organs through their nervous connection with the sense organs. When thus modified the theory of course loses its simplicity and its direct explaining power, which made it so attractive. In order to retain any of its value for explaining the movements of organisms, it would have to hold at least that the connections between the sense organs and the motor organs are of a perfectly definite character so that when a certain sense organ is stimulated a certain motor organ moves in a certain way. When we find, as we do in the flatworm (see the following paper), that to the same stimulus on the same part of the body, under the same external conditions the animal reacts sometimes in one way, sometimes in another, the tropism theory, of course, fails to supply a determining factor for the behavior."

It seems to me that the mechanism by means of which the asymmetrical response is brought about is immaterial, so long as that response can be shown to be the result of asymmetrical stimulation. Asymmetrical response might occur either from direct stimulation of the motor organs as was implied in the earlier papers on the infusoria, or by means of a more complex method, consisting of stimulation of the sense organ, transmission to the central nervous system and thence to the motor organs.

The outcome in either case would fulfill the demands of the tropism theory, if asymmetrical response to asymmetrical stimulation be taken as its criterion. In the quotation just cited, the objection that such transmission compels stereotyped behavior is hardly valid, since stereotyped reaction is by no means the only alternative of asymmetrical stimulation. That flatworms do not respond uniformly to directive stimuli cannot be disputed, but that fact does not exclude the possibility of all tropic reaction on their part. The imperfection of response may be simply the result of imper- 
fections in the worm's nervous circuit, assuming that planarian reactions are due to indirect rather than to direct stimulation of the motor organs. In fact, repeated evidence of the failure of a constant and perfectly invariable orientation on the part of planarians has been given in the preceding pages. Such failure, moreover, is quite as likely to occur in the application of the tropism theory to behavior as it is in the case of the trial and error theory, since stereotyped reactions and forced movements, as Holmes' ('05a, p. I I2) has emphasized, are no more characteristic of tropisms, which depend upon a differentiated stimulation and response, than they are of trial and error movements, resulting from a single motor reflex given in response to all kinds of stimulation.

Furthermore, it has been urged that tropism indicates a simpler form of reaction than trial and error for the reason that it involves only a local part of an organism while the motor reflex of trial and error requires that the organism act as a whole. Consequently, since motor reflex has been indisputably demonstrated as the method of infusorian phototaxis, Jennings ('o4a, p. 95) asks, "Should we conclude that the reactions in the higher metazoa are simpler and less unified than in the protozoa?"

That the motor reflex, which occurs with machine-like uniformity, regardless of the point where the stimulation is received, is more complex in character than the stimulation of an asymmetrical part of an organism which may depend for its response upon sense-organ, nervous transmission and motor apparatus is an assumption difficult to sustain. It seems more reasonable to agree with Harper ('O5) in placing tropism higher in the evolutionary scale than trial and error.

The fallacy that "tropism leads nowhere; it is a fixed final thing like a crystal" (Jennings, '04c, p. 25I), while trial and error alone offers possibilities of the higher evolution of phototaxis, has already been answered by Holmes, who points out that trial and error, at least that phase of trial and error depending upon motor reflex, is even more fixed and stereotyped than the reactions occurring in accordance with the tropism schema. To quote: "The end result of both methods is the same, i.e., to get the organism away 
from the stimulus. In the one case it is accomplished by direct reflex without more ado; in the other, only after a considerable waste of energy in inconsequential vermiculations" (Holmes, 'o5a, p. IIO).

It is at least conceivable that under the tropism schema, as the nervous differentiation of an animal becomes more complete, the ability of the organism to interfere with and modify its machinelike responses to external stimuli might also increase, resulting in a flexibility of behavior which would present quite as much variation for natural selection to act upon as that evolved by the trial and error method. This point of view by no means denies that trial and error is the usual "method of intelligence" (C. L. Morgan 'oo, p. I39). It is simply an attempt to recognize in the method of tropism also one of the possibilities of evolutionary progress in behavior and as such holding a higher position in the scale of evolutionary methods than trial and error by motor reflexes.

It has been shown (p. I43) that planarian responses of an apparently asymmetrical character may occur as a result of symmetrical stimulation. Similar instances in the case of planarians have also been demonstrated by Mast ('o3) with reference to thermal stimuli. This, however, is no exception to the validity of the tropism theory, in which asymmetrical responses result from asymmetrical stimulation. Because a planarian may make an apparently phototropic response when subjected to symmetrical stimulation, is not evidence against the supposition that the usual phototropic response is due to asymmetrical stimulation.

The "wigwag" movements of planarians, to which repeated reference has been made in the preceding pages, resemble superficially the "random movements" of the earthworm as described by Holmes. They do not, however, ordinarily appear to be the basis of trial and error selection resulting in orientation, since in a majority of cases, after a worm halts and makes wigwag movements it continues on its way without a change of direction. The movements of Bdelloura candida, as shown in Fig. I2, form an exception to ordinary planarian behavior in this respect.

As a rule wigwag movements are probably occasioned by a general disturbance arising from some stimulation which throws 
the worm into a different physiological state. Exploring movements, such as these seem to be, may bring about asymmetrical stimulation, in which case the worm makes a tropic response.

It was particularly noticed that when planarians received light from below, the anterior end of the body was frequently tilted back and forth as if to make it possible for the light when coming from such an unusual direction to enter the pigment cups of the eyes. The phenomenon suggested the craning of necks and bobbing of heads among a crowd of people who are all trying to see the same object at once.

Wigwag movements seem to be oftener connected with changes in the intensity of light than with changes in its direction. When the latter occur, tropic response is immediately the result.

In the course of the experiments previously described wherein the worms glided from an area of one intensity of non-directive light into another it was noticed that in a majority of cases when the critical line was not crossed at right angles, no change in course occurred, even when the worm halted and made wigwag movements. Of course at a certain instant of any diagonal crossing of the critical line one eye must receive more stimulus than the other, in which case according to an inflexible tropism theory asymmetrical response ought to occur. But such a response does not frequently appear and the reason for this becomes clear when it is remembered that a considerable number of responses were shown to occur which were called "latent wigwags" (Fig. 4, E), because they failed to make their appearance until in some instances the worm had passed more than the length of its body beyond the critical line. Since, therefore, latency of response to intensity is by no means uncommon, it is evident that the brief interval of asymmetrical stimulation occurring when a worm glides diagonally into an area of different intensity is not sufficient to result in an asymmetrical response.

Two conclusions, then, seem reasonable, namely, that phototaxis as related to planarians is primarily due to asymmetrical response resulting from asymmetrical stimulation, and that wigwag movements, together with similar apparent trial and error forms of behavior, contribute chiefly to this end, i. e., to phototaxis. 
Summary. Orientation may occur without phototaxis.

Two theories have been advanced to explain orientation and phototaxis in lower organisms, namely, the trial and error theory and that of the tropisms. The former may be based upon "motor reflexes" or upon "random movements" according to the symmetry of the animal.

The tropism theory rests upon asymmetrical response to asymmetrical stimulation. It does not necessarily depend upon the direct stimulation of the motor organs, nor is it essentially stereotyped in its character any more than are trial and error responses by motor reflex or random movements.

The tropic form of response may, and probably does, require a more complex mechanism than that which causes the motor reflex, consequently it is the form of response to be logically expected among planarians, since the motor reflex has been proven to be the form utilized by the protozoa.

Tropisms, as well as trial and error movements, provide, through the modifying control of an evolving central nervous system, sufficient latitude of variation for natural selection to work upon in the evolution of higher forms of behavior.

Asymmetrical response may, in certain cases, result from symmetrical stimulation, but ordinarily its cause is asymmetrical stimulation.

Wigwag movements are occasioned most frequently by changes in intensity, and they may result in orientation and phototaxis by assisting an organism to secure asymmetrical stimulation.

Latency of reaction accounts for some of the failures in orientation which often occur even when asymmetrical stimulation is acting upon an organism.

Finally, the orientation and phototaxis of planarians is more consistently explained by the theory of tropisms than by the theory of trial and error.

\section{ADAPTATION.}

It remains, finally, to inquire how far the reactions of planarians to light are adaptive; that is, how far the response to light is "of 
such a kind that it better insures the existence of the individual, or of the race" (T. H. Morgan '03, p. I).

It is evident that the generally negative character of the reactions of planarians to light indicates a tendency on the part of these worms to reduce as much as possible the amount of light stimulation received or to avoid it altogether. The rigor effects of excessive stimulation furnish evidence also that light is a factor in a planarian's environment which it finds unavoidable and unwelcome and to which it is adapted only in a negative fashion. In fact the vague distinction separating "lower" from "higher" animals consists largely in the ability of higher animals to assume an active aggressive rather than a passive defensive relation toward the factors making up their environment. For example, the evolution in animals of the visual organs, which in the planarians is only inceptive, enlarges the possible range of photic responses until light becomes an essential factor in an animal's environment, contributing largely to its welfare by enabling it to see its food, to avoid its enemies and to select its mates. It is plain that light plays no such important part in the activities of planarians, for, as has already been pointed out, light per se is not essential to planarians, since they are known to live successfully in dark caves. Moreover, so far as known, light does not influence the regenerative or reproductive processes of planarians in any way whatsoever. The formation of pigment may perhaps be regarded as an adaptation to light conditions, inasmuch as animals possessing pigment are thereby shielded to a certain degree from excessive stimulation.

With reference to activities connected with nutrition and reproduction, planarians are not dependent upon light stimulation. They are otherwise equipped, since they doubtless find their food by chemotactic means and avoid whatever enemies they may have, not aggressively nor actively by retreating from visible foes but rather in a passive way by remaining concealed from enemies that might see them. They have no organs of defense but survive by escaping attention. In this sense their negative phototaxis may be regarded as of protective value and consequently adaptive.

Furthermore, the geographical distribution of fresh water pla- 
narians has been shown by Borelli ('93) and Wilhelmi ('04) to be chiefly dependent upon temperature and almost not at all upon the amount of illumination to which they are subjected. Voigt ('o4) noticed that worms when hungry may be seen wandering about even in patches of bright sunlight with apparent disregard of light. This seems to be a case of the light reactions becoming overbalanced by other responses.

Summary. Light is not an essential factor in planarian activities, since the behavior necessary to the welfare of the individual and the race is mainly referable to other factors.

A planarian's response to light is of a passive character, which may have an adaptive significance only in so far as its phototaxis tends to conceal the worm from its enemies. The presence of pigment may also be regarded as an adaptive condition induced by the animal's relation to light.

The evolution of the photoreceptive apparatus of the planarian has not reached the degree of differentiation necessary to enable it to secure for itself such adaptations to the factor of light in its environment as would make aggressive activity possible to it in a manner characteristic of higher animals.

\section{Bibliography}

ArLoing, S., '87a-[Letter on Mechanism of Destruction of Microbes by Light.] Ann. Inst. Pasteur., vol. i, pp. 594-596.

'87b-Les spores du Bacillus anthracis sont réellement tuées par la lumière solaire. Comp. Rend. Acad. Sci., Paris, tom. 104, pp. $701-703$.

Bardeen, C. R., 'ora-On the Physiology of the Planaria maculata with especial Reference to the Phenomena of Regeneration. Amer. Jour. Physiol., vol. v, no. I, pp. I-55.

'orb-The Function of the Brain in Planaria maculata. Amer. Jour. Physiol., vol.v, no. 3, pp. 175-179.

Barthélémy, A., '84-Sur la physiologie d'une Planaire verte (Convoluta Schultzii). Comp. Rend. Acad. Sci., Paris, tom. 99, pp. 197-200. BeEr, T., 'oI-Ueber primitive Sehorgane. Wiener klin. Wochenschr., Igor,

Nr. II-I3. 
Berger, F. W., 'oo-Physiology and Histology of the Cubomedusie. Mem. Biol. Lab., Johns Hopkins Univ., vol. iv, pt. 4, pp. I-84, pl. I-3. Birge, E. A., '97-The Vertical Distribution of the Limnetic Crustacea of Lake Mendota. Biol. Centralbl., Bd. I7, Nr. Io, pp. 37 I-374.

Bонn, G., 'оза-Sur les mouvements oscillatoires des Convoluta roscoffensis. Comp. Rend. Acad. Sci., Paris, tom. I37, pp. 576-578.

'o3b-Sur le phototropisme des Artiozoaires supérieurs. Comp. Rend. Acad. Sci., Paris, tom. I37, pp. 1292-I294.

'o3c-Les Convoluta roscoffensis et la théorie des causes actuelles. Bull. Mus. Hist. Nat., Paris., tom. 9., pp. 352-364.

Borelli, A., '93-Osservazioni sulla Planaria alpina (Dana) e catalogo dei Dendroceli d'aqua dolce trovati nell' Italia del Nord. Boll. Mus. Zool. ed Anat. comp. R. Univ. Torino, vol. viii, no. I37, pp. I-I 3 .

Buchner, H., '92-Ueber den Einfluss des Lichtes auf Bakterien. II. Mittheilung. Centralbl. f. Bakteriol. u. Parasitenk., Bd. I2, No. 7, pp. 21 7-2I9.

Carpenter, F. W., '05-The Reactions of the Pomace Fly (Drosophila ampelophila Loew) to Light, Gravity and Mechanical Stimulation. Amer. Nat., vol. xxxix, no. 459, pp. I57-I 7I.

Carrière, J., '82-Die Augen von Planaria polychroa Schmidt und Polycelis nigra Ehrb. Arch. f. mikr. Anat., Bd. 20, pp. I60-174, Taf. 9.

Снiснкоғғ, G. D., '92-Recherches sur les Dendrocoeles d'eau douce (Triclades). Arch. de Biol., tom. 12, pp. 435-560, pl. 15-20.

Сонn, F., '53-Ueber eine Gattung aus der Familie der Volvocinen. Zeit. f. wiss. Zool., Bd. 4, pp. 77-г 6 .

'64-Ueber die Gesetze der Bewegung mikroskopischer Thiere und Pflanzen unter Einfluss des Lichtes. Jahresber. Schles. Gesellsch. f. vaterl. Cultur, Bd. 42, pp. 35-36.

Collin, A., '9r-Mittheilung über Planaria alpina (Dana). Sitzungsber. Gesellsch. naturf. Freunde, Berlin, Jahrg. I89i, Nr. 9, pp. I $77^{-1} 80$.

Curtis, W. C., '02-Life History and Reproduction of Planaria maculata. Proc. Boston Soc. Nat. Hist., vol. xxv, pp. 515-559.

Dalyell, J. C., 'I4-Observations on Some Interesting Phenomena in Animal Physiology, Exhibited by Several Species of Planariæ, illustrated by colored figures of living animals. Edinburgh, $8^{\circ}$, xi $+15^{I}$ pp., I pl.

'53-The Powers of the Creator Displayed in the Creation; or, Observations on Life Amidst the Various Forms of the Humbler Tribes of Animated Nature. London, $4^{\circ}$, vol. ii, 359 pp., 46 pl. 
Dandrieu (de Carcassonne), '88-Influence de la Lumière dans la Destructions des Bactéries; pour servir à l'Étude du "Tout à l’Égout." Ann. d’Hyg. pub. et de Méd. lég., Paris, sér. 3, tom. 20, no. 5, pp. $44^{8-45}$ I.

Darwin, C., '44-Brief Descriptions of Several Terrestrial Planariæ and of Some Marine Species, with an Account of their Habits. Ann. and Mag. Nat. Hist., vol. xiv, pp. 24I-25I, I pl.

'8 $\mathbf{I}$-The Formation of Vegetable Mold through the Action of Worms, with Observations on their Habits. New York, 12 ${ }^{\circ}, 326$ pp.

Davenport, C. B., and Cannon, W. B., '97-On the Determination of the Direction and Rate of Movement of Organisms by Light. Jour. of Physiol., vol. xxi, no. I, pp. 22-32.

Dearborn, G. V. N., 'oo-Notes on the Individual Psycho-physiology of the Crayfish. Amer. Jour. Physiol., vol. iii, no. 9, pp. 404-433.

Delage, Y., '86-Études histologique sur les Planaires rhabdocœles acœles (Convoluta Schultzii O. Schm.). Arch. Zool. Expér. et Gén., sér. 2, vol. iv, pp. Io9-I44, pl. 5-6.

Downes, A., And Blunt, T. P., '77-Researches on the Effect of Light upon Bacteria and other Organisms. Proc. Roy. Soc., London, vol. xxvi, pp. 488-500.

'78-On the Influence of Light upon Protoplasm. Proc. Roy. Soc., London, vol. xxvii, pp. 199-2 I2.

Duclaux, E., '85a-Influence de la lumière du soleil sur la vitalité des germes de microbes. Comp. Rend. Acad. Sci., Paris, tom. roo, pp. I I9-I 2 I.

'85b-Influence de la lumière du soleil sur vitalité des micrococcus. Comp. Rend. Acad. Sci., Paris, tom. Ior, pp. 395-398.

'90-Action de la Lumière sur les Microbes. Revue critique. Ann. Inst. Pasteur, vol. iv, pp. 792-80o.

Duges, A., '28-Recherches sur l'organization et les moeurs des Planariées. Ann. Sci. Nat., tom. I5, pp. I39-183.

Engelmann, T. W., '79-Ueber Reizung contraktilen Protoplasmas durch plötzliche Beleuchtung. Arch. f. ges. Physiol., Bd. I9, pp. I-7.

'83-Bacterium photometricum. Ein Beitrag zur vergleichenden Physiologie des Licht-und Farbensinnes. Arch. f. ges. Physiol., Bd. 30, pp. 95-I24, Taf. I.

Famintzin, A., '67-Die Wirkung des Lichtes auf Algen und einige andere ihnen nahe verwandte Organismen. Jahrb. f. wiss. Bot. (Pringsheim), Bd. 6, pp. I-48, Taf. I-3.

Frandsen, P., 'OI-Studies on the Reaction of Limax maximus to Directive Stimuli. Proc. Amer. Acad. Arts and Sci, vol. xxxvii, pp. I85-227. 
FüHner, N., 'o6-Notizen zur Biologie von Convoluta roscoffensis Graff. Biol. Centralbl., Bd. 26, Nr. I, pp. 24-26.

Gamble, F. M., and Keeble, F., '03-The Bionomics of Convoluta roscoffensis, with Special Reference to its Green Cells. Quart. Jour. Micr. Sci., vol. Ixvii, pp. 363-431, pl. 30-31.

Geddes, P., '79-Observations on the Physiology and Histology of Convoluta Schultzii. Proc. Roy. Soc., London, vol. xxviii, pp. 449-457.

Gissler, C. F., '82-A Marine Planarian and its Habitation. Amer. Nat., vol. xvi, no. I, pp. 52-53, fig. I-2.

Graber, V., '83-Fundamentalversuche über die Helligkeits- und Farbenempfindlichkeit augenloser und geblendeter Thiere. Sitzungsb. $\dot{\mathrm{d}}$. Wien. Akad., Bd. 87, pp. $201-236$.

Graff, L. von, '84-Zur Kenntnis der physiologischen Function des Chlorophylls im Thierreich. Zool. Anz., Bd. 6, Nr. 177, pp. 520-527.

Groom, T. T., und Loeb, J., '9o-Der Heliotropismus der Nauplien von Balanus perforatus und die periodischen Tiefenwanderungen pelagischer Tiere. Biol. Centralbl., Bd. Io, Nr. 5, pp. I60-I 77.

Haberlandt, G., '9I-Ueber den Bau und die Bedentung der Chlorophyllzellen von Convoluta roscoffensis. Appendix (pp. 75-9o) to L. von Graff, Die Organization der Turbellaria acœla. Leipzig. $4^{\circ}$, Holzsch. u. 90 Taf.

Harper, E. H., '05-Reactions to Light and Mechanical Stimuli in the Earthworm Perichæta bermudensis (Beddard). Biol. Bull., vol. $x$, no. I, pp. I 7-34.

Hesse, R., '96-Untersuchungen über die Organe der Lichtempfindung bei niederen Thieren. I. Die Organe der Lichtempfindung bei Lumbriciden. Zeit. f. wiss. Zool., Bd.61, pp. 393-419, Taf. 20, I Fig. '97-Untersuchungen über die Organe der Lichtempfindung bei niederen Thieren. II. Die Augen der Plathelminthen, insonderheit der tricladen Turbellarien. Zeit. f. wiss. Zool., Bd. 62, pp. 527-582, Taf. 27 u. 28,3 Fig.

Hodge, C. F., And Aikens, H. A., '95-The Daily Life of a Protozoan: A Study in Comparative Psycho-physiology. Amer. Jour. Psychol., vol. vi, no. 4, pp. 524-533.

Hogg, C. '97-On Bipalium kewense, Moseley. Trans. Nat. Hist. Soc., Glasgow, n. s., vol. v, pt. I, pp. 53-54.

Holmes, S. J. 'oI-Phototaxis in the Amphibia. Amer. Jour. Physiol., vol. v, no. 4, pp. 2 I I -234 .

'o3-Phototaxis in Volvox. Biol. Bull., vol. iv, pp. 319-326. 
Holmes, S. J., '05a-The Selection of Random Movements as a Factor in Phototaxis. Jour. Comp. Neurol. and Psychol., vol. xv, nio. 2, pp. $9^{8-1} 12$.

'05b-The Reactions of Ranatra to Light. Jour. Comp. Neurol. and Psychol., vol. xv, pp. 305-349.

Holt, E. B., and Lee, F. S., 'or-The Theory of Phototactic Response. Amer. Jour. Physiol., vol. iv, no. 9, pp. 460-48r.

IıjмA, I., '84-Untersuchungen über den Bau und die Entwickelungsgeschichte der süsswasser Dendrocoelen (Tricladen). Zeit. f. wiss. Zool., Bd. 40, pp. 359-464, Taf. 20-23.

Jäninchin, E., '96-Beiträge zur Kenntnis des Turbellarien Auges. Zeit. f. wiss. Zool., Bd. 62, pp. 250-288, Taf. I0-II, 7 Textfig.

Jamieson, J., '82-The Influence of Light on the Development of Bacteria. Nature, vol. xxvi, pp. $244^{-245}$.

Janowski, T., 'go-Zur Biologie der Typhusbacillen. Die Wirkung des Sonnenlichts. Centralbl. f. Bakt. u. Parasitenk., Bd. 8, Nr.6, pp. I67I72; Nr. 7, 193-199; Nr. 8, 230-234; Nr. 9, 262-266.

Jennings, H. S., 'o4a-The Theory of Tropisms. Carnegie Inst. of Washington, Pub. no. 16, pp. 89-107.

'04b-Physiological States as Determining Factors in the Behavior of Lower Organisms. Carnegie Inst. of Washington, Pub. no. I6, pp. 109-128.

'O4c-The Method of Trial and Error in the Behavior of Lower Organisms. Carnegie Inst. of Washington, Pub. no. I6, pp. 237-252.

Kennel, J. von, '88-Untersuchungen an neuen Turbellarien. Zool. Jahrb. Abt. f. Anat. und Ont., Bd. 3, pp. 447-486, Taf. I8-I 9 .

Lang, A., '84-Die Polycladen (Seeplanarien) des Golfes von Neapel und der angrenzende Meeresabschnitte. Fauna u. Flora d. Golfes von Neapel. XI. Monographie. $x+688$ pp. 39 Taf. Leipzig.

Lehnert, G. H., '9I-Beobachtungen an Landplanarien. Arch. f. Naturg., Jahrg. 57, pp. 306-350.

Leidy, J., '58-Note on Finding Rhincodemus sylvaticus at Night. Proc. Acad. Nat. Sci., Philadelphia, I858, pp. I 7 I-I 72.

Lillie, F. R., 'OI-Notes on Regeneration and Regulation in Planarians. Amer. Jour. Physiol., vol. vi, no. 2, pp. I29-I4I.

Loeb, J., '9o--Der Heliotropismus der Thiere und seine Uebereinstimmung mit dem Heliotropismus der Pflanzen. Würzburg, $8^{\circ}$, i $18 \mathrm{pp}$.

'93a-On the Influence of Light on the Periodical Depth-migrations of Pelagic Animals. Bull. U. S. Fish Com., vol. xiii, pp. $65-68$. 
Loeв, J., '93b-Ueber künstliche Umwandlung positiv heliotropischer Thiere in negativ heliotropische und umgekehrt. Arch.f. ges. Physiol., Bd. 54, pp. 8I-I07, 6 Holzsch.

'94-Beiträge zur Gehirnphysiologie der Würmer. Arch. f. ges. Physiol., Bd. 56, pp. 247-269, Fig. I-4.

Mast, S. O., 'O3-Reactions to Temperature Changes in Spirillum, Hydra and Fresh-Water Planarians. Amer. Jour. Physiol., vol. x, no. 4, pp. 165-igo.

Maupas, E., '87-Sur la puissance de multiplication des Infusories ciliés. Comp. Rend. Acad. Sci., Paris, tom. 104, pp. 1006-1008.

Morgan, C. L., 'oo-Animal Behavior. London, $8^{\circ}, 344$ pp.

Morgan, T. H., 'O3-Evolution and Adaptation. New York, $8^{\circ}, \mathrm{x}+470 \mathrm{pp}$. Moseley, H. N., '74-On the Anatomy and Histology of the Land Planarians of Ceylon; with Some Account of their Habits, and a Description of Two New Species, and with Notes on the Anatomy of Some European Aquatic Species. Phil. Trans. Roy. Soc. London, vol. clxiv, pp. 105-17i, pl. Io-15.

Nagel, W. A., '94-Beobachtungen über den Lichtsinn augenloser Muscheln. Biol. Centralbl., Bd. x4, Nr. i I, pp. 385-390.

Oltmanns, F., '92-Ueber die photometrischen Bewegungen der Pflanzen. Flora, Bd. 75, pp. 183-266, Taf. 4 .

PAnsinı, '89-Action de la Lumière solaire sur les micro-organismes. Ann. Inst. Pasteur, tom. 3, pp. 686.

Parker, G. H., '02-The Reactions of Copepods to various Stimuli, and the Bearing of this on Daily Depth Migrations. Bull. U. S. Fish Com., Igor, pp. I03-I23.

'03-The Phototropism of the Mourning-cloak Butterfly, Vanessa antiopa Linn. Mark Anniversary Vol., pp. 453-469, pl. 3.3.

Parker, G. H., And Arkin, L., 'oi-The Directive Influence of Light on the Earthworm Allolobophora fotida Sav. Amer. Jour Physiol., vol. $\mathrm{v}$, no. 3 , pp. $\mathrm{x} 5 \mathrm{x}-\mathrm{x} 57$

Parker, G. H., and Burnett, F. L., 'oo-The Reactions of Planarians, with and without Eyes, to Light. Amer. Jour. Physiol., vol. iv, no. 8, pp. $373-385$, fig. $1-4$.

Pearl, R., '03-The Movements and Reactions of Fresh-water Planarians: A Study of Animal Behavior. Quart. Jour. Micr. Sci., vol. xlvi, pp. 509-7 I 4.

Pearl, R., and Cole, L. J., 'O2-The Effect of very Intense Light on Organisms. Michigan Acad. Sci., Third Report, pp. $77-78$. 
RÁDL, E., 'oI-Ueber den Phototropismus einiger Arthropoden. Biol. Centralbl., Bd. 2I, Nr. 3, pp. 75-86.

Raum, J., '89-Der gegenwärtige Stand unserer Kenntnisse über den Einfluss des

Lichtes auf Bakterien und auf den thierischen Organismus. Zeit.

f. Hyg., Bd. 6, pp. 312-368.

Roux, E., ' 87 -De l'action de la lumière et de l'air sur les spores de la bactéridie du charbon. Ann. Inst. Pasteur, tom. I, pp. 445-452.

Schouteden, H., 'o2-Le Phototropisme de Daphnia magna Straus (Crust.). Ann. Soc. ent. Belgique., tom. 46, pp. 352-362.

Schultze, M., '5I-Beiträge zur Naturgeschichte der Turbellarien. Erste Abt. Greifswald, $4^{\circ}, 78$ pp. 7 Taf.

Sekera, E., 'O3-Einige Beiträge zur Lebensweise von Vortex helluo (viridis M.

Sch.) Zool. Anz., Bd. xxvi, no. 708, pp. 703-710.

SMith, A. C., '02-The Influence of Temperature, Odors, Light and Contact on the Movements of the Earthworm. Amer. Jour. Physiol., vol. vi, no. 7 , pp. $459-486$.

Strasburger, E., '78-Wirkung des Lichtes und der Wärme auf Schwärmsporen. Jena. Zeit., Bd. I2, pp. 551-625.

Towle, E. W., 'oo-A Study in the Heliotropism of Cypridopsis. Amer. Jour. Physiol., vol. iii, no. 8, pp. 345-365.

Tyndall, J., ' 78 -Note on the Influence Exercised by Light on Organic Infusions. Proc. Roy. Soc., London, vol. xxviii, pp. 212-213.

Verworn, M., 'oI-Allgemeine Physiologie. 2te Aufl. Jena, $8^{\circ}$, 631 pp.

VoIgt, W., 'O4-Ueber die Wanderungen der Strudelwürmer in unseren Gebirgsbächen. Verh. naturh. Vereins preuss. Rheinlande, Westfalens und Regierungsbez. Osnabrück, Jahrg. 61, pp. 102-178.

Walter, H. E., 'o6-The Behavior of the Pond Snail; Lyminæus elodes Say. Brooklyn Inst. Arts and Sci., Cold Spring Harbor Monographs, VI, 35 pp.

WARD, H. M., '94-Further Experiments on the Action of Light on Bacillus anthracis and on the Bacteria of the Thames. Proc. Roy. Soc., London, vol. lvi, pp. 315-374.

Whitman, C. 'O., '99-Animal Behavior. Wood's Hole Lectures for 1898 . Boston, pp. 285-338.

Wilhelmi, J., '04-Beiträge zur Kenntnis der Verbreitung und Biologie der Süsswassertricladen. Zool. Anz., Bd. xxvii, Nr. II, pp. 355-365; Nr. 12, 369-375.

Willem, V., '9I-La vision chez les gasteropodes pulmonés. Comp. Rend. Acad. Sci., Paris, tom. II2, pp. 247-248. 
Woodworth, W. McM., '97-Contributions to the Morphology of the Turbellaria: II. On some Turbellaria from Illinois. Bull. Mus. Comp. Zoöl. Harvard Coll., vol. xxxi, pp. I-I6, pl. I.

Yerkes, R. M., '99-Reaction of Entomostraca to Stimulation by Light. Amer. Jour. Physiol., vol. iii, no. 4, pp. 157-182.

'03.-A Study of the Reactions and Reaction Time of the Medusa Gonionema Murbachii to Photic Stimuli. Amer. Jour. Physiol., vol. ix, no. 5, pp. 279-307.

Zeleny, C., '05-The Rearing of Serpulid Larvæ with Notes on the Behavior of the Young Animals Biol. Bull., vol. viii, no. 5, p. 308. 
E. L. MARK, Director.

** Abbreviations used:-

B. M. C. Z. . . . . . . . for Bull. Mus. Comp. Zoöl.

P. A. A. . . . . . . for Proceed. Amer. Acad. Arts and Sci.

P. B.S. N. H. . . . . . for Proceed. Bost. Soc. Nat. Hist.

NoTE. - Copies of the List of Contributions, Numbers 1-150, will be
sent on application.

151. Bigelow, H. B. - The Sense of Hearing in the Goldfish Carassius auratus L. Amer. Nat., 38(448): 275-284. Apr. [June], 1904.

152. Allen, G. M. - The Heredity of Coat Color in Mice. P. A. A., 40(2): 59-163. July, 1904.

153. Sargent, P. E. - The Optic Reflex Apparatus of Vertebrates for Short-circuit Transmission of Motor Reflexes through Reissner's Fibre; its Morphology, Ontogeny, Phylogeny, and Function. - Part I. The Fish-like Vertebrates. B.M.C.Z., 45(3): 127-258. 11 pls. July, 1904.

154. MAst, S. O.-A Simple Apparatus for Aërating Liquid Solutions. Amer. Nat., 38(453) : 655-660. Sept. [Oct.], 1904.

155. PARKER, G. H., AND StarratT, S. A. - The Effect of Heat on the Color Changes in the Skin of Anolis carolinensis Cuv. P.A. A., 40 (10): 455-466. Nov., 1904.

156. RAND, H. W.-The Behavior of the Epidermis of the Earthworm in Regeneration. Arch. f. Entwickelungsmechanik, 19(1): 16-57. Taf. 1-3. Feb., 1905.

157. SMallwood, W. M. - The Maturation, Fertilization, and Early Cleavage of Haminea solitaria (Say). B.M.C.Z., 45(4) : 259-318. 13 pls. Dec., 1904.

158. Castle, W. E. - Heredity of Coat Characters in Guinea-Pigs and Rabbits. Publ. Carnegie Inst. Washington, No. 23. 78 pp. 6 pls. Feb., 1905.

159. PARKER, G. H. - The Reversal of Ciliary Movement in Metazoans. Amer. Jour. of Physiol., 13(1) : 1-16. Feb., 1905.

160. Petronkefitch, A. - Natural and Artificial Parthenogenesis. Amer. Nat., 39(458) : 65-76. Feb. [Mar.], 1905.

161. Sмrth, G.-The Effect of Pigment-Migration on the Phototropism of Gammarus annulatus S. I. Smith. A mer. Jour. of Physiol., 133 (3) : 205-216. Apr., 1905.

162. CARPENTER, F. W. - The Reactions of the Pomace Fly (Drosophila ampelophila Loew) to Light, Gravity, and Mechanical Stimulation. Amer. Nat., 39(459): 15i-171. Apr., 1905.

163. Petres, A. W.-Phosphorescence in Ctenophores. Jour. of Exp. Zoöl., 2(1): 103-116. Apr., 1905.

164. HАHN, C. W.-Dimorphism and Regeneration in Metridiun. Jour. of Exp. Zoöl., $2(2)$ : 225-235. May, 1905.

165. RaND, H. W., AND Ulrich, J. L. - Posterior Connections of the Lateral Vein of the Skate. Amer. Nat., :39(462) : 349-364. June, 1905.

166. RAND, H. W.-The Skate as a Subject for Classes in Comparative Anatomy; Injection Methods. Amer. Nat., 39(462) : 365-379. June, 1905.

167. RoMeiger, T. II.-A Case of Abnormal Venous System in Necturus maculatus. Amer. Nat., :39(462) : 391-396. June, 1905.

168. Parker, G. H. - The Reversal of the Effective Stroke of the Labial Cilia of SeaAnemones by Organic Substances. A mer. Jour. of Physiol., 14(1) : 1-6. July 1905.

169. P\RKER, G. II. - The Movements of the Swimming-Plates in Ctenophores, with Reference to the Theories of Ciliary Metachronism. Jour. of Exp. Zoöl., 2(3) : 407-423. Aug., 1905.

170. Blackman, M. W. - The Spermatogenesis of the Myriapods. III. The Spermatogrenesis.of Scolopendra heros. B.M.C.Z., 18(1): I-137. 9 pls. Oct., 1905. 

THE MUSEUM OF COMPARATIVE ZOÖLOGY AT HARVARD COLLEGE. (Continued.)

171. PARker, G. H. - The Stimulation of the Integumentary Nerves of Fishes by Light. Amer. Jour. of Physiol., 11(5) : 413-420. Nov., 1905.

172. Carpenter, F. W.-The Development of the Oculomotor Nerve, the Ciliary Gauglion, and the Abrucent Nerve in the Chick. B.M.C.Z., 48(2): 139-229. 7 pls. Jan., 1906.

173. Parker, G. H.-Double Hens' Eggs. Amer. Nat., 10(469) : 13-25. Jan., 1906.

174. Sмiтh, G. - The Eyes of Certain Pulmonate Gasteropods, with special Reference to the Nenrofibrillae in Limax maximus. B.M.C.Z., 18(3): 231-283. 4 pls. Apr., 1906.

175. Castle, W. E., and Forbes, A.- Ileredity of Hair-Length in Guinea-Pigs and its Bearing on the Theory of Pure Gametes. Publ. Carnegie Inst. Washington, No. 19 : 1-14. May, 1906.

176. Castle, W. E. - The Origin of a Polydactylons Race of Guinea-Pigs. Publ. Carnegie Inst. Washington, No. 19 : 15-29. Mray, 1906.

177. Castle, W. E., Carpenter, F. W., Clark, A. H., Mast, S. O., and Barrows, W. M. - The Effects of Inbreeding, Cross-brecding, and Selection upon the Fertility and Variability of Drosoplila. P.A.A., 41(33) : 729-786. May, 1906.

178. Peanse, A. S. - Reactions of Tubularia crocea (Ag.). Amer. Nat., 10(474): 401-407. Juuc, 1906.

179. MarK, E. L., AND Copeland, M. - Some Stages in the Spermatogenesis of the Honey Bee. P.A.A., 42(5): 101-112. 1 pl. June, 1906.

180. Parker, G. H., and Metcalf, C. R. - The Rcactions of Eartluworms to Salts: A Study in Protoplasmic Stimulation as a Basis of Interpreting the Sense of Taste. Amer. Jour. of Physiol., 17(1) : 55-74. Sept., 1906.

181. Woodworth, C. W. - The Wing Veins of Inscets. Univ. California Publ., Agr. Exp. Sta., Tcch. Bull. - Entomol., 1(1) : 1-152. Sept. [Oct.], 1906.

182. MASt, S. O. - Light Reactions in Lower Organisms. I. Stentor coeruleus. Jour. of Exp. Zoöl., :3(3) : 359-399. Sept., 1906.

183. PARKER, G. H. - The Influence of Light and Heat on the Movement of the Melanophore Pigment, especially in Lizards. Jour. of Exp. Zoöl. 3(3): 401-114. Sept., 1906.

184. Larrabee, A. P. - The Optic Chiasma of Teleosts: a Study of Inheritance. P. A. A., 42 (12) : 215-231. Oct., 1906.

185. Cole, L. J. - An Experimental Study of the Image-Forming Powers of Various Types of Eyes. P. A. A., 12 (16): 333-417. Jan., 1907.

186. Esterly, C. O.- The Reactions of Cyclops to Light and Gravity. Amer. Jour. of Physiol., $18(1): 47-57$. Feb., 1907.

187. MARK, E. L. - An Electric Wax.Cutter for Use in Reconstructions. P. A. A., 42(23) : 627-636. Nar., 1907.

188. MacCurdy, H., and Castle, W. E. - Selection and Cross-Breeding in Relation to the Inheritance of Coat-Pigment aud Coat-Patterns in Rats and Guinea-Pigs. Publ. Carnegie Inst. Washington, No. Fo: 50. 2 pls. May, 1907.

189. RAND, H. W.-The Functious of the Spiracle of the Skate. Am. Nat., 41(485): 287-302. Мay, 1907 .

190. MaRK, E. L., AND Copeland, M.-Maturation Stages in the Spermatogencsis of Vespa maculata Linn. P. A. A., 13(3): 69-74. June, 1907.

191. Barrows, W. M. - The Reactions of the Pomace Fly, Drosophila ampelophila Loew, to Odorous Substances. Jour. of Exp. Zoöl., 4 (4) : 515-537. Oct., 1907.

192. Congdon, E. D. - The Effect of Temperature on the Migration of Retinal Pigment in Decapod Crustaceans. Jour. of Exp. Zoöl., 4(4) : 539-548. Oct., 1907.

193. Walter, H. E.-The Reactions of Planarians to Light. Jour. of Exp. Zoöl., 5) $(1,2): 35-162$. Nov., Dec., 1907. 


\section{CONTRIBUTIONS FROM THE ZOOLLOGICAL LABORATORY OF THE MUSEUM OF COMPARATIVE ZOÖLOGY AT HARVARD COLLEGE. (Continued.)}

\section{E. L. MARK, Director.}

Abbreviations used:-

B. M. C. Z. . . . . . . for Bull. Mus. Comp. Zoöl.

P.A. A. ......... for Proceed. Amer. Acad. Arts and Sci.

P. B.S. N. H. . . . . . . for Proceed. Bost. Soc. Nat. Hist.

NoTE. - Copies of the List of Contributions, Numbers 1-150, will be

sent on application.

151. BIGELOW, H. B. - The Sense of Hearing in the Goldfish Carassius auratus L. Amer. Nat., 38 (448): 275-284. Apr. [June], 1904.

152. Allen, G. M. - The Heredity of Coat Color in Mice. P. A. A., 40(2): 59-163. July, 1904.

153. SARGENT, P. E. - The Optic Reflex Apparatus of Vertebrates for Short-circuit Transmission of Motor Reflexes through Reissner's Fibre; its Morphology, Ontogeny, Phylogeny, and Function. - Part I. The Fish-like Vertebrates. B.M.C.Z., 45(3): 127-258. 11 pls. July, 1904.

154. Mast, S. O.-A Simple Apparatus for Aërating Liquid Solutions. Amer. Nat., 38 (453) : 655-660. Sept. [Oct.], 1904.

155. PARKer, G. H., aNd Starratt, S. A. - The Effect of Heat on the Color Changes iu the Skin of Anolis carolinensis Cuv. P.A. A., 4O(10): 455-466. Nov., 1904.

150. RAND, H. W. - The Behavior of the Epidermis of the Earthworm in Regeneration. Arch. f. Entwickelungsmechanik, 19(1): 16-57. Taf. 1-3. Feb., 1905.

157. Smaluwood, W. M. - The Maturation, Fertilization, and Early Cleavage of Haminea solitaria (Say). B.M.C.Z., 45(4) : 259-318. 13 pIs. Dec., 1904.

158. CAsthe, W. E. - Heredity of Coat Characters in Guinea-Pigs and Rabbits. Publ. Carnegie Inst. Washington, No. 23. 78 pp. 6 pls. Feb., 1905.

159. PARKER, G. H. - The Reversal of Ciliary Movement in Metazoans. Amer. Jour. of Physiol., 13(1) : 1-16. Feb., 1905.

160. Petrunkevitch, A. - Natural and Artificial Parthenogenesis. Amer. Nat., 39(458) : 65-i6. Feb. [MIar.], 1905.

161. SMrTH, G. - The Effect of Pigment-Migration on the Phototropism of Gammarus annulatus S. I. Smith. Amer. Jour. of Physiol., 13(3) : 205-216. Apr., 1905.

162. CARPENTER, F. W. - The Reactions of the Pomace Fly (Drosophila ampelophila Loew) to Light, Gravity, and Mechanical Stimulation. Amer. Nat., 39(459): 157-171. Apr., 1905.

163. Peters, A. W. - Phosphorescence in Ctenophores. Jour. of Exp. Zoöl., :(1): 103-116. Apr., 1905.

164. H HEN, C. W. - Dimorphism and Regeneration in Metridium. Jour. of Exp. Zoöl., 2(2) : 225-235. May, 1905.

165. RAND, H. W., AND ULRICH, J. L. - Posterior Connections of the Lateral Vein of the Skate. Amer. Nat., 39(462) : 349-364. June, 1905.

166. RAND, H. W.-The Skate as a Subject for Classes in Comparative Anatomy; Injection Methods. Amer. Nat., 39(462): 365-379. June, 1905.

167. RoMeiser, T. H. - A Case of Abnormal Venous System in Necturus maculatus. Amer. Nat., 39(462) : 391-396. June, 1905.

168. PARKER, G. H. - The Reversal of the Effective Stroke of the Labial Cilia of SeaAnemones by Organic Substances. Amer. Joul. of Physiol., 14(1) : 1-6. July 1905.

169. P\RKER, G. H. - The Movements of the Swimming-Plates in Ctenophores, with Refcrence to the Theories of Ciliary Metachronism. Jour. of Exp. Zoöl., $2(3)$ : 407-423. Aug., 1905.

170. BlacksıN, M. W. - The Spermatogenesis of the Myriapods. III. The Spermatogeneris of Seolopendra heros. B.M.C. Z., $18(1)$ : 1-137. 9 pls. Oct., 1905. 


\section{CONTRIBUTIONS FROM THE ZOOLOGICAL LABORATORY OF THE MUSEUM OF COMPARATIVE ZOÖLOGY AT HARVARD COLLEGE. (Continued.)}

171. PArker, G. II. - The Stimulation of the Integumentary Nerves of Fishes by Light. Amer. Jour. of Physiol., 1\$(5) : 413-420. Nov., 1905.

172. Carpenter, F. W. - The Developinent of the Oculomotor Nerve, the Ciliary Ganglion, and the Abducent Nerve in the Chick. B.M.C.Z., 48(2): 139-229. 7 pls. Jan., 1906.

173. Parker, G. H.-Double Hens' Eggs. Amer. Nat., 40(469) : 13-25. Jan., 1906.

174. Sмгтн, G. - The Eyes of Certain Pulmonate Gasteropods, with special Reference to the Neurofibrillae in Limax maximus. B.M.C.Z., $48(3): 231-283.4$ pls. Apr., 1906.

175. Castle, W. E., AND ForBes, A.-Heredity of Hair-Length in Guinea-Pigs and its Bearing on the Theory of Pure Gametes. Publ. Carnegie Inst. Washington, No. 49 : 1-14. May, 1906.

176. Castle, W. E. - The Origin of a Polydactylous Race of Guinea-Pigs. Publ. Carnegie Inst. Washingtou, No. $49: 15-29$. May, 1906.

177. Castle, W. E., Carpenter, F. W., Clark, A. H., Mast, S. O., and Barrows, W. M. - The Effects of Inbreeding, Cross-breeding, and Selection upon the Fertility and Variability of Drosophila. 'P.A.A., 41(33) : 729-786. May, 1906.

178. Prarse, A. S. - Reactions of Tubularia crocea (Ag.). Amer. Nat., 40(474): 401-407. June, 1906.

179. MARK, E. L., AND Coprland, M. - Some Stages in the Spermatogenesis of the Honey Bee. P.A.A., 42(5) : 101-112. 1 pl. June, 1906.

180. Parker, G. H., and Metcalf, C. R. - The Reactions of Earthworms to Salts: A Study in Protoplasmic Stimulation as a Basis of Interpreting the Sense of Taste. Amer. Jour. of Physiol., 17 (1) : 55-74. Sept., 1906.

181. Woonworth, C. W. - The Wing Veins of Insects. Univ. California Publ., Agr. Exp. Sta., Tech. Bull. - Entomol., 1(1) : 1-152. Sept. [Oct.], 1906.

182. MAst, S. O.-Light Reactions in Lower Organisms. I. Stentor coeruleus. Jour. of Exp. Zoöl., 3(3) : 359-399. Sept., 1906.

183. Parker, G. H.- The Influence of Light and Heat on the Movement of the Melanophore Pigment, especially in Lizards. Jour. of Exp. Zoöl. 3(3): 401-414. Sept., 1906.

184. LaRRABEe, A. P. - The Optic Chiasma of Teleosts: a Study of Inheritance. P. A. A., 42 (12) : 215-231. Oct., 1906.

185. CoLE, L. J.-An Expcrimental Study of the Image-Forming Powers of Various Types of Eyes. P. A. A., 42 (16): 333-417. Jan., 1907.

186. EsterLY, C. O.-The Reactions of Cyclops to Light and Gravity. Amer. Jour. of Physiol., 18(1): 47-57. Feb., 1907.

187. Mark, E. L. - An Electric Wax-Cutter for Use in Reconstructions. P. A. A., 42(23): 627-636. Mar., 1907.

188. MacCURDY, H., AND CASTLE, W. E. - Selection and Cross-Breeding in Relation to the Inheritance of Caat-Pigment and Coat-Patterns in Rats and Guinea-Pigs. Publ. Carnegie Inst. Washington, No. ro : 50. 2 pls. May, 1907.

189. RAND, H. W. - The Functions of the Spiracle of the Skate. Am. Nat., 41 (485) : 287-302. May, 1907.

190. MARK, E. L., AND Copeland, M.--Maturation Stages in the Spermatogenesis of Vespa maculata Linn. P.A.A., 43 (3) : 69-74. June, 1907.

191. Barrows, W. M. - The Reactions of the Pomace Fly, Drosophila ampelophila Loew, to Odorous Substances. Jour. of Exp. Zoöl., 4(4) : 515-537. Oct., 1907.

192. Conadon, E. D. - The Effect of Temperature on the Migration of Retinal Pigment in Decapod Crustaceans. Jour. of Exp. Zoöl., 4(4): 539-548. Oct., 1907.

193. WAltek, H. E. - The Reactions of Planarians to Light. Jour. of Exp. Zoöl., $5(1,2): 35-162$. Nov., Dec., 1907. 




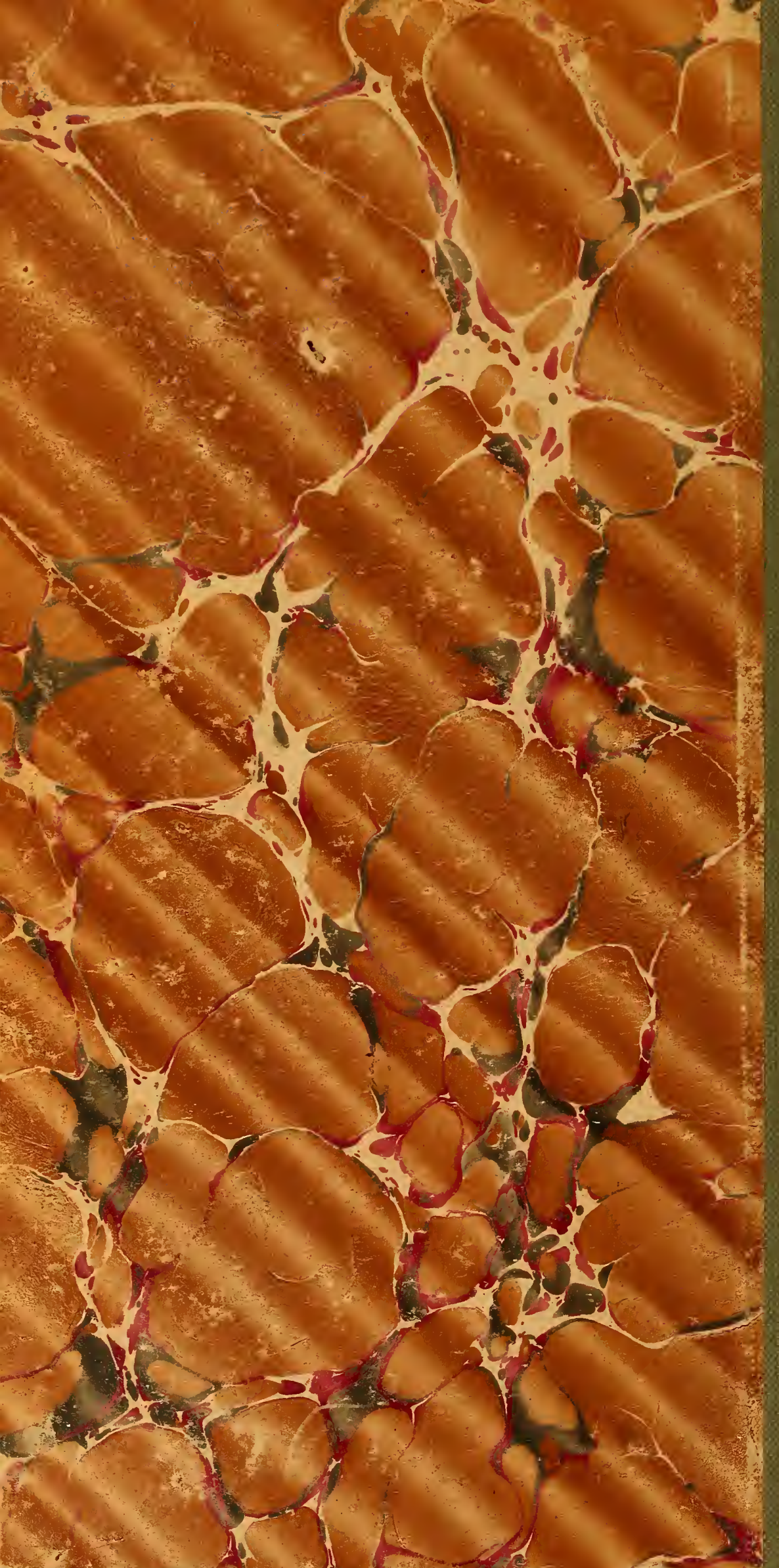

